CENTRO UNIVERSITÁRIO FEI

JOÃO PAULO DA SILVA

ANÁLISE NUMÉRICA DOS EFEITOS PULSATIVOS EM UM MOTOR MONOCILÍNDRICO TURBOALIMENTADO

São Bernardo do Campo 
Silva, João Paulo da.

Análise numérica dos efeitos pulsativos em um motor monocilíndrico turboalimentado / João Paulo da Silva. São Bernardo do Campo, 2021.

117 f. : il.

Dissertação - Centro Universitário FEI.

Orientador: Prof. Dr. Roberto Bortolussi.

Coorientador: Prof. Me. Rafael Serralvo Neto.

1. Turbocompressores. 2. Pulsação. 3. Motores. I. Bortolussi, Roberto, orient. II. Título.

Elaborada pelo sistema de geração automática de ficha catalográfica da FEI com os dados fornecidos pelo(a) autor(a). 
JOÃO PAULO DA SILVA

\section{ANÁLISE NUMÉRICA DOS EFEITOS PULSATIVOS EM UM MOTOR MONOCILÍNDRICO TURBOALIMENTADO}

Dissertação apresentada ao Centro Universitário FEI, como parte dos requisitos necessários para obtenção do título de Mestre em Engenharia Mecânica. Orientado pelo Prof. Roberto Bortolussi.

São Bernardo do Campo 
Aluno: João Paulo da Silva

Matrícula: 218118-8

Título do Trabalho: Análise numérica dos efeitos pulsativos em um motor monocilíndrico turboalimentado.

Área de Concentração: Sistemas Mecânicos

Orientador: Prof. Dr. Roberto Bortolussi

Data da realização da defesa: 22/02/2021

\section{ORIGINAL ASSINADA}

\section{Avaliação da Banca Examinadora:}

A banca considerou o aluno aprovado e este se comprometeu a fazer as alterações propostas durante a defesa.

São Bernardo do Campo, 22 / 02 / 2021.

\section{MEMBROS DA BANCA EXAMINADORA}

Prof. Dr. Roberto Bortolussi

Prof. Dr. Paulo Eduardo Batista de Mello

Prof. Dr. Clayton Barcelos Zabeu
Ass.:

Ass.:

Ass. :

A Banca Julgadora acima-assinada atribuiu ao aluno o seguinte resultado:

APROVADO $\square \quad$ REPROVADO

\section{VERSÃO FINAL DA DISSERTAC̄ÃO}

APROVO A VERSÃo FINAL DA DISSERTAÇÃO EM QUE FORAM INCLUÍDAS AS RECOMENDAÇÕES DA BANCA EXAMINADORA
Aprovação do Coordenador do Programa de Pós-graduação

Prof. Dr. Rodrigo Magnabosco 
Dedico este trabalho aos meus pais e ao meu irmão, que não mediram esforços para me ajudar e incentivar nos diversos desafios e dificuldades que surgiram durante o caminho. 


\section{AGRADECIMENTOS}

Gostaria de expressar minha mais profunda gratidão a cada pessoa por seu extraordinário apoio e suas contribuições à minha jornada e à realização deste projeto.

Agradeço ao Professor Roberto Bortolussi pela orientação, conversas e discussões sobre os mais diferentes assuntos relacionado ao trabalho.

Em especial ao Professor Rafael Serralvo Neto, pela amizade que criamos, pelo incentivo, inspiração e apoio em todos os momentos, além de fazer o possível para dar o suporte necessário às atividades que foram realizadas.

Ao Mestre Eduardo Sala Polati, pela amizade, orientação e troca de informações.

Ao Departamento de Engenharia Mecânica da FEI, especialmente ao Professor Marko Ackermann, por todo o apoio e por acreditar neste projeto.

As funcionárias da coordenação do Centro de Laboratórios Mecânicos, Adelaide Bispo, Marcela Gomes e Cátia Cilene, por não pouparem esforços para que esse projeto fosse concretizado.

Aos técnicos do Laboratório de Motores, Adilson, Adriano, Maurício e Valdir, que, através de suas amizades, tornaram a minha caminhada mais agradável, incentivando a seguir em frente apesar das dificuldades e por sempre estarem dispostos a ajudar, independentemente do tipo de problema.

Aos técnicos do Centro de Laboratórios Mecânicos, em especial Luiz Henrique, Ailton, Douglas Melo, Douglas Mathias, Luis Lento, Valdison, Edilson, Luciano, Antônio, Samuel, Daniel, Anderson, William, Davi, e Alexandre por sempre estarem dispostos a ajudar no projeto.

A AVL na figura de Johann Krammer por colaborar com o projeto fornecendo o software de simulação de motores de combustão interna AVL Boost

A BorgWarner do Brasil, nas figuras de Celso Samea, Vagner Augusto Davanzo e João Campos pelo fornecimento das peças utilizadas e por todas as informações fornecidas através da parceria.

Agradeço a Equipe Fórmula FEI, em especial ao José Tadeu Jr., João Bruno Palermo, José Tales Magalhães, Stefan Buck, João Pedro Verselli, Lucas Miranda Lira, Lucas Resende, 
Daniel Souza, Davi Carmelutti e Augusto Chilotti. O período no qual participei da equipe e tive a oportunidade de ser companheiro de vocês me proporcionou muitos momentos de alegria, aprendizado e conhecimento pessoal. Com certeza será algo que ficará guardado em minha memória e no coração pelo resto de minha vida, me orgulhando em cada momento relembrado. 
"Forte é quem, depois de tanto perder, reerguese e segue lutando" (Ayrton Senna) 


\section{RESUMO}

Durante os úlltimos anos, houve um crescente estudo em diferentes áreas do setor automobilístico para aplicações de turbocompressores, com o objetivo de aumentar a eficiência global dos motores de combustão interna em favor do ganho de potência, torque, redução de consumo específico e consequentemente a redução de emissão dos gases poluentes. Os fabricantes de automóveis têm utilizado o conceito de downsizing de maneira bastante consistente nesta ultima década, aplicando praticamente em toda a gama de produtos. Os motores estão cada vez menores, tanto em deslocamento volumétrico, como em número de cilindros e associados a uma tecnologia eletrônica avançada. Além disso, a busca por combustíveis renováveis tem ganhado espaço através do mundo, como alternativa ao uso de combustíveis fósseis. Baseado nisso, essa pesquisa tem como objetivo simular a aplicação de um sistema turbocompressor em um motor monocilíndrico movido a etanol e estudar a influência do efeito pulsativo dos gases de exaustão no seu desempenho. O objeto de estudo foi um motor Yamaha WR450 de $450 \mathrm{~cm}^{3}$ que equipa o protótipo RS12 da equipe Fórmula FEI. Inicialmente, utilizou-se a aquisição de dados do veículo para o estudo das principais condições de utilização do motor e para entender onde esse motor naturalmente aspirado não atende as necessidades da equipe. Posteriormente, modelou-se o motor com auxilio de um programa de simulação computacional unidimensional AVL BOOST, nele foram inseridos todos os dados construtivos e medidos durante as provas pelas quais o veículo é submetido na competição Fórmula SAE nacional. A partir dos resultados do modelo aspirado, construíu-se um segundo modelo com a aplicação de um turbocompressor comercial e analisou-se como características de um motor com reduzido número de cilindros pode influenciar na sobrealimentação de ar. Foram modeladas duas diferentes configurações de coletor de exaustão para se estudar um melhor aproveitamento da dinâmica dos gases no preenchimento da turbina: uma com volume muito pequeno (com o menor comprimento possível) e outra com um volume grande (2L). Ao final, pode-se decidir qual aplicação proporciona o melhor compromisso para ganho de desempenho em termos de torque e potência, na faixa de rotação determinada.

Palavras-chave: Turbocompressores. Pulsação. Motores. 


\begin{abstract}
Over the past few years, there has been a growing study in different areas of the automotive sector for turbocharger applications, with the aim of increasing the overall efficiency of internal combustion engines in favor of gaining power, torque, improve specific consumption and consequently improve level emission of polluting gases. Car manufacturers have been using the concept of downsizing consistently over the past decade, applying it to the entire product range. The engines are getting smaller, both in volumetric displacement and in number of cylinders and associated with advanced electronic technology. In addition, the search for renewable fuels has been gaining space across the world, as an alternative for the replacement of fossil fuels. Based on this, this project aimed to simulate the application of a turbocharger system in a single cylinder engine powered by ethanol and to study the influence of the pulsating effect of exhaust gases on its performance. The object of study was a $450 \mathrm{~cm}^{3}$ Yamaha WR450 engine that equips the Formula FEI team's RS12 prototype. Initially, vehicle data acquisition was used to study the main conditions of use of the engine and to understand where this naturally aspirated engine doesn't meet the team's needs. Subsequently, the engine was modeled in the one-dimensional simulation software AVL BOOST, in which all was insert the constructive data and the data acquired during the tests for which the vehicle is submitted in the Brazilian Formula SAE competition. From the results of the aspirated model, a second model was built with the application of a commercial turbocharger and it was analyzed how the characteristic pulsating effect of an engine with a reduced number of cylinders can influence the engine supercharger. In order to minimize them, two different exhaust manifold configurations were modeled: one with a very small volume and the other with a large volume. At the end, it is possible to decide which application provides the best compromise for gaining performance in terms of torque and power, in the determined speed range.
\end{abstract}

Keywords: Turbochargers. Pulsation. Engines. 


\section{LISTA DE ILUSTRAÇÕES}

Figura 1- Sequência de montagem para motores sobrealimentados

Figura 2 - Ciclo termodinâmico de motor quatro tempos - (a) Ciclo para motores naturalmente aspirados em carga parcial, (b) Ciclo para motores com aplicação de

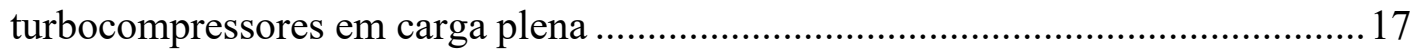

Figura 3 - Relação entre potência indicada e fluxo de ar..................................................... 20

Figura 4 - Processo idealizado de admissão em motores de quatro tempos ............................ 23

Figura 5 - Efeito de Pe/Pi sobre eficiência volumétrica para motores com pequenos ângulos de sobreposição.

Figura 6 - (a) Diagrama de tempo de válvulas circular; (b) Diagrama de tempo de válvulas do

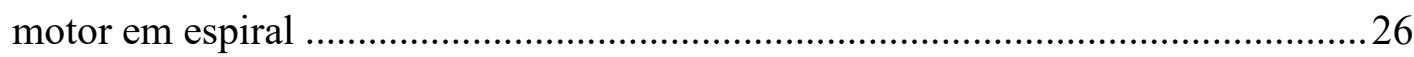

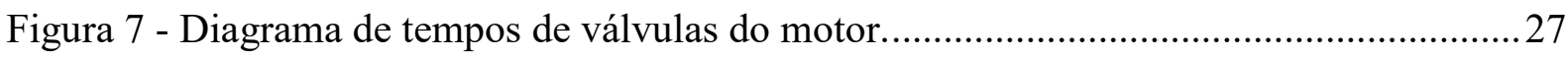

Figura 8 - Diagrama pressão volume ciclo Diesel........................................................... 28

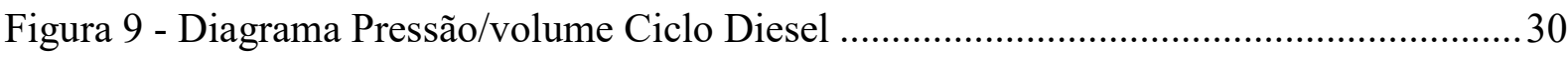

Figura 10 - Diagrama Pressão/volume Ciclo Diesel .......................................................... 31

Figura 11 - Princípio de funcionamento de um turbocompressor ..........................................32

Figura 12 - Figura 12 - Anatomia de um turbocompressor ................................................... 34

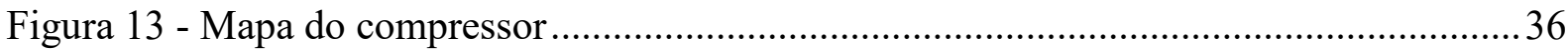

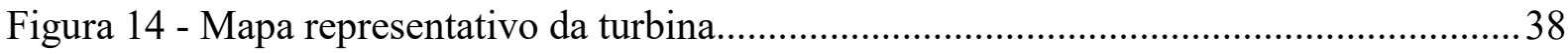

Figura 15 - Região de operação do motor no diagrama do compressor ................................... 41

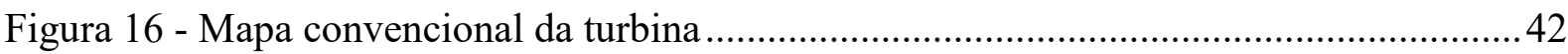

Figura 17 -Influência da eficiência do trocador de calor na massa especifica do ar ................44

Figura 18 -Influência da eficiência do trocador de calor na massa especifica do ar ................ 45

Figura 19 - Energia cinética teórica dos gases de exaustão................................................. 46

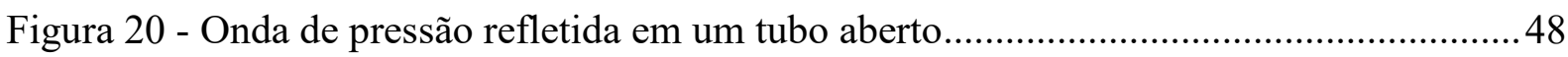

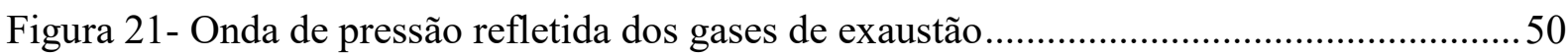




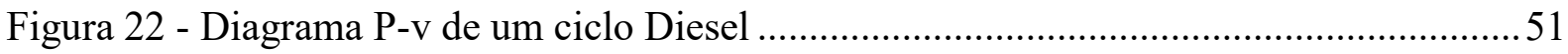

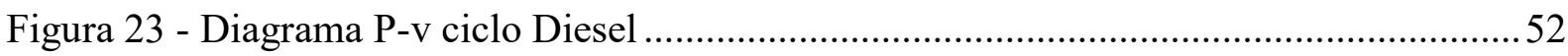

Figura 24 - Coletor de exaustão com grande volume.......................................................5

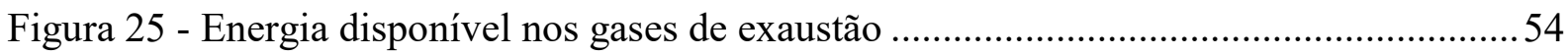

Figura 26 - Coletor de exaustão com volume mínimo ...........................................................55

Figura 27 -Energia disponível nos gases de exaustão coletor com pequeno volume................56

Figura 28 - Curvas de torque e potência obtidas na simulação .................................................58

Figura 29 - Curvas de torque e potência obtidas através de simulação .....................................59

Figura 30 - Comparação entre resultados de curvas de torque................................................ 60

Figura 31 - Curva de potência com a variação de volume de plenum no coletor de exaustão. 61

Figura 32 - Coletores de exaustão utilizados nos testes em bancada ......................................62

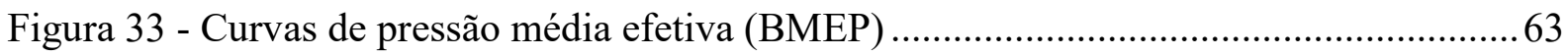

Figura 34 - BMEP e avanço de ignição versus MAP para coletores com pressão constante e efeito pulsativo no motor turboalimentado (50000 rev/min 10:1 CR) .................64

Figura 35 - Comparação de resultados nas curvas de torque e potência .................................64

Figura 36 - Veículo fórmula FEI RS9 com instrumentação em dinamômetro..........................66

Figura 37 - Curva de pressão média efetiva (BMEP) do motor Yamaha WR450F ….............67

Figura 38 - Aproximação da taxa de liberação de Calor ......................................................... 71

Figura 39 - Influencia do fator de forma na taxa de liberação de calor da combustão............. 72

Figura 40 - Parâmetro de forma para diferentes aplicações ................................................. 72

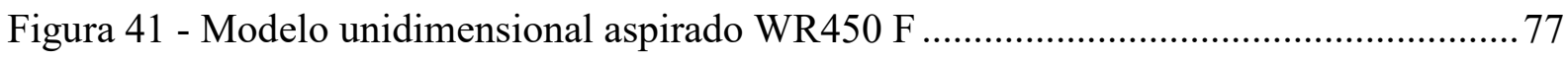

Figura 42 - Modelo unidimensional com aplicação de turbocompressor................................ 79

Figura 43 - Modelo unidimensional turbocomprimido com adição de um plenum no coletor de

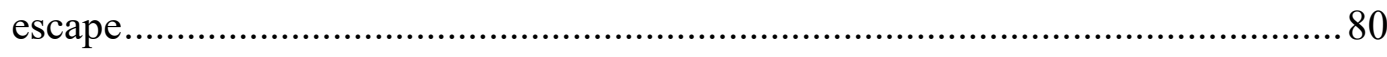

Figura 44 - Cabeçote Yamaha WR450F montado em bancada de fluxo ................................ 81

Figura 45 - Diagrama de tempo de válvulas Yamaha WR450F ............................................. 81 
Figura 46 - Processo de medição de componentes do motor Yamaha WR450F 82

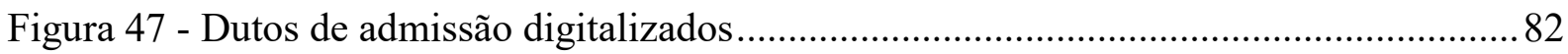

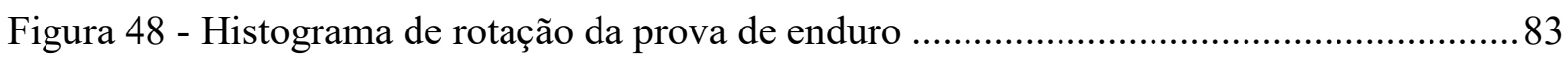

Figura 49 - Histograma de temperatura dos gases de exaustão da prova de enduro ................ 84

Figura 50 - Histograma de temperatura de admissão da prova de enduro .............................. 84

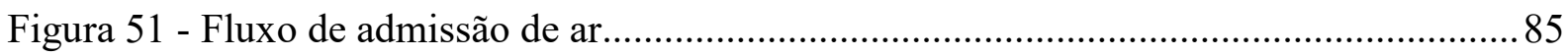

Figura 52 - Mapa de eficiência do compressor com curva de plena carga e rotação constante87

Figura 53 -Mapa de eficiência do compressor com região de operação do motor ....................89

Figura 54 - Curva de torque e potência do motor obtidas em dinamômetro de chassi ............91

Figura 55 - Curva de potência Yamaha WR450F ……....................................................... 92

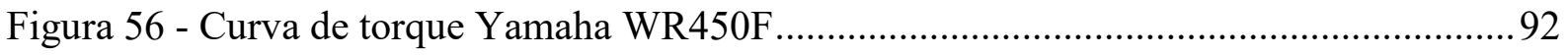

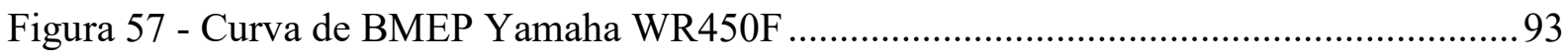

Figura 58 - Resultados dos pontos de operação do motor em plena carga obtidos em simulação

Figura 59 - Comparativo das curvas de torque entre os modelos do motor naturalmente aspirado

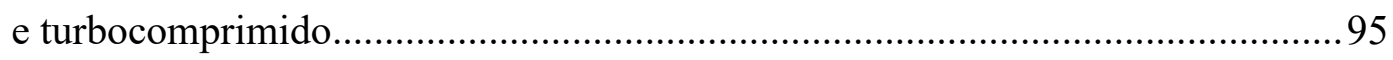

Figura 60 - Comparativo da curva de potência entre os modelos do motor naturalmente aspirado

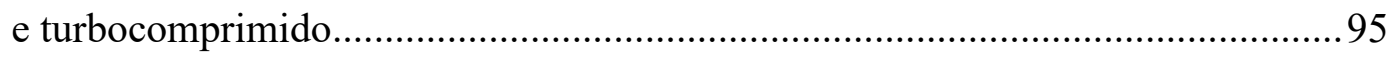

Figura 61 - Comparativo das curvas de IMEP entre os modelos do motor naturalmente aspirado

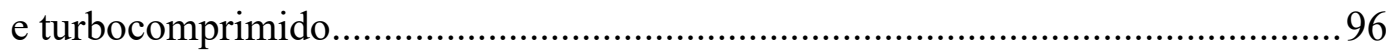

Figura 62 - Análise do impacto da alteração do volume do coletor de exaustão na curva de

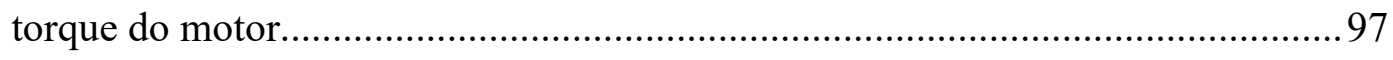

Figura 63 - Análise do impacto da alteração do volume do coletor de exaustão na curva de potência do motor.

Figura 64 - Análise do impacto da alteração do volume do coletor de exaustão na curva de

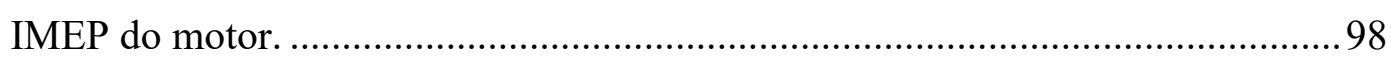

Figura 65 - Pressão dos gases no coletor de exaustão ao longo de 1 ciclo de operação do motor. 
Figura 66 - Comparativo entre curvas de torque do motor aspirado, turboalimentado com coletor de exaustão dimensionado por efeito pulsativo e pressão constante. 100

Figura 67 - Comparativo entre curvas de potência do motor aspirado, turboalimentado com coletor de exaustão dimensionado por efeito pulsativo e pressão constante........ 100

Figura 68 - Comparativo entre curvas de IMEP do motor aspirado, turboalimentado com coletor de exaustão dimensionado por efeito pulsativo e pressão constante. 101 


\section{LISTA DE TABELAS}

Tabela 1 - Comparativo entre motores dos veículos RS5 e RS6 .......................................... 12

Tabela 2 - Parâmetros de entrada do modelo Wiebe ................................................................... 73

Tabela 3 - Variáveis para cálculo do modelo de transferência de calor .................................. 75

Tabela 4 - Parâmetros de entrada do modelo de atrito ............................................................ 76

Tabela 5 - Valores de vazão mássica com aumento de pressão …….................................... 86

Tabela 6 - Vazão mássica para diferentes tipos de carga e rotação......................................... 88 


\section{LISTA DE SÍMBOLOS}

A - Área de troca de calor

$a$ - Parâmetro de eficiência da queima do combustível

BDC - Bottom dead center (Ponto Morto Inferior)

BMEP - Brake Mean Effective Pressure (Pressão média efetiva)

BSFC - Brake Specific Fuel Consumption (Consumo especifico do motor)

$c_{m}-$ Velocidade média do pistão $[\mathrm{m} / \mathrm{s}]$

$c_{u}-$ Velocidade circunferencial $[\mathrm{rad} / \mathrm{s}]$

$D$ - Diâmetro do cilindro [mm]

DOHC - Dual Overhead Camshaft (comando de válvulas duplo com acionamento no cabeçote

E - Erro entre valores teóricos e medições

EC, EVC - Exhaust valve close (fechamento da válvula de exaustão)

EO, EVO - Exhaust valve opening (Abertura da válvula de exaustão)

$F, A / F-$ relação ar-combustivel

FMEP $P_{A U X}$ - Friction Mean Effective Pressure in Auxiliary losses (Perdas por atrito nos componentes auxiliares)

$F M E P_{C S}$ - Friction Mean Effective Pressure in the Crankshaft (Perdas por atrito no virabrequim)

FMEP $P_{I P}-$ Friction Mean Effective Pressure in the injection pump (Perdas por atrito em bombas injetoras mecânicas)

$F M E P_{P}-$ Friction Mean Effective Pressure in the piston group (Perdas por atrito no pistão e seus componentes)

$F M E P_{V T}$ - Friction Mean Effective Pressure in the valvetrain (Perdas por atrito nos componentes do trem de válvulas)

$h_{c}$ - Coeficiente de transferência de calor

IC, IVC - Intake valve close (fechamento da válvula de admissão) 
IMEP - Idicated Mean Effective Pressure (Pressão media efetiva indicada)

IO, IVO - Intake valve opening (abertura da válvula de admissão)

$k$ - Constante adiabática dos gases ideais

$m_{e}$ - Massa de ar fresca

$m$ - Fator de forma da queima de combustível

$m_{a}, W_{a}, \dot{m}-$ Massa de ar

$n, N$ - Rotação do virabrequim

$\mathrm{N}$ - Número de medições ou amostras

NA - Naturalmente aspirado

$N_{i}$ - Potência indicada

OHV - Overhead valve (Comando de válvulas lateral com válvulas acionadas no cabeçote por varetas)

$p$ - Pressão do cilindro

$P a$ - Pressão ambiente

Pi, $M A P_{\text {req }}, M A P$ - Manifold absolute pressure (Pressão absoluta no coletor de admissão)

$P e-$ Pressão dos gases de exaustão

PMI - Ponto morto inferior

PMS - Ponto morto superior

$P_{1}$ - Pressão do ar na entrada do compressor

$P_{2}$ - Pressão do ar na saída do compressor

$P_{c y l}-$ Pressão no interior do cilindro

$P_{e x}-$ Pressão dos gases de exaustão

$P_{p}$ - Pressão no duto de exaustão

$p_{a}$ - Pressão ambiente

$p_{c, 0}$ - Pressão no interior do cilindro [ $\mathrm{MPa}$ ] 
$p_{c, 1}$ - Pressão no cilindro no momento em que as válvulas de admissão são fechadas (IVC) $[\mathrm{MPa}]$

$p_{e x}$ - Pressão no coletor de exaustão

$p_{\text {in }}$ - Pressão de admissão

PCI - Poder calorífico inferior

$Q_{p}-$ Taxa de transferência de calor

$R-$ Constante dos gases ideias

ROHR - Rate of Heat Release (Taxa de liberação de calor)

SLM - Modelo de atrito de Shayler, Leong e Murphy

SOHC - Single Overhead camshaft (comando de válvulas único com acionamento no cabeçote)

TC - Turbocompressor

TDC - Top dead center (Ponto Morto Superior)

$T_{1}$ - Temperatura do ar na entrada do compressor

$T_{2}$ - Temperatura do ar na saída do compressor

$T_{3}$ - Temperatura na saída do intercooler

$T_{c, 1}-$ Temperatura no cilindro no momento em que as válvulas de admissão são fechadas (IVC)

$\left[{ }^{\circ} \mathrm{C}\right]$

$T_{\text {cool }}$ - Temperatura do fluido utilizado para o resfriamento

Tm - Temperatura do ar no coletor de admissão

$T_{p}-$ Temperatura das paredes

$v_{\text {Toil }}-$ Viscosidade do óleo lubrificantes na temperatura de trabalho

$v_{\text {Toil }=90^{\circ} \mathrm{C}}-$ Viscosidade do óleo lubrificante na temperaura de $90^{\circ} \mathrm{C}$

$\mathrm{V}_{2}, V_{c l}$ - Volume da câmara de combustão

$V_{D}-$ Deslocamento por cilindro $[\mathrm{m} / \mathrm{s}]$

$V, V 1, V_{s w}, V_{d}$ - deslocamento volumétrico do motor

$x_{b}$ - Fração de combustível queimada 
$W$ - Trabalho útil

\section{LISTA DE SÍMBOLOS GREGOS}

$\epsilon$ - Efetividade da troca de calor

$\eta_{c}-$ Eficiência do compressor

$\eta_{t}-$ Rendimento térmico do motor

$\eta v, V E$ - Rendimento volumétrico do motor

$\theta$ - Ângulo de rotação do virabrequim

$\theta_{t}$ - Período necessário para que a onda refletida retorne ao cilindro no momento em que o pistão atinge o PMS

$\pi_{c}-$ Relação de compressão do ar

$\rho_{e}$ - Massa especifica do ar

$\rho_{1}-$ Massa específica de ar na entrada do compressor

$\rho_{2}-$ Massa específica de ar na saída do compressor 


\section{SUMÁRIO}

1 INTRODUÇÃO

1.1 CENÁRIO 11

1.2 OBJETIVOS 14

$\begin{array}{lll}\text { 1.2.1 } & \text { Objetivo principal } & 14\end{array}$

$\begin{array}{lll}\text { 1.2.2 } & \text { Objetivos secundários } & 15\end{array}$

2 REVISÃO BIBLIOGRÁFICA

2.1 MOTORES DE COMBUSTÃO INTERNA (CICLO OTTO) 16

2.2 O SURGIMENTO DOS TURBOCOMPRESSORES 18

2.3 CONSUMO DE AR EM MOTORES QUATRO TEMPOS 19

2.4 DIAGRAMA DE TEMPO DE VÁLVULAS DO MOTOR 25

2.4 BENEFÍCIOS DA SOBREALIMENTAÇÃO 27

2.5 PRINCÍPIO DE FUNCIONAMENTO DE UM SISTEMA $\begin{array}{ll}\text { TURBOCOMPRESSOR } & 31\end{array}$

$\begin{array}{llr}2.5 .1 & \text { Turbina } & 34\end{array}$

$\begin{array}{lll}\text { 2.5.2 Compressor } & 35\end{array}$

$\begin{array}{lll}\text { 2.5.3 Rolamentos } & 35\end{array}$

2.4.1 MAPAS 36

$\begin{array}{lll}2.4 .2 & \text { Compressor radial } & 36\end{array}$

$\begin{array}{lll}\text { 2.4.2 } & \text { Mapa da Turbina } & 37\end{array}$

2.5 MATCHING - ADEQUAÇÃO ENTRE TURBOCOMPRESSOR E MOTOR 38

2.5.1 Determinação da relação de pressão necessária. 39

2.5.2 Característica do fluxo de ar dos motores turboalimentados 40

2.5.3 Fluxo de admissão e a variação de massa específica 42

2.6 EXTRAÇÃO DOS GASES DE EXAUSTÃO 46 
2.7 UTILIZAÇÃO DOS GASES DE EXAUSTÃO: PRESSÃO CONSTANTE E EFEITO PULSATIVO

2.8 APLICAÇÕES DE TURBOCOMPRESSORES EM MOTORES DE BAIXO DESLOCAMENTO 56

2.9 CALIBRAÇÃO COM UTILIZAÇÃO DE UMA VELA INSTRUMENTADA 65

$3 \quad$ METODOLOGIA $\quad 68$

$\begin{array}{lll}3.1 & \text { PROPOSTA } & 68\end{array}$

$\begin{array}{lll}3.2 & \text { SOFTWARE AVL BOOST } & 69\end{array}$

$\begin{array}{lll}\text { 3.2.1 } & \text { Modelo de combustão } & 70\end{array}$

$\begin{array}{lll}\text { 3.2.2 } & \text { Modelo de transferência de calor } & 73\end{array}$

$\begin{array}{lll}\text { 3.2.3 } & \text { Modelo de atrito } & 75\end{array}$

3.3 DETERMINAÇÃO DOS PARÂMETROS DE ENTRADA DO MODELO $\begin{array}{ll}\text { NATURALMENTE ASPIRADO } & 77\end{array}$

3.4 CONSTRUÇÃO DO MODELO TURBOALIMENTADO 78

$4 \quad$ Procedimento experimental $\quad 80$

$5 \quad$ ANÁLISE DOS RESULTADOS

5.1 ANÁLISE DE DADOS DO MOTOR ASPIRADO 83

5.2 DIMENSIONAMENTO DO TURBOCOMPRESSOR 85

5.3 RESULTADOS SIMULAÇÃO MODELO ASPIRADO 90

5.4 RESULTADOS MODELO TURBOALIMENTADO 93

6 CONCLUSÕES $\quad 102$

7 CONSIDERAÇÕES PARA TRABALHOS FUTUROS 103

$\begin{array}{ll}\text { REFERENCIAS } & 105\end{array}$ 


\section{INTRODUÇÃO}

O Downsizing é uma solução promissora para os motores de combustão interna no mercado atual, uma vez que se busca a redução de massa, melhoria de eficiência energética e economia de combustível, resultando em motores de dimensões cada vez menores. Sendo assim, para se alcançar todos esses objetivos e atingir valores de torque e potência de acordo com a expectativa dos consumidores, faz-se necessário a integração de diferentes tecnologias. O turbocompressor retorna como uma tecnologia que proporciona uma sobrevida aos motores movidos à combustíveis fosseis devido aos seus benefícios no ganho de potência especifica, torque especfíico e o impacto direto nas emissões de gases de efeito estufa. Entretanto, a integração do sistema torna-se uma tarefa difícil à medida que os motores se tornam menores, com número de cilindros cada vez menores tornando o seu projeto mais desafiador em termos de vibrações mecânicas e fluxo de gases.

Neste cenário, é necessário estudar melhor o desempenho da turbina e do compressor, de forma a se alcançar uma boa interação entre o conjunto e o motor, trazendo ganho nos valores de torque e potência do motor, sem que seja comprometido os limites de temperaturas do ar, gases de exaustão, surge e choke do compressor.

A maioria dos estudos voltados para esta área dedica-se a investigação do fluxo de gases na turbina em diferentes regimes, com a finalidade de entender o modo como isso a afeta no comportamento do compressor. Assim, na aplicação na qual se deseja estudar, esse efeito se intensifica, exigindo uma atenção ainda maior.

\subsection{CENÁRIO}

O conceito do projeto de powertrain utilizado pela equipe formula FEI para o veículo movido a combustão dos últimos anos tem sido a aplicação prática de downsizing, com o objetivo de se obter performance através de modificações dos três parâmetros básicos de desempenho: potência (motor e transmissão), massa e aderência (suspensão, pneus e aerodinâmica). Dessa forma, a escolha da utilização de um motor de menor deslocamento volumétrico $\left(480 \mathrm{~cm}^{3}\right)$, quando comparado ao limite do regulamento $\left(710 \mathrm{~cm}^{3}\right)$ e alto torque, 
proporciona redução de massa em relação aos motores de maior deslocamento volumétrico, tornando o veículo mais compacto, influenciando diretamente em seu desempenho dinâmico.

Até o ano de 2009 a equipe formula FEI utilizou um motor quatro cilindros Honda CBR 600RR. No ano seguinte optou-se pela utilização de um motor monocilíndrico Yamaha WR450 originalmente de $450 \mathrm{~cm}^{3}$, o que proporcionou uma redução considerável de potência, entretanto permitiu ganhos em outros subsistemas na concepção do projeto do veículo. A Tabela 1 apresenta o comparativo entres os motores:

Tabela 1 - Comparativo entre motores dos veículos RS5 e RS6

\begin{tabular}{c|c|c}
\hline Motor & Honda CBR 600RR & Yamaha WR450F \\
\hline Massa $(\mathrm{kg})$ & 58 & 28 \\
Relação Massa/potencia $(\mathrm{kg} / \mathrm{kW})$ & 3,46 & 4,57 \\
Consumo $(\mathrm{L} / 100 \mathrm{~km})$ & 20 & 12,5 \\
Potência & $61 \mathrm{~kW} @ 13000 \mathrm{rpm}$ & $35 \mathrm{~kW} @ 8200 \mathrm{rpm}$ \\
Torque & $55,9 \mathrm{Nm} @ 8795 \mathrm{rpm}$ & $45 \mathrm{Nm} @ 6000 \mathrm{rpm}$ \\
Combustível & Gasolina & Etanol \\
\hline
\end{tabular}

Fonte: Equipe fórmula FEI 2010

Ao optar pelo motor Yamaha WR450F a equipe abriu mão de uma entrega de potência maior em rotações mais altas para poder utilizar uma aplicação onde a entrega de torque máximo é dada em uma faixa de rotação mais baixa. Devido a isso, foi possível desenvolver um veículo que proporciona maior força trativa em menores velocidades, conseguindo desenvolver maiores valores de aceleração na saída das curvas presentes no traçado da competição. O reduzido número de cilindro, apesar de penalizar o ganho de potência, ofereceu uma redução considerável de massa e dimensões, algo que possibilitou a construção de um pacote mais compacto que beneficiasse não só o desempenho em termos de torque e potência, mas como o dinâmico e aerodinâmico. 
O regulamento da competição Fórmula SAE, tanto nacional, quanto internacional permite a utilização de motores naturalmente aspirado e com de turbocompressores para a sobrealimentação de ar no sistema de admissão. Para qualquer uma das aplicações, é imposto a utilização de um restritor de ar no coletor de admissão com diâmetro definido.

Para os veículos movidos a gasolina é necessário usar um diâmetro máximo do restritor de $20 \mathrm{~mm}$ e para a utilização de etanol, o diâmetro do restritor imposto pelo regulamento deve ter um valor máximo de $19 \mathrm{~mm}$. A Figura 1 apresenta a sequência de instalação exigida pelo regulamento para a utilização do sistema turbocompressor.

Figura 1- Sequência de montagem para motores sobrealimentados

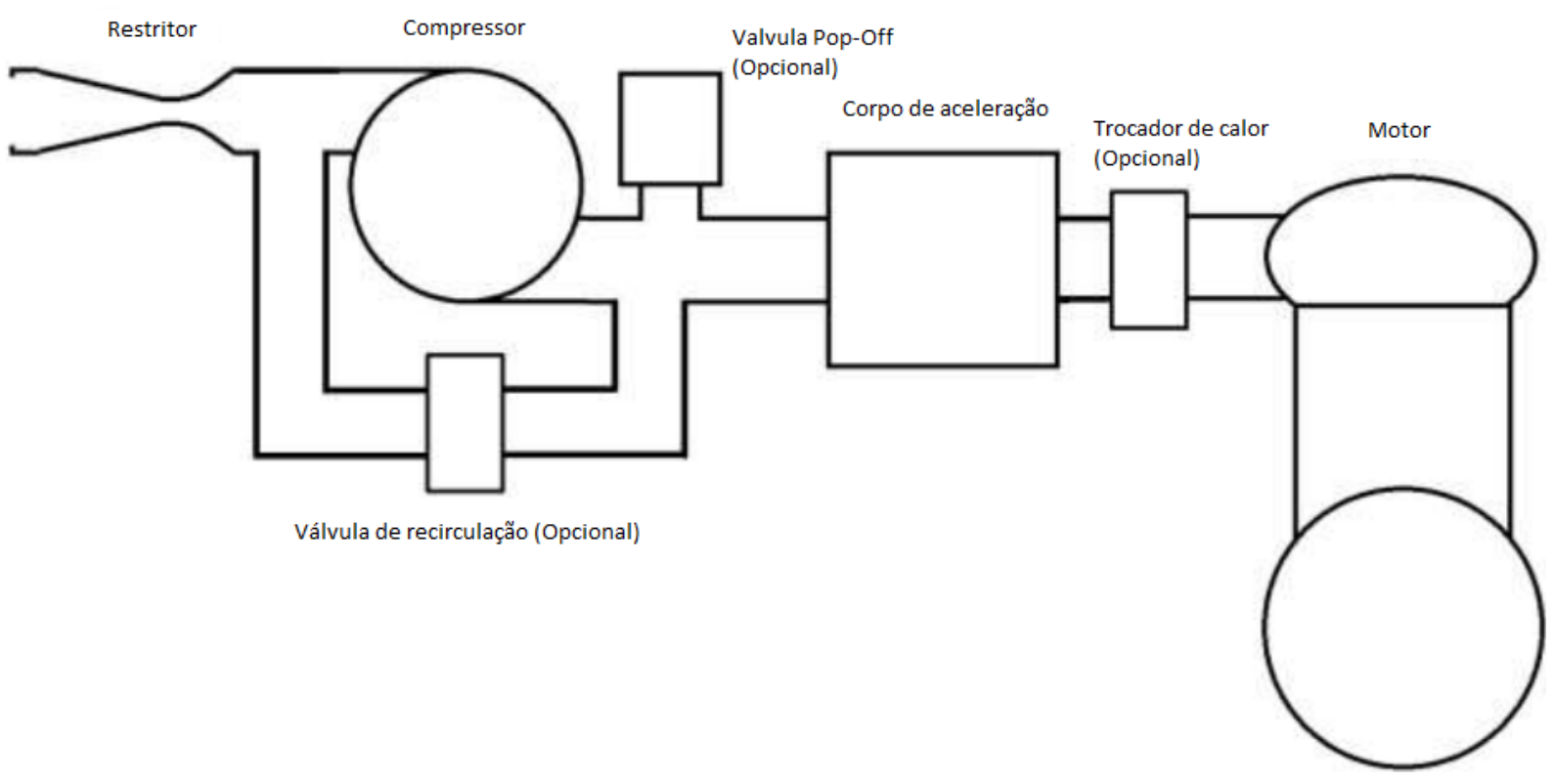

Fonte: Autor "adaptado de" Formula SAE Rules, 2020, p.72

O veículo desenvolvido ao longo dos anos, demonstrou resultados significativos, proporcionando muitas conquistas nos campeonatos nacionais e bons resultados nas competições internacionais.

Como um próximo passo para o desenvolvimento, não só do veículo, mas também dos estudos dos motores combustão interna, a sobrealimentação surgiu como um modo de não se alterar drasticamente os conceitos do pacote compacto do chassi e ao mesmo tempo conseguir um ganho de desempenho considerável em termos de torque e potência, podendo atingir valores de peso potência superiores à de equipes que utilizam motores de maior cilindrada. 
A construção de um motor monocilíndrico turboalimentado gera uma série de desafios. O primeiro deles seria encontrar um compromisso entre motor (junto com seus componentes) e turbocompressor de modo que os efeitos pulsativos provenientes dos gases de exaustão não prejudiquem a compressão do ar de admissão e, consequentemente a alimentação de ar do motor. O outro seria estudar como o restritor de ar na entrada do compressor afetaria o seu desempenho relação aos limites de surge.

Entretanto, apesar de todos os desafios, a correta utilização deste novo powertrain em desenvolvimento pode proporcionar resultados promissores de desempenho do veículo como um todo, além da produção de novas tecnologias pelos integrantes do time.

\subsection{OBJETIVOS}

Nesse tópico serão destacados os objetivos principais e secundários que se deseja atingir com a realização da pesquisa.

\subsubsection{Objetivo principal}

O objetivo principal deste trabalho é desenvolver um modelo numérico unidimensional que possibilite estudar a aplicação de um turbocompressor em um motor monocilíndrico, analisar o impacto dos efeitos pulsativos no compressor (através de duas configurações diferentes de coletor de exaustão) e como isso pode afetar no desempenho de motor com reduzido número de cilindros.

Os mapas de turbina e compressor utilizados para a aplicação foram levantados em bancada (gas stand) e os aspectos relacionados as variações instantâneas em razão de pressão presentes em uma condição de regime transiente não foram abordadas. 


\subsubsection{Objetivos secundários}

Como objetivos secundários deseja-se estudar o grau de confiança da ferramenta AVL BOOST, assim como a correlação dos resultados reais com os obtidos em simulação. Além disso, pretende-se analisar se a adequação do turbocompressor ao motor terá resultados satisfatórios. Por fim, os resultados obtidos servirão como auxílio na tomada de decisão de qual configuração de motor poderá ser construída. 


\section{REVISÃO BIBLIOGRÁFICA}

Neste tópico será abordada uma breve história sobre a invenção dos motores de combustão interna, sobre o surgimento da aplicação de turbocompressores, o princípio de funcionamento dos motores, os conceitos fundamentais da sobrealimentação, como realizar os cálculos para o dimensionamento do turbocompressor e a influência que as mudanças no sistema podem proporcionar quanto ao desempenho do veículo como um todo.

\subsection{MOTORES DE COMBUSTÃO INTERNA (CICLO OTTO)}

Os motores de combustão interna com ignição por centelha tiveram seu início de utilização no ano de 1862, quando o francês Beau de Rochas propôs um ciclo com uma determinada sequência de etapas que viria a se tornar características de motores de ciclo Otto: admissão, compressão, expansão e exaustão. Sendo assim, descreveu-se cada etapa que define o ciclo de trabalho como (OBERT ,1973):

- Admissão: um fluxo de ar misturado juntamente com combustível pulverizado pelo injetor é admitido pela válvula de admissão, preenchendo o interior do cilindro, enquanto que válvula de exaustão permanece fechada. O fator que provoca essa indução é o movimento descendente do pistão, que se desloca do ponto morto superior (PMS) em direção do ponto morto inferior (PMI), gerando uma região de baixa pressão no interior do cilindro.

- Compressão: momento onde ambas as válvulas se fecham e há o movimento de ascensão do pistão, fazendo com que a mistura seja comprimida, aumentando a pressão e a energia interna dentro do cilindro.

- Expansão: quando o pistão se aproxima novamente do PMS, a vela dispara uma centelha que inicia o processo de queima da mistura ar-combustível. A medida que a frente de 
chama se propaga no interior da câmara de combustão, a temperatura aumenta juntamente com a pressão. Isso faz com que todo o gás presente lá dentro sofra expansão e empurre o pistão em direção ao PMI novamente.

- Exaustão: no momento em que o pistão chega no PMI a válvula de exaustão se abre e inicia-se o movimento de ascensão do pistão e expulsão dos gases resultantes do processo de queima, completando assim, o ciclo.

O ciclo pode ser representado pelo diagrama da Figura 2 (Heywood,1988)

Figura 2 - Ciclo termodinâmico de motor quatro tempos - (a) Ciclo para motores naturalmente aspirados em carga parcial, (b) Ciclo para motores com aplicação de turbocompressores em carga plena

Quatro tempos NA

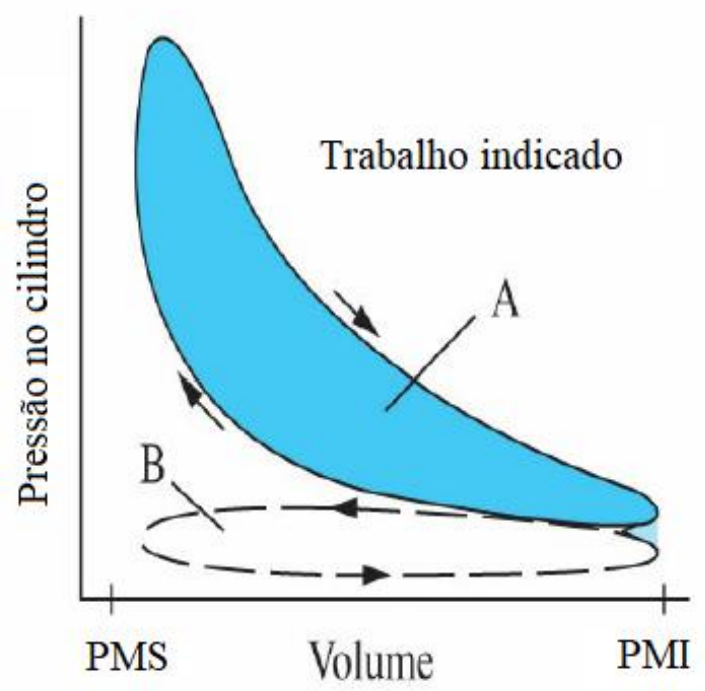

(a)
Quatro tempos TC

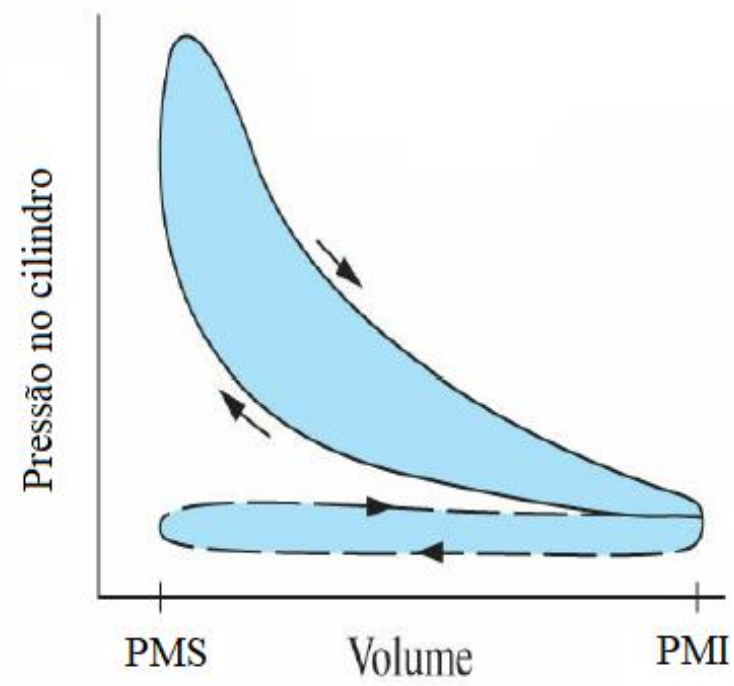

(b)

Fonte: Autor "adaptado de" Heywood, 2018, p.91

Em 1876, Nikolaus Otto, a partir da teoria fundamentada por Beau de Rochas, construiu o primeiro motor a combustão de quatro tempos. (OBERT,1973)

Desde então, os motores têm sido instrumento de pesquisa, onde se busca o aumento de sua eficiência. Várias modificações geométricas e construtivas e no seu ciclo térmico vem sendo aplicadas e desenvolvidas. 
$\mathrm{Na}$ busca por desempenho e eficiência energética para atender as diferentes legislações e necessidades de mercado, a eletrônica tem sido aliada no processo de automação de diversos dispositivos tais como: a injeção eletrônica, comando de válvulas variável ou até mesmo eletrônico, aceleradores by wire e, por fim, válvulas de alívio de turbocompressores.

\subsection{O SURGIMENTO DOS TURBOCOMPRESSORES}

A invenção do turbocompressor foi creditada ao engenheiro suíço Alfred Buechi em 1905, após a publicação de uma patente compondo uma aplicação em um motor. Este documento apresentava um turbocompressor diferente do que é conhecido nos dias atuais, havia uma turbina de fluxo axial e um compressor que compartilhavam um eixo com o motor. Este projeto não obteve sucesso comercial, porém deu origem a uma série de estudos do uso dos gases em turbinas e compressores visando melhoria de desempenho (MILLER 2008).

Em 1916, o professor Auguste C.E Rateau, aplicou os conceitos de Buechi em uma patente que só foi divulgada no ano de 1921. Paralelamente a isso, em 1917 a National Advisory Comitte for Aeronautics aproximou Safornd A. Moss da General Electric para um rápido desenvolvimento do turbocompressor para dar suporte a motores de aplicação aeronáutica durante a guerra. A pesquisa levou à conclusão que o turbocompressor era uma solução para os motores dos caças militares atingirem grandes velocidades e altitudes.

O fim da primeira guerra mundial retardou o desenvolvimento dos turbocompressores, porém adicionou tempo para a resolução de problemas de projetos e realização de testes. A General Electric continuou a pesquisa durante a segunda guerra, sendo os turbocompressores desenvolvidos por Moss utilizados em todos os caças e bombardeiros.

Os turbocompressores começaram a ganhar popularidade no pós-guerra, se tornando gradualmente um grande impulso econômico. Muitas montadoras começaram a aplicá-lo em seus motores de ciclo Diesel, para ganho de potência, conseguindo assim, vantagem em termos de desempenho.

Durante os anos 60 iniciou-se as aplicações em motores para automóveis comerciais. Entretanto, a maioria dos motores disponíveis não eram projetados para atingir os níveis de pressão e temperatura que a aplicação exigia. Além disso, a aplicação em motores de ciclo Otto 
necessitava a utilização do carburador para dosagem da quantia de combustível, fazendo com que o projeto do turbocompressor fosse repensado para resolução de problemas de durabilidade e funcionamento do carburador. Desta forma, o consumidor preferia ter um motor de maior deslocamento naturalmente aspirado que proporcionava grandes valores de potência e desempenho.

Com a crise do petróleo em 1970, paralelamente com os movimentos ambientais a favor da redução da emissão de poluentes iniciado em 1977, Detroit tornou-se o foco da eficiência energética e da baixa emissão de carbono. Motores menores queimavam menos combustível e eram mais econômicos, entretanto o mercado americano exigia aplicações que demandavam mais potência.

Em 1980 retorna a ideia de que o turbocompressor poderia ser o caminho para o ganho de potência em motores de baixo deslocamento. Entretanto a aplicação com turbocompressores ainda causava problemas, devido ao posicionamento do carburador, uma vez que a dosagem de combustível nos carburadores à época era baseada na velocidade do escoamento e se mostrava indiferente à massa específica do ar admitido, tornando o controle da dosagem de combustível mais complexa.

A introdução do sistema eletrônico de gerenciamento de injeção de combustível tornou a aplicação dos turbocompressores mais fácil que em outros tempos. Sendo assim, houve um interesse muito maior por parte da indústria e do consumidor neste tipo de projeto.

\subsection{CONSUMO DE AR EM MOTORES QUATRO TEMPOS}

A potência indicada de um motor pode ser escrita pela equação 1 (BRUNETTI, 2012):

$$
N_{i}=m_{a} \cdot F \cdot P C I . \eta_{t}
$$

Onde $N_{i}$ é a potência indicada, $m_{a}$ é a vazão em massa de ar seco que escoa para os cilindros, $F$ é a relação combustível-ar e $\eta_{t}$ é o rendimento térmico do motor. 
A equação 1 mostra que a potência indicada é função do rendimento térmico, que por sua vez, está relacionado a massa de ar admitida, taxa de compressão, fração de combustível, troca de calor, dentre outros. Admitindo que o tipo de combustível não veja alterado, é possível manter-se o rendimento térmico do motor em um valor muito próximo de constante, tornando a potência indicada diretamente proporcional a vazão de ar. A Figura 3 mostra como a proporcionalidade da potência indicada é mantida segundo as condições impostas (TAYLOR, 1971):

Figura 3 - Relação entre potência indicada e fluxo de ar

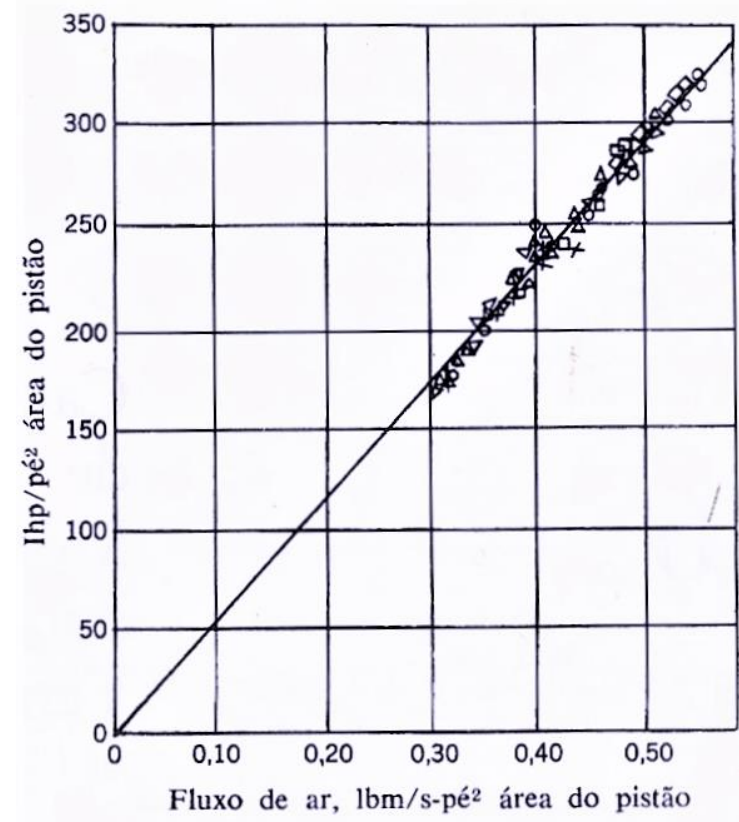

Fonte: Taylor, 1971.

A relação entre potência indicada e fluxo de ar. O diagrama foi levantado com um motor de taxa de compressão 5 e $F=1,2$. Os diferentes símbolos representados no gráfíco representam diferentes diâmetros de válvulas, formas e curso. A proporcionalidade encontrada foi considerada válida para diferentes tipos e tamanhos de motores de ignição por centelha.

É importante ressaltar que a equação 1 só é válida para um valor de $\mathrm{F}$ próximo do estequiométrico, pois este afeta a potência de forma não linear. 
Para motores a combustão, a variação da potência pode ser feita através do aumento da vazão de ar e consequentemente da fração de combustível. Um dos modos de se fazer isso sem alterar as propriedades geométricas do motor é através da variação da densidade do ar com o aumento da pressão de ar na admissão.

O rendimento volumétrico é definido como sendo a relação entre a massa de ar fresca que entra no cilindro durante o curso de admissão e a massa de ar que preencheria o volume deslocado pelo cilindro com a densidade do ar atmosférica do local. Essa relação pode ser definida pela equação 2 para um motor 4 tempos (TAYLOR ,1971):

$$
\eta v=\frac{2 m_{e}}{\rho_{e} \cdot V \cdot n}
$$

Onde $m_{e}$ é a massa de ar fresca que é admitida para o interior do cilindro, $\rho_{e}$ é a densidade (massa especifica) do ar nas condições de entrada (temperatura ambiente do vão do motor), $\mathrm{V}$ é o deslocamento volumétrico e $n$ é a rotação.

A eficiência volumétrica é utilizada como medida de desempenho do conjunto do cilindro como elemento de bombeamento. Para se avaliar o desempenho define-se como densidade da massa de ar fresca o valor na entrada da válvula, ou uma região muito próxima. Quando $\rho e$ é determinado dessa forma, a eficiência volumétrica resultante mede as condições de bombeamento do ar para o cilindro e a perda de cargas na válvula.

Nem sempre é possível se obter a medida exata do valor de densidade na entrada da válvula, portanto mede-se a densidade próximo da tomada de ar. Portanto, quando a massa especifica do ar fresco é tomada nas condições atmosféricas, a eficiência volumétrica é resultante do desempenho do escoamento sobre todo o sistema de admissão, incluindo perdas no coletor de admissão, cilindros e válvulas.

Neste caso, a eficiência volumétrica passa ser considerada como eficiência volumétrica global. A eficiência volumétrica global em motores sobrealimentados, por ser uma variável que traz impactos de mais de um subsistema, é desconsiderada, uma vez que não diferencia o 
desempenho do compressor e dos cilindros. Neste caso é importante medir a temperatura e pressão da massa de ar na saída do compressor.

A potência indicada do motor pode ser escrita também em função da eficiência volumétrica, fazendo-se as transformações da equação 3 :

$$
m_{a}=\frac{\eta_{v} \cdot \rho_{e} \cdot V \cdot n}{2}
$$

Substitui-se a equação (3) em (1) e obtém-se:

$$
N_{i}=\frac{\rho_{e} \cdot V \cdot n \cdot F \cdot P C I \cdot \eta_{t} \cdot \eta_{v}}{2}
$$

Portanto, a eficiência volumétrica também influenciará no ganho ou na perda de potência indicada no motor. Devido a isso, compreende-se a importância do sistema de sobrealimentação nos veículos atuais. Neste tipo de motor a pressão de admissão será maior que a pressão de exaustão resultando em uma relação $P e / P i<1$. Essa relação provoca um ganho de área no diagrama do ciclo Otto, aumentando assim o trabalho produzido. Segundo Taylor (1971), isso pode ser mostrado através da análise de um diagrama do processo ideal de admissão de um motor no qual a pressão de admissão é maior que a pressão dos gases de exaustão. A Figura 4 apresenta a comparação entre dois ciclos ideais do processo de admissão, onde o ciclo (a) apresenta um processo cujo $P e / P i<1$ e o ciclo ideal (b) apresenta uma relação $P e / P i=1:$ 
Figura 4 - Processo idealizado de admissão em motores de quatro tempos

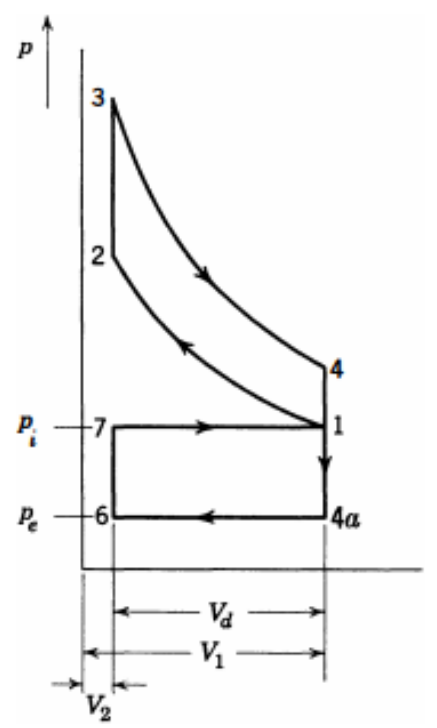

(a)

$p_{e} / p_{i}<1.0$

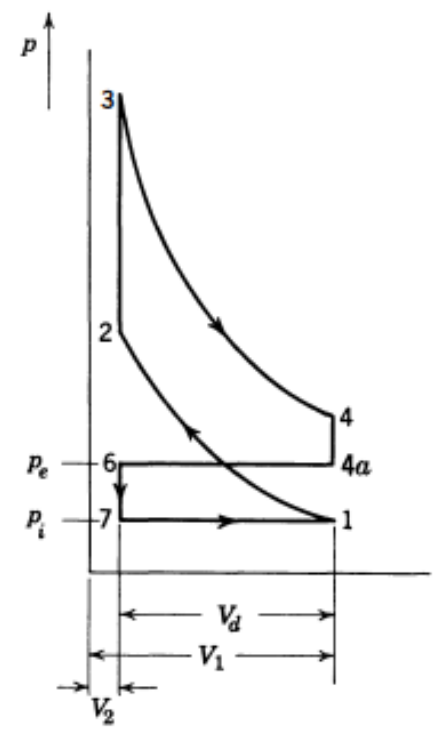

(b)

$p_{e} / p_{i}>1.0$

Fonte: Taylor, 1971

Nota-se que no ponto 6 que o pistão se encontra no PMS, e o volume da câmara V2 está preenchido com gases residuais a uma determinada temperatura e pressão. Neste instante a válvula de exaustão se fecha e a válvula de admissão se abre. Antes do início da descida do pistão, se $P i>P e$, a mistura fresca entra no cilindro comprimindo os gases resultantes da queima anterior ao processo. Caso $P i<P e$, os gases residuais acabam saindo do cilindro e ocupando o interior do duto de admissão, até que as pressões se igualem. Desta forma, no segundo caso, se os gases de exaustão escaparem para o duto de admissão, quando ocorrer a descida do pistão, estes serão succionados para dentro do cilindro novamente. Uma série de efeitos negativos são ocasionados por esse processo caso essa recirculação dos gases não seja desejada, que acaba resultando em uma perda de potência do motor, uma vez que a eficiência volumétrica tem seu valor reduzido quando comparado ao primeiro caso.

A Figura apresenta os valores de eficiência volumétrica através da razão $P e / P i$ para diferentes relações de compressão (r): 
Figura 5 - Efeito de Pe/Pi sobre eficiência volumétrica para motores com pequenos ângulos de sobreposição.

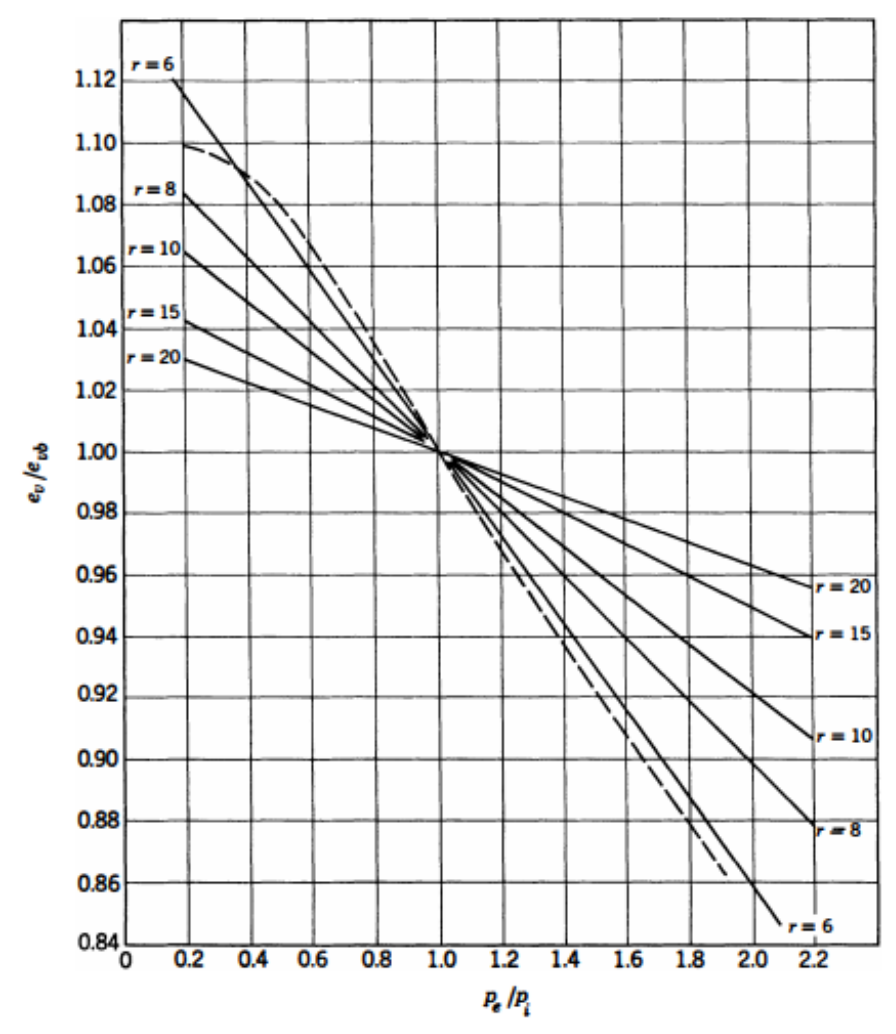

Fonte: Taylor, 1971

O diagrama da Figura 5 foi obtido para comandos de válvulas com pequeno ângulo de superposição. A eficiência volumétrica é definida pela relação $e_{v} / e_{v b}, e_{v}$ representa a eficiência volumétrica do motor e $e_{v b}$ a eficiência volumétrica quando $P e / P i=1$. A medida que o valor de Pe torna-se maior que o valor de Pi, indicando que a pressão dos gases de exaustão é maior que a pressão dos gases de admissão, a eficiência volumétrica começa a atingir valores menores que 1. Isso é ocasionado pelo retorno dos gases de exaustão para o duto de admissão, fazendo com que o resíduo torne a combustão incompleta. Quando Pe atinge valores menores que $\mathrm{Pi}$, a eficiência volumétrica tem seu valor aumentando, uma vez que, a baixa pressão no coletor de exaustão faz com que a inércia da massa de ar fresca de admissão preencha com maior facilidade o interior do cilindro, fazendo com que todos os gases residuais sejam retirados do seu interior, melhorando assim a eficiência da combustão. Este efeito pode ser notado para qualquer relação de compressão (r) na qual o motor trabalhe. (TAYLOR ,1971)

Sendo assim, para aumentar os valores de eficiência volumétrica, um dos caminhos é a utilização de um enquadramento de comando de válvulas com um ângulo de sobreposição 
(overlap) de duração longa. No caso dos motores sobrealimentados isso pode ter uma função complementar de resfriar a temperatura do gás de escape na entrada da turbina além de ajudar na limpeza da câmara de combustão de forma mais efetiva. Entretanto, para algumas aplicações de motores, quando se utiliza uma injeção de combustível indireta ou com carburador, isto pode ocasionar a passagem do combustível não queimado para o coletor de exaustão. (BRUNETTI ,2012).

Quando se adianta a abertura da válvula de admissão (abertura antes do pistão atingir PMS no curso de exaustão) implica que quando ocorrer o processo de admissão da massa de ar fresca a válvula estará totalmente aberta, oferecendo uma menor perda de carga naquela região.

Quando se atrasa o fechamento da válvula de exaustão (após pistão atingir o PMS no curso de exaustão) existirá uma redução na elevação de pressão no cilindro. Ambos efeitos combinados, tendem a resultar em uma melhora significativa da eficiência volumétrica.

\subsection{DIAGRAMA DE TEMPO DE VÁLVULAS DO MOTOR}

Na maioria dos motores a combustão $4 \mathrm{~T}$ a válvula de admissão está aberta e a de exaustão está fechada quando o pistão está no Ponto Morto Superior (PMS). Inicialmente o pistão acelera e depois desacelera descendo em seu curso, criando uma depressão dentro do cilindro que acaba induzindo a admissão de ar fresco para dentro da câmara de combustão, parando momentaneamente no Ponto Morto Inferior (PMI) (HEISLER, 2005).

No fim do curso, o pistão inverte a direção do seu movimento e no mesmo instante a válvula de admissão se fecha. O pistão se move para cima em direção ao cabeçote, comprimindo o ar e reduzindo o volume da câmara, elevando a pressão dentro do cilindro.

A medida que o pistão se aproxima do fim do curso de compressão, ele vai desacelerando até parar e mudar a direção do movimento. A carga do cilindro é inflamada por uma faísca para motores Otto, ou por combustão espontânea (motores Diesel) ocasionando a combustão da mistura e a queima do combustível. Este processo dá origem à expansão do gás que empurra o pistão no sentido do PMI. 
Ao alcançar o PMI, tem-se o início da subida do pistão novamente. Nesse instante a válvula de escape se abre, e o pistão empurra para fora os gases resultantes da queima do combustível, limpando a câmara de combustão e se preparando para o início do ciclo de admissão.

Para aumentar a eficiência da limpeza da câmara de combustão e acelerar a saída dos gases, a abertura da válvula de admissão é antecipada. Sua abertura é calculada para acontecer instante antes do pistão atingir o PMS do curso de exaustão, permanecendo aberta para o curso de admissão.

O período de abertura e fechamento das válvulas é dado em função da rotação do eixo do comando de válvulas, que por sua vez é sincronizado com a rotação do eixo do virabrequim, responsável por ditar o movimento do pistão.

Existe um período onde as duas válvulas se encontram abertas simultaneamente. Este intervalo é chamado de overlap (sobreposição). A presença do overlap é praticamente inevitável, ele pode trazer benefícios ou malefícios para o ciclo, em termos de potência e emissão de poluentes, dependendo do seu período de duração e faixa de rotação do motor.

O entendimento do diagrama de válvulas é relativamente simples. Quando se pensa isoladamente na rotação do eixo do comando de válvulas, o período de abertura das válvulas é representado por dois semicírculos que resulta em um diagrama circular do tempo de operação de ambas, exaustão e admissão. Em um diagrama de um motor quatro tempos, analisando as quatro etapas do motor, obtém-se um diagrama em espiral. A representação destes diagramas é demonstrada através da Figura 6.

Figura 6 - (a) Diagrama de tempo de válvulas circular; (b) Diagrama de tempo de válvulas do motor em espiral

a)

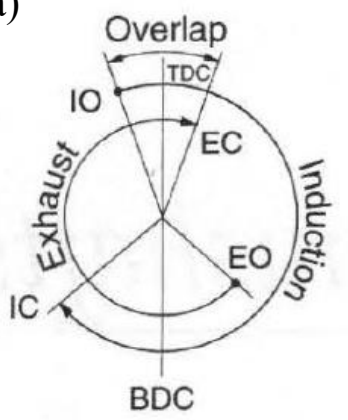

b)

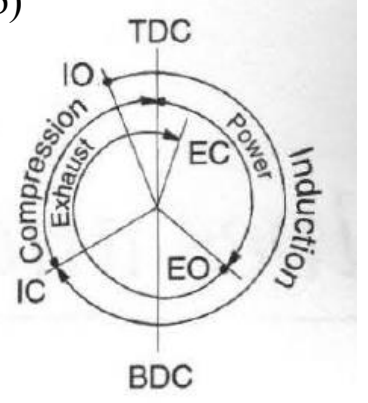

Fonte: Heinz Heisler, 2005. 
Para avaliar a abertura e fechamento das válvulas, o modo mais interessante de estudálo é através do diagrama que ilustra o levante (lift) em função do ângulo do virabrequim (crank angle). Esse diagrama permite uma série de avaliações como o perfil do came, levante máximo das válvulas, período de overlap e duração do ciclo. A Figura 7 demonstra o diagrama.

Figura 7 - Diagrama de tempos de válvulas do motor.

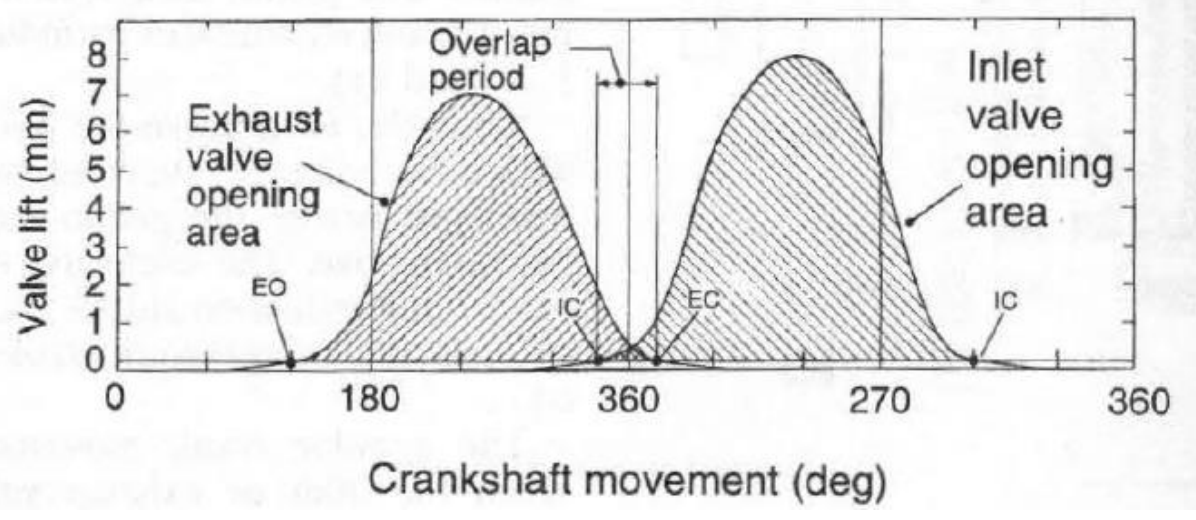

Fonte: Heinz Heisler, 2005

Todos os conceitos apresentados demonstram como as inúmeras variáveis que envolvem o funcionamento da admissão de ar podem impactar positivamente ou negativamente na alimentação de ar do cilindro e, consequentemente, no valor de potência indicada do motor. O aproveitamento da cinética dos gases de admissão e exaustão são fundamentais em um projeto, para que se possa sempre aproveitar da melhor forma o preenchimento e a liberação dos gases no interior do cilindro melhorando assim a eficiência volumétrica do motor e da queima do combustível, fazendo com que seja possível aproveitar melhor a energia produzida pela combustão.

\subsection{BENEFÍCIOS DA SOBREALIMENTAÇÃO}

Segundo Watson e Janota (1982) “a sobrealimentação pode ser definida como a indução de ar (ou mistura ar-combustível) para o interior do cilindro com uma densidade maior que o valor ambiente. Isso permite aumentar a fração de combustível necessária para a reação de combustão, aumentando assim a potência produzida pelo ciclo" 
O principal objetivo é proporcionar o aumento no ganho de potência e não de eficiência, entretanto isso pode ocorrer como um benefício extra. O diagrama pressão/volume (diagrama $\mathrm{P}-\mathrm{V}$ ) de um ciclo Diesel é representado na Figura 8:

Figura 8 - Diagrama pressão volume ciclo Diesel

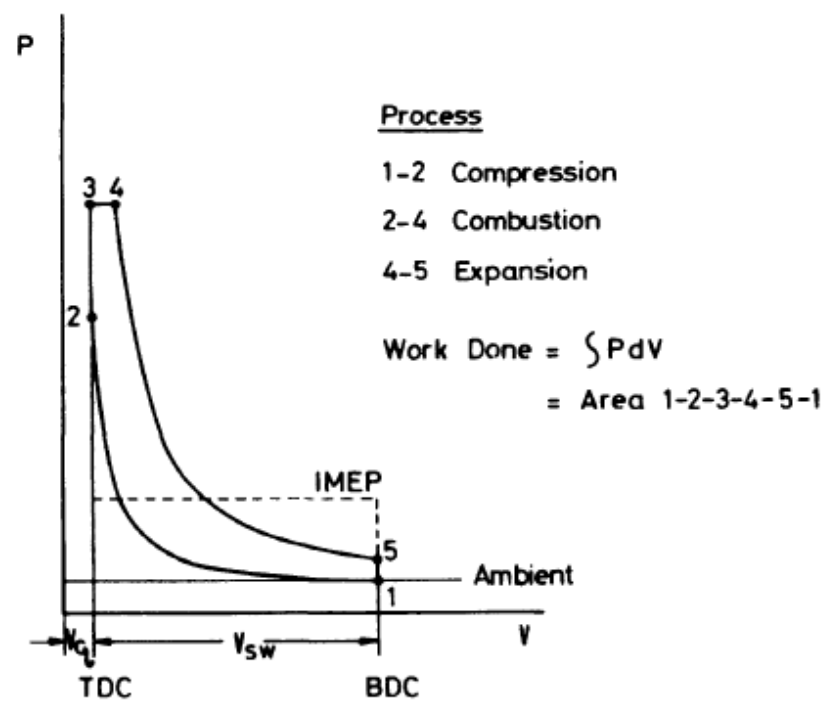

Fonte: Watson e Janota, 1982

O ponto 1 aponta o início do processo de compressão, quando o pistão está no PMI. O processo 1-2 representa o curso de compressão. A etapa 2-3 é o momento onde o pistão chega ao PMS e ocorre a combustão (instantânea), mantendo-se o volume constante. O processo 3-4 retrata o restante do processo de combustão à pressão constante enquanto o pistão movimentase ao longo do cilindro. Em 4-5 ocorre o processo de expansão do gás proveniente da queima da mistura. No ponto 5 a válvula de exaustão se abre e o gás deixa o interior do cilindro, fazendo com que o valor da pressão volte a se igualar com o valor atmosférico. Os processos de admissão e exaustão não são demonstrados neste diagrama.

O trabalho produzido é obtido durante o processo descrito nos pontos 3-4-5. O autor nomeia esta etapa como "curso de potência". No processo 1-2, acontece o efeito contrário, uma vez que é gasto uma certa fração do trabalho produzido para comprimir a mistura. Sendo assim, o 
trabalho útil realizado pelo ciclo é definido pela integração da área entre os pontos 1-2-3-4-51. Sendo assim define-se:

$$
W=\int p d V
$$

O processo descrito na Figura 8 ocorre durante uma das voltas do virabrequim (para motores de quatro tempos), enquanto a outra volta é utilizada para realizar os processos de admissão e exaustão dos gases. Desta forma, a área do diagrama multiplicada pela metade do valor da rotação do motor resulta na potência de saída do motor.

A Figura 9 faz a comparação entre os ciclos de motores naturalmente aspirados e sobrealimentados. É importante notar que os ciclos sobrealimentados iniciam com um valor de pressão maior no ponto 1'. O combustível extra pode ser queimado entre 2' e 4' devido a maior fração em massa do ar admitido. Devido a isso, Watson e Janota (1982) destaca duas condições claras: O ciclo sobrealimentado apresenta um considerável aumento no valor de potência e de pressão máxima devido a maior massa de ar que possibilita uma maior fração de queima de combustível. Deste modo o motor precisa ser projetado para suportar mecanicamente as condições solicitantes devido aos valores de pressão máxima, sem que haja a fratura de seus componentes internos e externos. 
Figura 9 - Diagrama Pressão/volume Ciclo Diesel

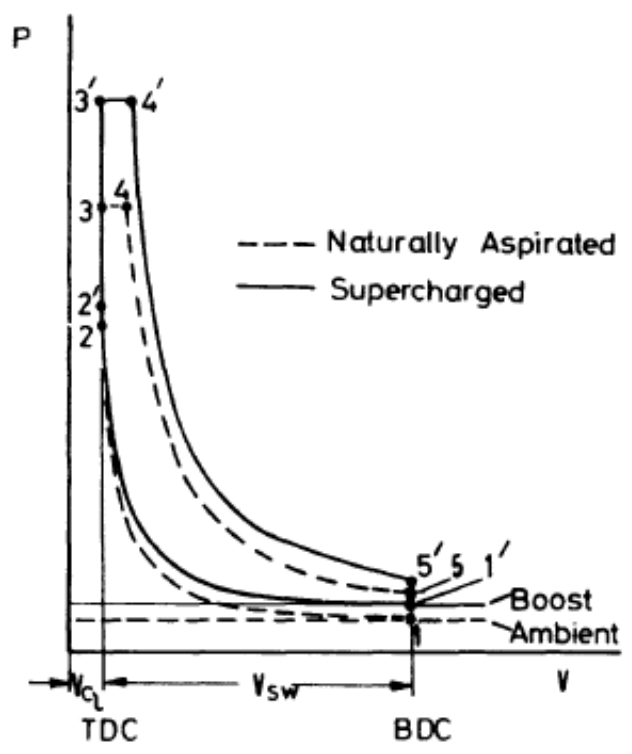

Fonte: Watson e Janota, 1982.

Uma forma de contornar o problema com o gradiente de pressão máxima seria a redução da taxa de compressão através do aumento do volume da câmara de combustão. Se a taxa de compressão for adequadamente selecionada, a máxima pressão do motor sobrealimentado pode atingir valores iguais aos motores naturalmente aspirados, permitindo um ganho considerável de potência de saída e evitando que haja um grande pico de pressão no momento da combustão que proporcione algum dano estrutural ao motor. Isto é mostrado na Figura 10: 
Figura 10 - Diagrama Pressão/volume Ciclo Diesel

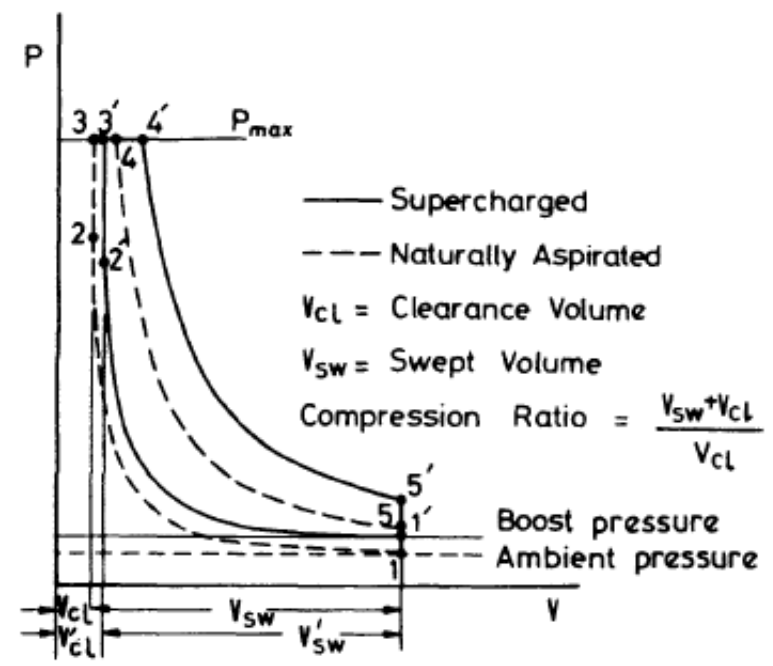

Fonte: Watson e Janota, 1982.

Os conceitos abordados servem para demonstrar como a sobrealimentação pode influenciar no ciclo termodinâmico do motor, quais os processos que são alterados e o porquê o trabalho realizado pelo motor acaba resultando em valor superior ao motor naturalmente aspirado. A teoria justifica a utilização do turbocompressor para se obter ganho de potência sem que seja alterado o volume do cilindro. Além disso, é possível conectar os conceitos discutidos nos tópicos 2.3 e 2.4 demonstrando que a massa de ar acrescentada dentro do cilindro, está relacionado a compressão do ar e também ao aumento da eficiência volumétrica do motor, permitindo que uma maior quantidade de combustível seja queimada, produzindo um valor de trabalho ainda maior.

\subsection{PRINCÍPIO DE FUNCIONAMENTO DE UM SISTEMA TURBOCOMPRESSOR}

A potência de um motor de combustão interna é apenas produzida pela queima do combustível. Sendo assim, quanto maior a quantidade de combustível, maior será a potência produzida pelo motor (MILLER, 2008)

Teoricamente, nas condições normais de alimentação de ar do motor, ou seja, quando a pressão do fluxo de admissão tem o mesmo valor da pressão atmosférica, cria-se uma limitação 
quanto a quantidade de ar que pode ser introduzida no interior do cilindro. O valor máximo de massa de ar fresco que o motor consegue admitir nessa condição é igual ao produto do volume de deslocado pela massa especifica do ar. Consequentemente limita-se a quantidade máxima de combustível que pode ser queimada. Sendo assim, a função do turbocompressor é proporcionar um aumento da vazão mássica de ar (através do aumento do valor da massa específica) na alimentação do motor sem que seja necessário modificar o seu deslocamento. Desta forma, é possível aumentar-se a quantidade de combustível, produzindo assim um valor de potência maior.

Watson e Janota (1982) afirmam que em muitos casos, um turbocompressor pode entregar um fluxo de ar adicional suficiente para que um motor de mesmas dimensões produza $100 \%$ ou mais potência que o mesmo motor naturalmente aspirado.

A Figura 11 mostra um sistema de turbocompressor com um trocador de calor (aftercooler).

Figura 11 - Princípio de funcionamento de um turbocompressor

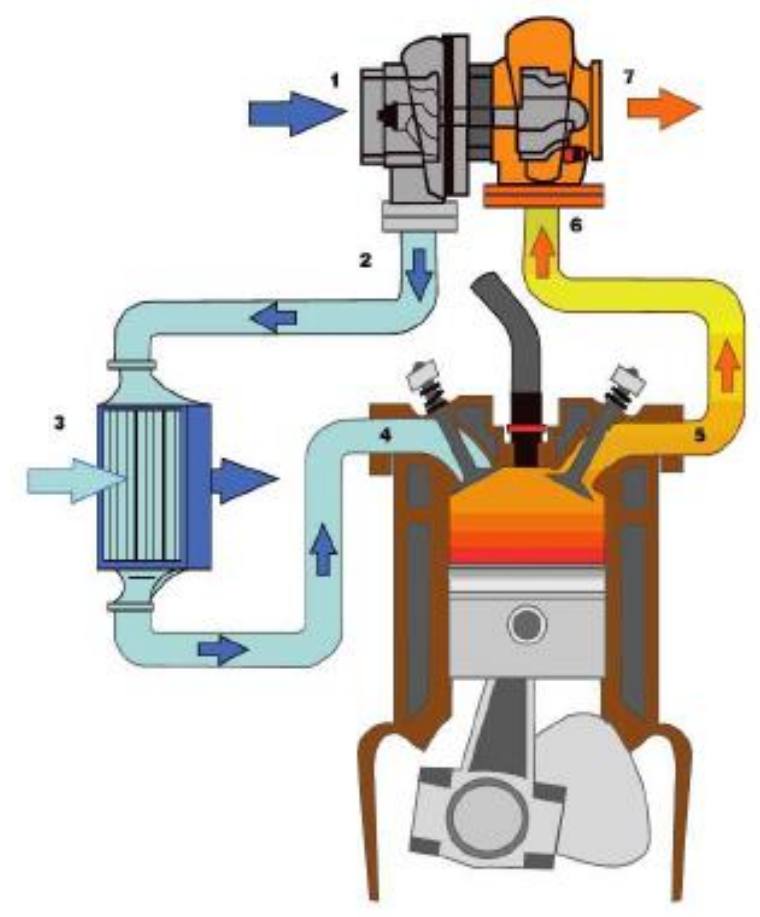

Fonte: Miller, 2008

Descreve-se o sistema da seguinte forma: 
- Entrada do compressor (1): após passar pelo filtro de ar, o fluxo de ar é succionado até a entrada do compressor, onde encontra o seu rotor.

- Saída do compressor (2): o ar é comprimido, aumentando o seu valor de massa específica. Este fluxo de ar com maior pressão e energia interna é então descarregado no duto pressurizado após o compressor.

- Resfriamento (3): com o aumento da pressão e massa específica, há um aumento de energia interna que provoca um aumento da temperatura do ar. Sendo assim, é necessário um trocador de calor (aftercooler) que reduza este valor e provoque um aumento da massa específica do fluxo.

- Válvula de admissão (4): o fluxo de ar é direcionado para o interior do coletor de admissão, caminhando em direção às válvulas de admissão. Posteriormente, é descarregado dentro do cilindro após sua abertura.

- Válvula de exaustão (5): uma carga de injeção de combustível é misturada com a massa de ar e posteriormente queimada pelo processo de combustão. Após a queima a válvula de exaustão se abre e o gás é descarregado no coletor de exaustão.

- Entrada da turbina (6): o gás proveniente do processo de combustão contendo energia em forma de calor e pressão entram em contato com as pás do rotor da turbina.

- Saída da turbina (7): o balanço da quantidade de movimento entre entrada e saída dos gases ao passar pelas pás do rotor gera o torque no eixo responsável pela sua rotação, que por sua vez é compartilhado com o rotor do compressor presente no sistema de admissão.

Entender os princípios de funcionamento do turbocompressor é fundamental para se projetar uma boa aplicação e combinação com o motor. Basicamente, o projeto aborda três áreas: a turbina, o compressor e o sistema de rolamentos que envolvem turbina e compressor. Cada uma dessas áreas é dependente da outra para efetividade total do sistema. Sendo assim, normalmente os fabricantes separam os engenheiros de projeto nestas áreas de especialização. A Figura 12 ilustra o mecanismo de um turbocompressor padrão (MILLER, 2008). 
Figura 12 - Figura 12 - Anatomia de um turbocompressor

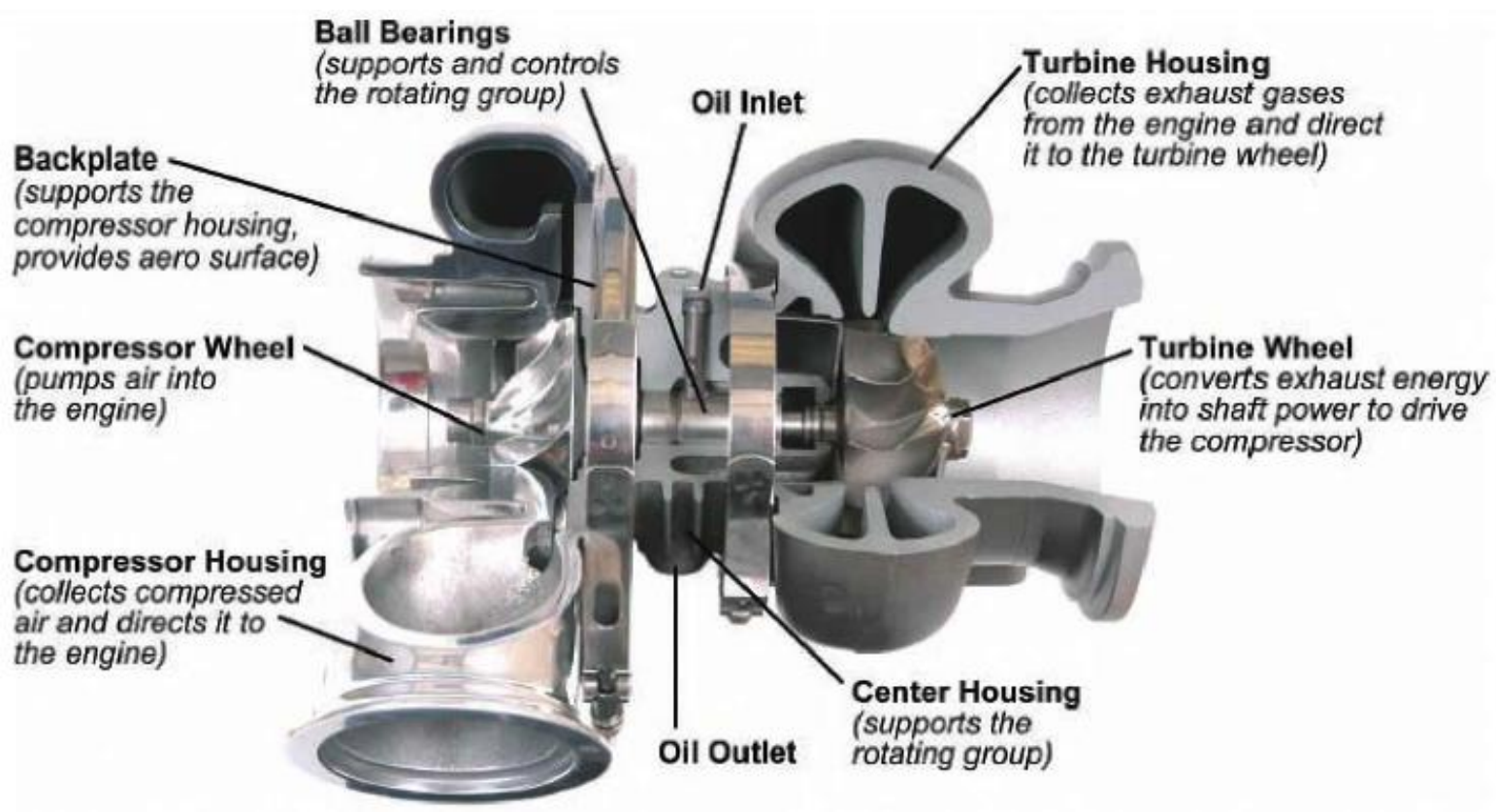

Fonte: Miller, 2008

\subsubsection{Turbina}

A turbina do turbocompressor converte a energia dos gases de escapamento em energia mecânica do eixo do rotor. Uma aplicação apropriada irá proporcionar maior contrapressão no sistema de exaustão, que por sua vez, aumentará a pressão dos gases que irão passar pelas pás do rotor. Este balanço entre a entrada e saída dos gases nas pás gera torque no eixo do rotor, que será utilizado no acionamento do compressor na compressão dos gases de admissão.

A turbina possui dois componentes principais: a carcaça e o rotor. Os gases de exaustão do motor são direcionados para a turbina através do coletor de exaustão. O escoamento preenche a carcaça e cria-se uma pressão estática através da voluta. Uma vez que há um gradiente de pressão, o gás percorre a geometria da pá de forma a se expandir e transformar a energia de pressão a energia térmica em movimento rotativo do rotor. (MILLER, 2008)

Portanto, o projeto das pás do rotor é um parâmetro crítico para eficiência total do turbocompressor. A correta seleção do tamanho da turbina em relação a vazão de gases que passará através dela, torna-se fator importante no desempenho que se reflete no motor. 


\subsubsection{Compressor}

O compressor é dividido basicamente em duas partes principais: o rotor e sua carcaça. O rotor do compressor compartilha o mesmo eixo do rotor da turbina, fazendo com que a energia térmica e a pressão provenientes dos gases de exaustão transformada em rotação do eixo seja aproveitada para girar o eixo do rotor do compressor e comprimir o ar. Sendo assim, o trabalho do eixo empregado pelo compressor é gerado pela turbina. A energia extraída da turbina é aproveitada na compressão do ar que é admitido no motor.

Geralmente, os compressores de aplicação automotiva são radiais, ou seja, o ar é succionado na direção axial ao eixo do rotor, acelerado ao longo das pás, comprimindo-o e aumentando o gradiente de pressão enquanto sua direção é alterada, de forma com que o gás seja tenha uma direção de saída a $90^{\circ}$ em relação a direção de entrada.

O ar deixa o rotor do compressor e entra em uma parte chamada de difusor. Neste local, a energia cinética dos gases é convertida em aumento de entalpia e, consequentemente, aumento de pressão. Após isso o fluxo de ar deixa o compressor e caminha em direção ao motor ou ao algum tipo de aftercooler (MILLER, 2008).

Portanto o compressor tem a função de aumentar a pressão de admissão durante o processo de sobrealimentação. Este valor de pressão adicional altera o valor de massa específica do ar, fazendo-o aumentar, permitindo que maior quantidade de ar ocupe um mesmo volume e, consequentemente, haja aumento de eficiência volumétrica.

\subsubsection{Rolamentos}

O eixo compartilhado pelos rotores é envolvido por rolamentos. A função deste sistema é suportar os altos valores de rotação que podem exceder valores de até $100.000 \mathrm{rpm}$. Em resumo, o sistema de rolamento precisa não só suportar o movimento rotativo, mas também absorver carregamentos axiais provenientes dos rotores.

Existem muitos tipos de rolamentos para aplicações em turbo compressores, estes devem proporcionar a menor perda de energia por atrito possível. Seu projeto inclui lubrificação, selos mecânicos, isolamento térmico e dissipação do calor produzido pelo atrito. 


\subsubsection{MAPAS}

Neste tópico serão abordados os conceitos necessário para a interpretação dos diagramas de pressão em função da massa de ar e eficiência do compressor e da turbina de um sistema turbocompressor, com o objetivo de demonstrar como é feita sua análise e dimensionamento.

\subsubsection{Compressor radial}

O compressor é uma máquina de fluxo, o que permite a construção de curvas características muito similares às das bombas e dos ventiladores. Os valores de vazão de ar medidos pelo motor nas condições de referência devem ser corrigidos para que depois possam ser inseridos no diagrama, conhecido como " mapa do compressor". A Figura 13 ilustra um mapa comum de compressor onde pode ser facilmente notado os seus limites de aplicação (BRUNETTI, 2012)

Figura 13 - Mapa do compressor

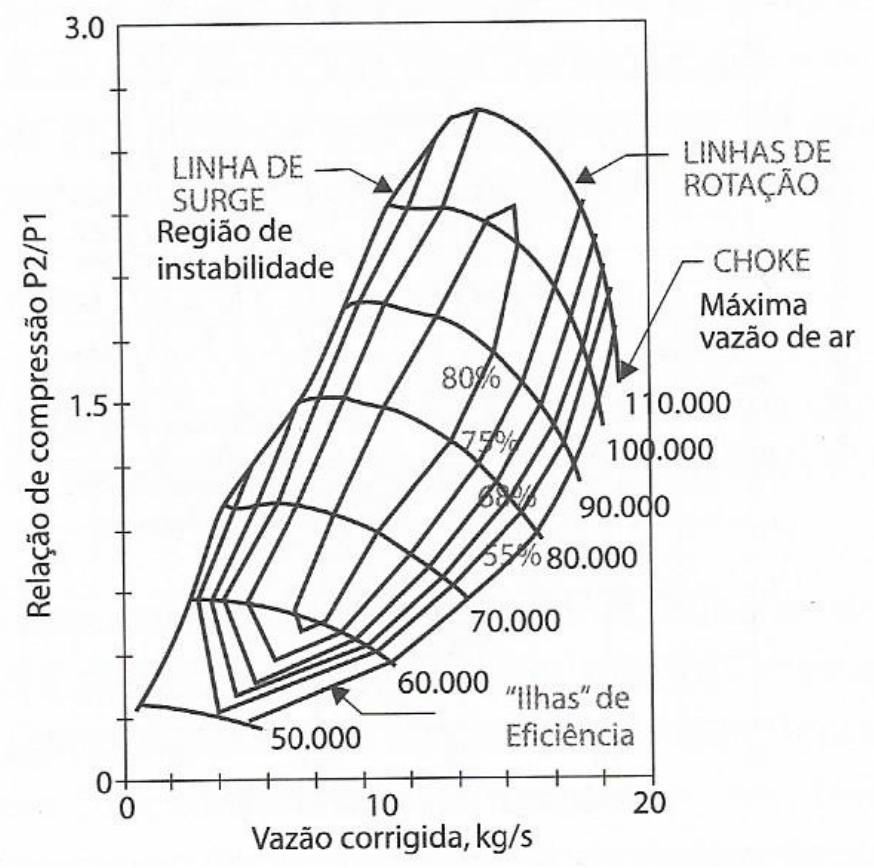

Fonte: Brunetti, 2012

A parte superior é chamada de "zona de overspeed", onde a elevada rotação do rotor impõe grandes valores de força centrifuga, comprometendo a resistência do material de 
fabricação. O lado direito é denominado "região de choke", nela atinge-se valores de número de Mach igual a 1 na região de seção mínima de passagem da máquina, estagnando o fluxo de ar. O lado esquerdo apresenta a "região de Surge". Esta zona é definida como um limite de instabilidade, onde o escoamento apresenta variações de pressão. Sendo assim, o compressor não consegue fornecer ar de maneira constante, gerando variações de carga no motor. $\mathrm{O}$ trabalho nesta região, além de causar a instabilidade citada, coloca em perigo o sistema de mancais do turbocompressor.

$\mathrm{Na}$ região central do mapa, localizam-se as ilhas de eficiência isentrópica de compressão. Portanto, conclui-se que a utilização do compressor centrífugo é possível apenas para uma determinada faixa estreita de operação, que pode não atender as variadas gamas de cilindradas e rotações características de motores.

\subsubsection{Mapa da Turbina}

A turbina comumente utilizada em aplicações automotivas tem construção radial. O estudo do fluxo de ar através da turbina é muito assemelhado ao estudo feito para o compressor.

Para se atingir o objetivo de fazer com que o compressor execute o trabalho de compressão na zona de melhor rendimento, o fabricante possui diversos modelos de rotores e carcaça, em diversas escalas podendo variá-los para chegar ao ajuste ideal para o motor no qual está sendo aplicado.

Para a correta aplicação da turbina ideal, faz-se necessário o cálculo da vazão em massa proveniente dos gases de exaustão, para que assim se escolha o rotor e a carcaça apropriada

para atender as condições requeridas pelo motor. É preciso selecionar a turbina cuja massa de gás e a pressão calculados combinem com a velocidade necessária para girar o compressor do modo desejado. O cálculo geralmente é simplificado, pois a velocidade de rotação tem apenas um pequeno efeito na capacidade do fluxo da turbina, e só é possível se alterar esta capacidade com a mudança das características da carcaça, que provoca um pequeno efeito na razão de expansão dos gases da turbina ou na rotação. Caso isso não seja possível é necessário se alterar a escolha do compressor e repetir a análise com os novos mapas. A Figura 14 apresenta uma representação do mapa da turbina (BAINES, 2005). 
Figura 14 - Mapa representativo da turbina

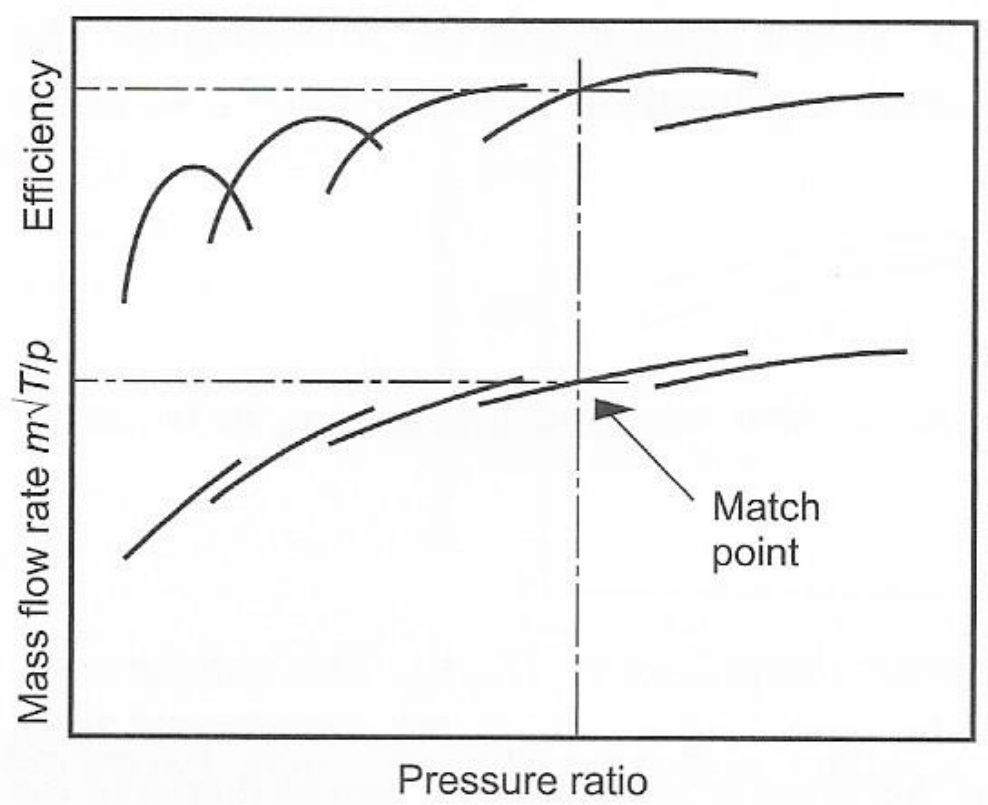

Fonte: Baines, 2005

Os mapas do turbocompressor são construídos, validados e otimizados para representar seu ponto de operação diferentes condições. Para isso, o turbocompressor é testado em uma bancada chamada de Gas stand. O número de pontos testados é definido para diferentes valores de rotação do eixo entre turbina e compressor, onde as temperaturas precisam ser estacionárias no momento em que os valores das grandezas relevantes ao mapa serão medidas. (JOHANSSON ET AL)

É importante ressaltar que a metodologia utilizada para medição das grandezas que constituem os mapas, por se tratar de um estado de regime permanente, desconsideram os efeitos que fogem a essas condições, podendo levar os resultados do teste práticos reais a ter discrepâncias.

\subsection{MATCHING - ADEQUAÇÃO ENTRE TURBOCOMPRESSOR E MOTOR}

Os dois maiores desafios para a seleção do turbocompressor para um determinado motor é adequar a máquina de fluxo, com faixa de operação específica, a uma máquina de deslocamento positivo (motor), que tem uma ampla gama de faixas de operações, ou seja, variações no seu ponto de operação. Sendo assim, ao se projetar um motor turboalimentado 
busca-se o melhor compromisso entre estes objetivos conflitantes, para que possa haver eficiência elevada em diferentes pontos de operação (BRUNETTI, 2012).

A adequação entre o motor e o turbocompressor inicia-se pela escolha do compressor que tenha as características necessárias para atender as necessidades de consumo de ar e pressões do motor com a finalidade de se extrair um valor alvo de potência e torque. Uma vez selecionado o compressor, faz-se necessário a escolha da turbina que será montada ao conjunto. Assume-se que a potência da turbina tem mesmo valor que a potência do compressor, uma vez que ambos compartilham o mesmo eixo.

Este processo é interativo até que se chegue a um conjunto de compressor e turbina que satisfaça as exigências do motor.

\subsubsection{Determinação da relação de pressão necessária.}

Segundo Hartman (2007), para se calcular a vazão em massa de ar que o compressor irá demandar faz-se necessário definir o valor de potência que se deseja atingir. Inicia-se o projeto pelo cálculo da massa de ar necessária para atingir o objetivo pré-determinado. Define-se: (HARTMAN, 2007)

$$
W_{a}=H P \cdot A / F \cdot \frac{B S F C}{3,6 \cdot 10^{6}}
$$

Onde HP é a potência que se deseja atingir, $A / F$ é razão entre ar e combustível e BSFC é consumo específico do motor.

Definida a massa de ar necessária para a produção do valor de potência, determina-se a pressão necessária para alterar o valor de massa específica do ar para a produção do valor de vazão calculado.

$$
M A P_{r e q}=\frac{2 \cdot W_{a} \cdot R \cdot(T m)}{V E \cdot N \cdot V_{d}}
$$

Sendo $M A P_{\text {req }}$ a pressão necessária no coletor de admissão em $\mathrm{Pa}, W_{a}$ é a massa de ar em $\mathrm{kg} / \mathrm{s}$, R é constante dos gases no valor de $287,053 \mathrm{~J} / \mathrm{kgK}, \mathrm{Tm}$ é a temperatura no coletor de 
admissão em $\mathrm{K}$, VE é a eficiência volumétrica do motor, $\mathrm{N}$ a rotação do motor em $\mathrm{rad} / \mathrm{s}$ e $V_{d} \mathrm{o}$ deslocamento volumétrico do motor em $\mathrm{m}^{3}$.

Portanto, fazendo a divisão da pressão absoluta estática necessária ao compressor medida no coletor de admissão pelo valor da pressão atmosférica, obtém-se a relação de pressão do compressor:

$$
\pi_{c}=\frac{P_{2}}{P_{1}}
$$

\subsubsection{Característica do fluxo de ar dos motores turboalimentados}

A vazão mássica de ar imposta pelo compressor é função da sua rotação, variação da massa específica e diferença de pressão entre os coletores de admissão e exaustão no momento que há o intervalo de overlap das válvulas. Se um motor está sobre uma rotação constante, porém variando a carga, então a massa de ar irá aumentar à medida que o valor da sua massa especifica é modificada. (WATSON E JANOTA, 1982)

Quando é feito o ajuste do compressor ao motor (matching), o objetivo é escolher o compressor que em uma condição de rotação constante do motor, a pressão e o valor de vazão mássica de ar fiquem localizados no centro da sua ilha de máxima eficiência. Se o conjunto receber um trocador de calor para resfriamento do ar (aftercooler) a carga aumenta e a diminuição da temperatura irá aumentar o valor da massa específica do ar mais rapidamente e consequentemente isso irá modificar a inclinação da linha de rotação constante.

Da mesma forma que se pode fixar um valor de rotação e alterar-se a carga é possível fazer o processo inverso. A medida com que se aumentam os valores de rotação do motor, aumenta-se a vazão mássica admitida e também sua eficiência volumétrica. $\mathrm{O}$ a área efetiva de passagem do escoamento de gases na turbina permanece praticamente constante, o que consequentemente faz com que a pressão de entrada da turbina aumente. Watson e Janota (1982) ainda afirmam que se o motor opera sob cargas e rotações constantes é possível esboçar no mapa do compressor o a sua região de operação. Sendo assim, demonstra-se através da Figura 15 uma representação mais rica da região de operação do compressor em um determinado tipo de motor. (WATSON E JANOTA, 1982) 
Figura 15 - Região de operação do motor no diagrama do compressor

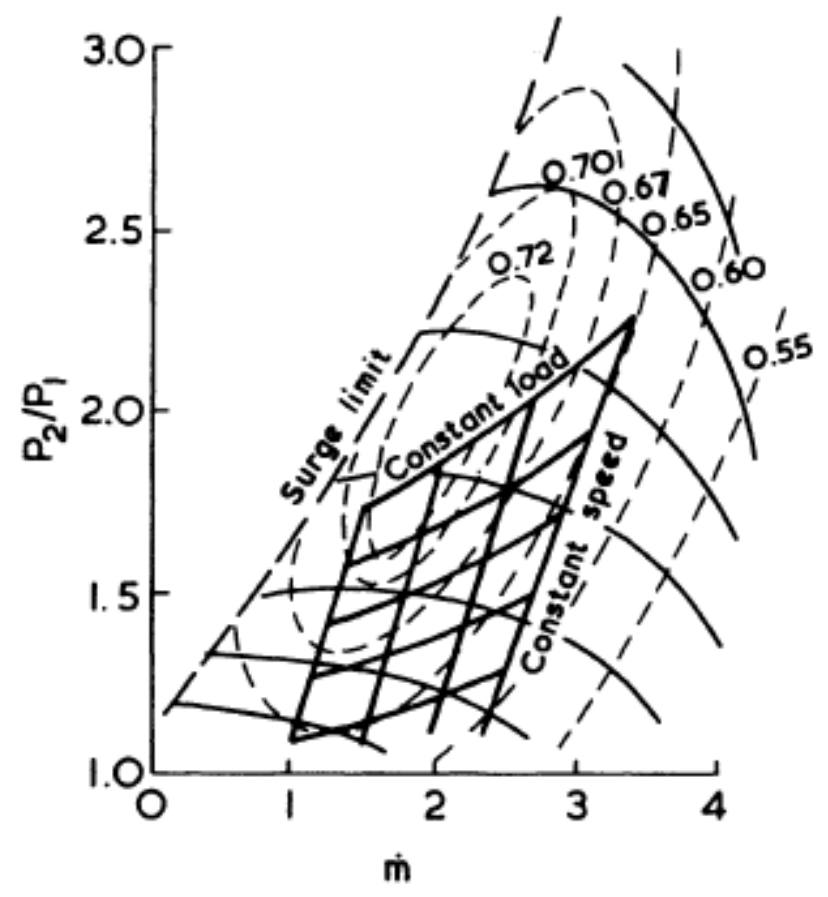

Fonte: Watson e Janota, 1982.

A região na qual o motor deve operar quando sobreposta no mapa do compressor deve estar contida entre a linha que determina a região onde ocorre o fenômeno de surge e a linha de baixa eficiência ou região de overspeed.

A distância entre a linha de surge e o primeiro ponto de operação do motor deve ser suficiente para permitir a ocorrência de três fatores. Primeiramente, o efeito de pulsação que ocorre no coletor de admissão, para evitar que o efeito de pulsação do escoamento leve a uma operação próxima a região de surge. Posteriormente, prevenir para que se o filtro de ar ou qualquer componente antes do compressor bloquear demasiadamente a passagem do ar, a queda de vazão não permita que o motor novamente operar naquela região. Por último, o efeito da altitude pode afetar os valores de massa de ar, e então, a zona na qual o motor irá operar. Sendo assim, a combinação dos três efeitos irá variar com a característica de cada motor e cada aplicação. Os autores afirmam que no geral uma margem de $10 \%$ de massa de ar entre o primeiro ponto de operação do motor e a linha de surge pode ser o suficiente. Para motores com um número pequeno de cilindros, $20 \%$ pode ser um valor mais seguro. (WATSON E JANOTA, 1982) 
Na maioria das aplicações a turbina pode operar eficientemente sobre uma faixa maior de fluxo de gases que os compressores. Sendo assim, é por este motivo que se torna mais importante a análise do compressor do que da turbina. Entretanto, se a turbina estiver operando com um fluxo de gases instável, encontrar um valor médio no mapa não retratará a realidade. O método correto para estimar a área de operação no mapa da turbina seria plotar os valores instantâneos do fluxo de gás e a relação de pressão em vários pontos de operação do motor.

A partir destes valores, seria possível estimar em qual faixa o motor começará a trabalhar de forma efetiva com o turbocompressor, podendo observar o valor da relação de expansão dos gases na turbina, assim como a eficiência na qual trabalhará. A Figura 16 demonstra o processo de seleção da turbina.

Figura 16 - Mapa convencional da turbina

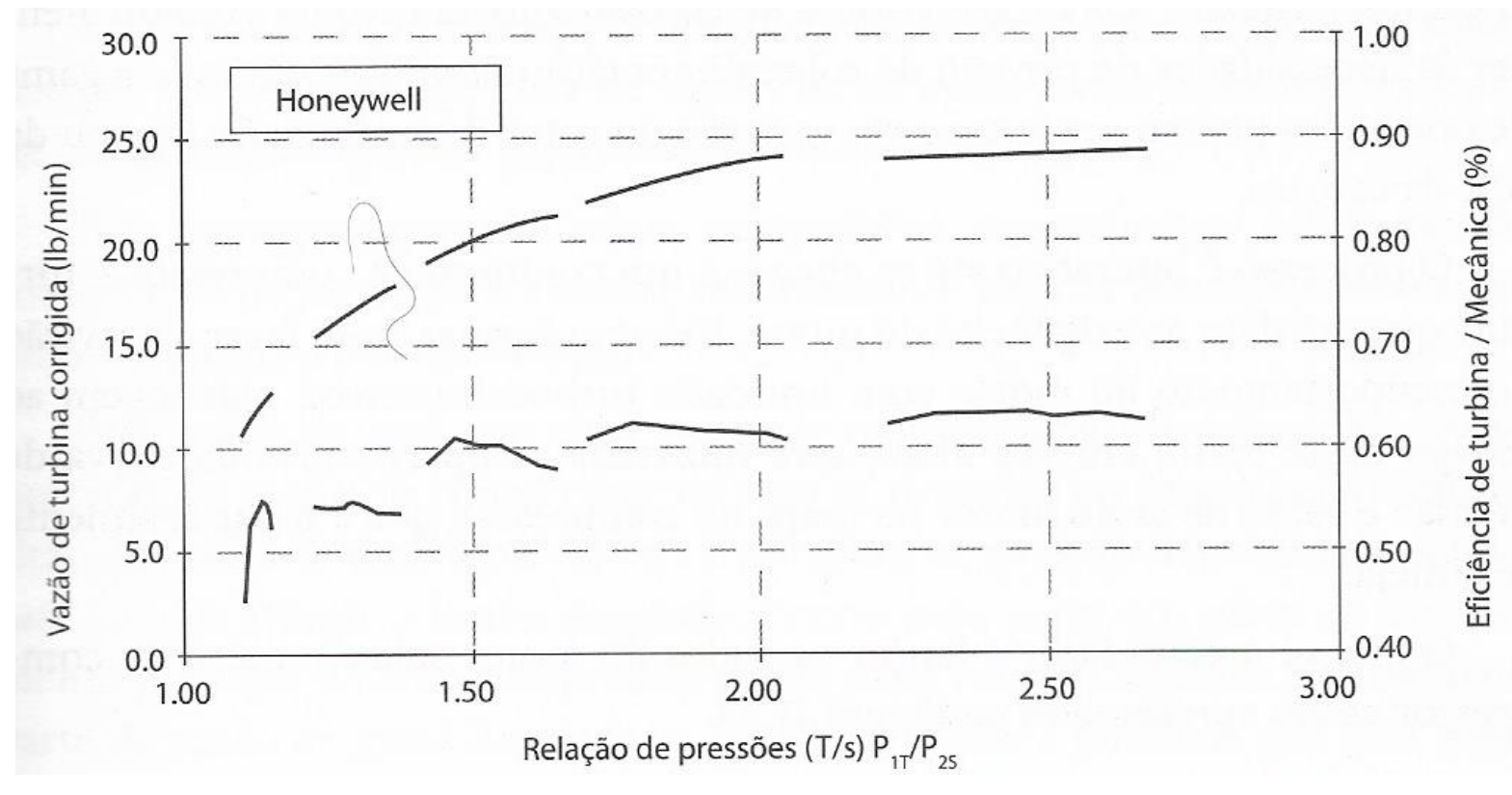

Fonte: Brunetti, 2012

\subsubsection{Fluxo de admissão e a variação de massa específica}

Para um motor sobrealimentado, o parâmetro crítico é a massa de ar que é admitida para dentro do cilindro, e consequentemente a massa específica do fluxo de ar. Quando há o aumento da temperatura existe uma redução no valor desta propriedade, fazendo com que não se introduza a quantidade que se deseja no interior do cilindro. Além disso, o fato de o compressor 
não ser isentrópico tende a aumentar a temperatura do na saída. A temperatura do ar após o compressor pode ser escrita pela equação 10: (BAINES, 2005)

$$
T_{2}=T_{1}\left\{1+\frac{1}{\eta_{c}}\left[\left(\frac{P_{2}}{P_{1}}\right)^{\frac{k-1}{k}}-1\right]\right\}
$$

Onde $T_{2}$ é a temperatura após o compressor em $\mathrm{K}, T_{1}$ é a temperatura na entrada do compressor em K, $\eta_{c}$ é o rendimento do compressor, $P_{2}$ pressão na saída do compressor, $P_{1}$ pressão na entrada do compressor e k é constante adiabática dos gases.

Watson e Janota (1982) acrescentam que o objetivo deve ser o aumento pressão com um mínimo de crescimento no valor de temperatura. Isso implica na aplicação de uma compressão isentrópica, onde o aumento de temperatura é dado pela equação 10 . A variação da massa específica da vazão de ar fresca pode ser escrita através da equação 10. Portanto, após uma série de manipulações matemáticas, escreve-se:

$$
\frac{\rho_{2}}{\rho_{1}}=\frac{P_{2} / P_{1}}{1+\frac{\left[\left(P_{2} / P_{1}\right)^{\frac{k-1}{k}}-1\right]}{\eta_{c}}}
$$

Sendo $\rho_{2}$ a massa específica do ar na saída do compressor em $\mathrm{kg} / \mathrm{m}^{3}, \rho_{1}$ a massa específica do ar na entrada do compressor em $\mathrm{kg} / \mathrm{m}, \eta_{c}$ é o rendimento do compressor, $P_{2}$ pressão na saída do compressor em bar, $P_{1}$ pressão na entrada do compressor em bar e k é constante adiabática dos gases.

Baines (2005) discute o conceito citado por Watson e Janota (1982) e faz uma demonstração através da Figura 17: 
Figura 17 -Influência da eficiência do trocador de calor na massa especifica do ar

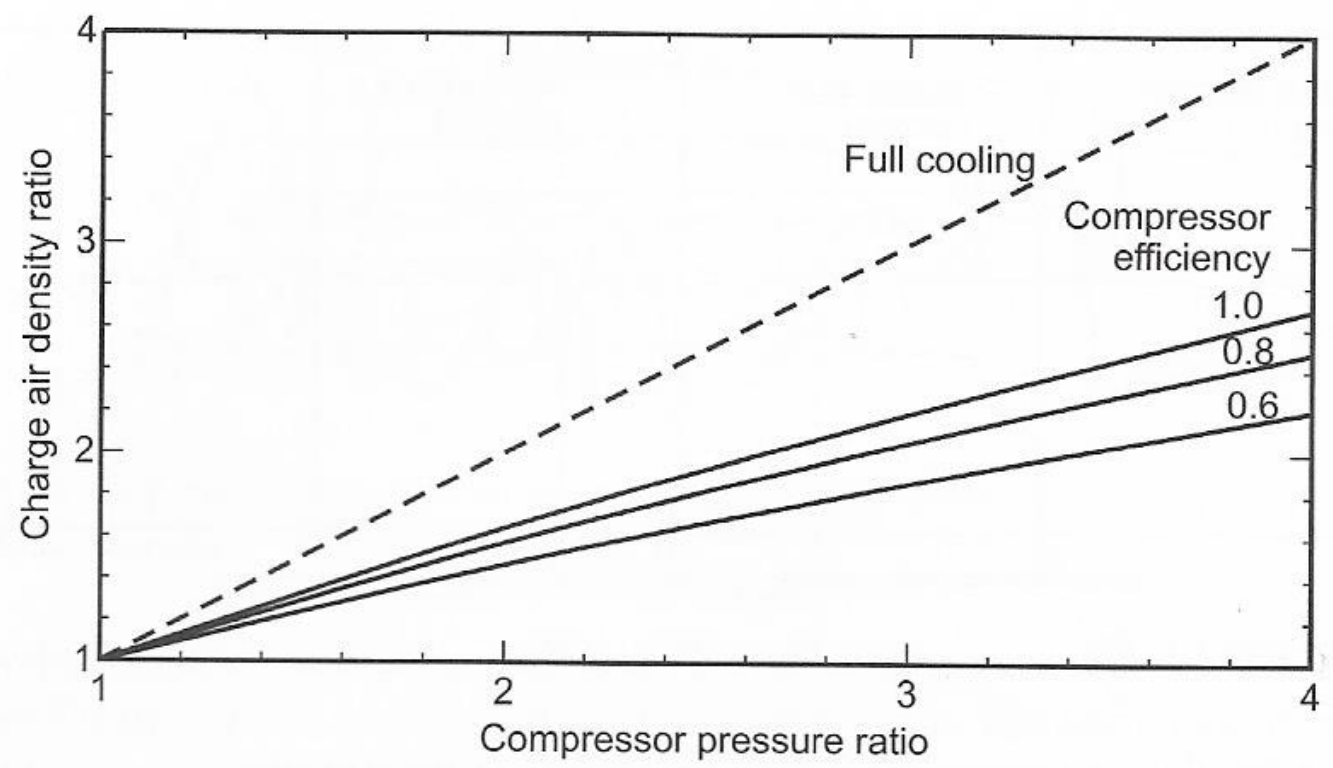

Fonte: Baines, 2005

A equação mostrada em forma gráfica para diferentes tipos de relação de pressão e eficiência. Na comparação é possível notar que a relação de massa específica que se deseja atingir pode ser alcançada com a resfriamento do fluxo de ar. A redução do valor densidade do ar com o aquecimento proporcionado pela compressão é substancial, principalmente para altos valores de relação de compressão. Para controlar este problema os autores propõem a utilização de um trocador de calor em conjunto com o sistema de turbocompressor.

Diminuir a temperatura do fluxo de admissão é um caminho direto para aumentar a relação de massa específica e se obter maior vazão de ar sendo induzida para o interior do cilindro. Além disso, trabalhar com valores de temperatura menores durante a operação do ciclo ajudam na redução da solicitação térmica do motor e turbina.

O trocador de calor, comumente chamado de intercooler é posicionado entre o motor e o compressor. A efetividade da troca de calor é dada pela equação:

$$
\epsilon=\frac{T_{2}-T_{3}}{T_{2}-T_{\text {cool }}}
$$


Sendo $T_{2}$ a temperatura do ar na entrada do trocador em $\mathrm{K}, T_{3}$ a temperatura de saída do ar do trocador de calor em $\mathrm{K}$ e $T_{\text {cool }}$ a temperatura do fluido utilizado para o resfriamento em $\mathrm{K}$.

A efetividade implica que a temperatura do ar pode ser reduzida para o valor de temperatura do fluido refrigerante (no caso, ar ou água) que será a menor possível. Se a efetividade da troca for igual a zero, isso significa que não há troca de calor. A temperatura $T_{3}$ na saída do intercooler pode ser calculada através da equação:

$$
T_{3}=T_{1}\left\{1+\frac{\left[\left(P_{2} / P_{1}\right)^{\frac{k-1}{k}}-1\right]}{\eta_{c}}\right\}(1-\epsilon)+\epsilon T_{\text {cool }}
$$

A equação demonstra que para um completo resfriamento do fluxo de admissão (quando o valor da temperatura após o compressor se igual ao da entrada do compressor) só será possível se a temperatura do fluido refrigerante for igual ou menor que a temperatura de entrada no compressor. A Figura 18 demonstra os benefícios do resfriamento do fluxo de admissão e como isso pode influenciar no aumento da razão de pressão. (BAINES)

Figura 18 -Influência da eficiência do trocador de calor na massa especifica do ar

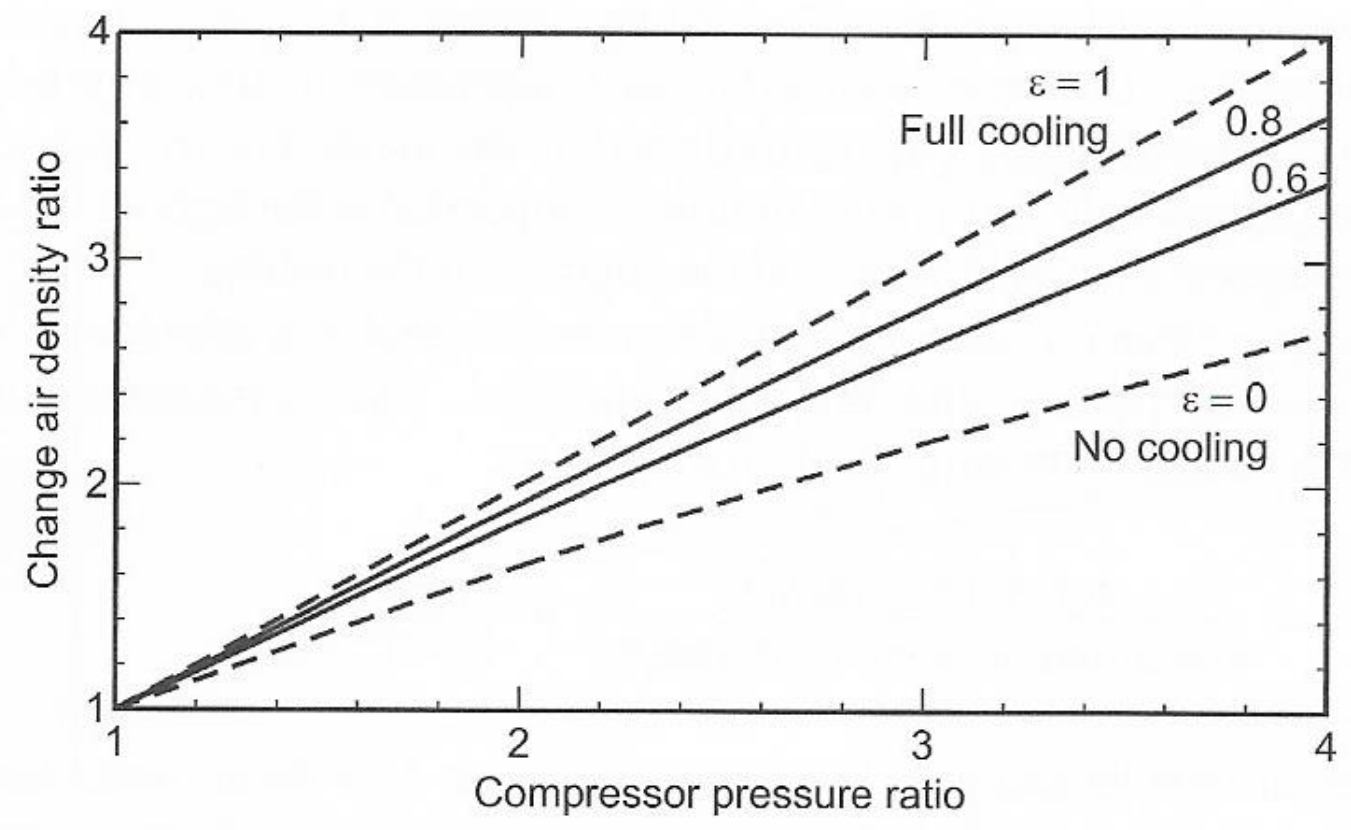

Fonte: Baines, 2005 


\subsection{EXTRAÇÃO DOS GASES DE EXAUSTÃO}

O mecanismo mais importante para a extração dos gases residuais provenientes do processo de combustão é o aproveitamento da sua energia cinética para produção de ondas de pressão seguidas de ondas de expansão, que formam uma região de depressão, no sistema de exaustão. (HEISLER, 1995)

Esta liberação repentina dos gases em alta pressão vindos do cilindro, rapidamente desloca a coluna de gás que ocupa o lado de fora da câmara de combustão, fazendo com que se atinja um valor de velocidade alto. Em outras palavras, a onda de pressão pulsa expelindo os gases do cilindro e transformando a energia de pressão em energia cinética. A figura 19.a demonstra o processo descrito.

Figura 19 - Energia cinética teórica dos gases de exaustão

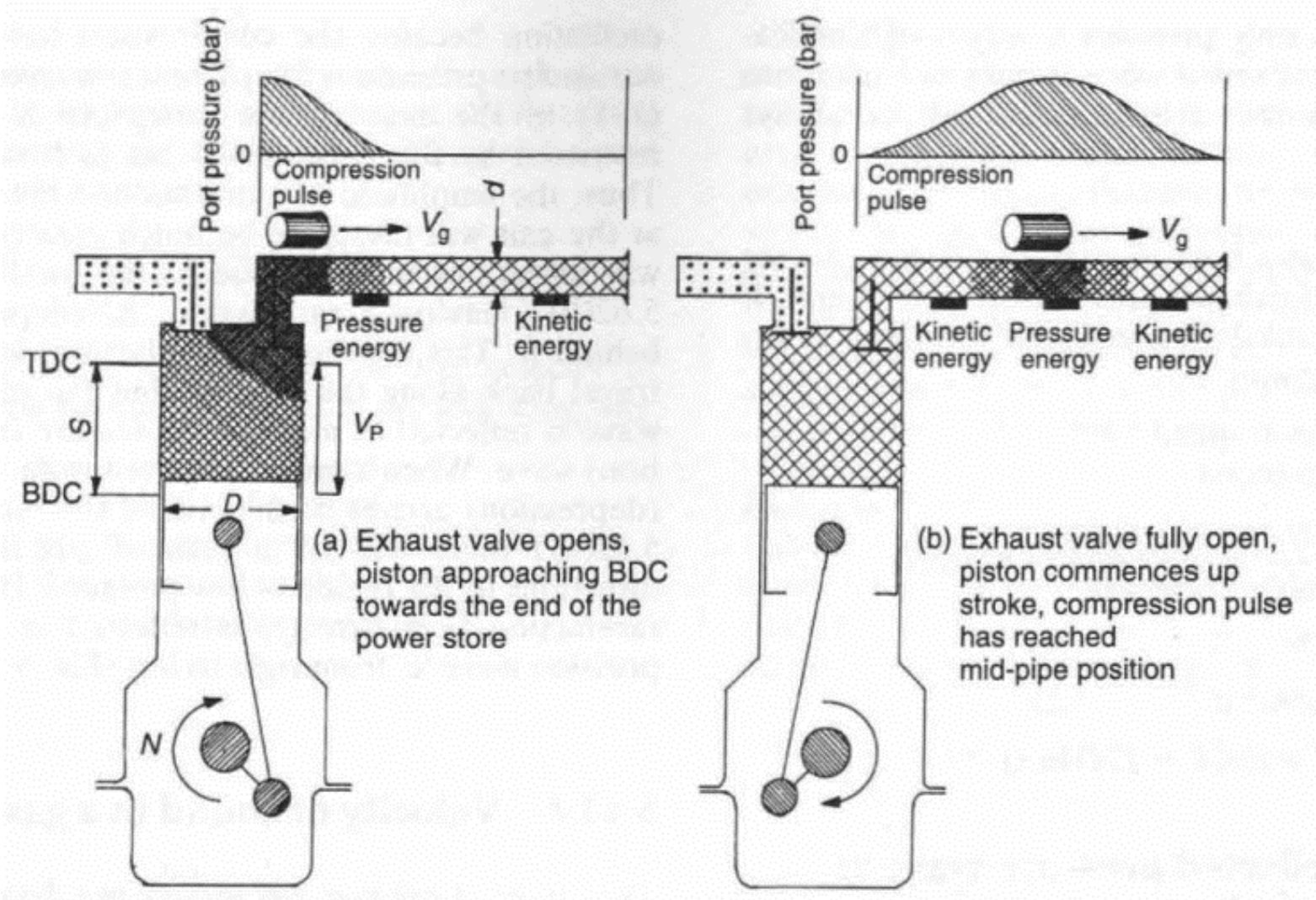

Fonte: Heisler, 1995 
Sendo assim, o pulso proveniente da exaustão caminha no coletor de exaustão com uma frente de pressão seguida por uma região de baixa pressão, fazendo com que haja um movimento de expansão e compressão dos gases durante o percurso (Figura 19.b). Portanto, quando o pistão inicia seu movimento de ascensão em direção ao PMS, a onda de pressão já teria alcançado o fim do coletor de exaustão.

A velocidade da onda de pressão excede o valor da velocidade de descarga do gás através do duto de exaustão devido ao movimento ascendente do pistão, fazendo com que o restante dos gases seja retirado do interior do cilindro. Os gases que estão atrás da onda de compressão se tornam menos densos, causando uma perda considerável de pressão no duto e no interior do cilindro, fazendo que haja uma pressão momentaneamente negativa (Figura 19.c).

Figura 19 - Energia cinética teórica dos gases de exaustão

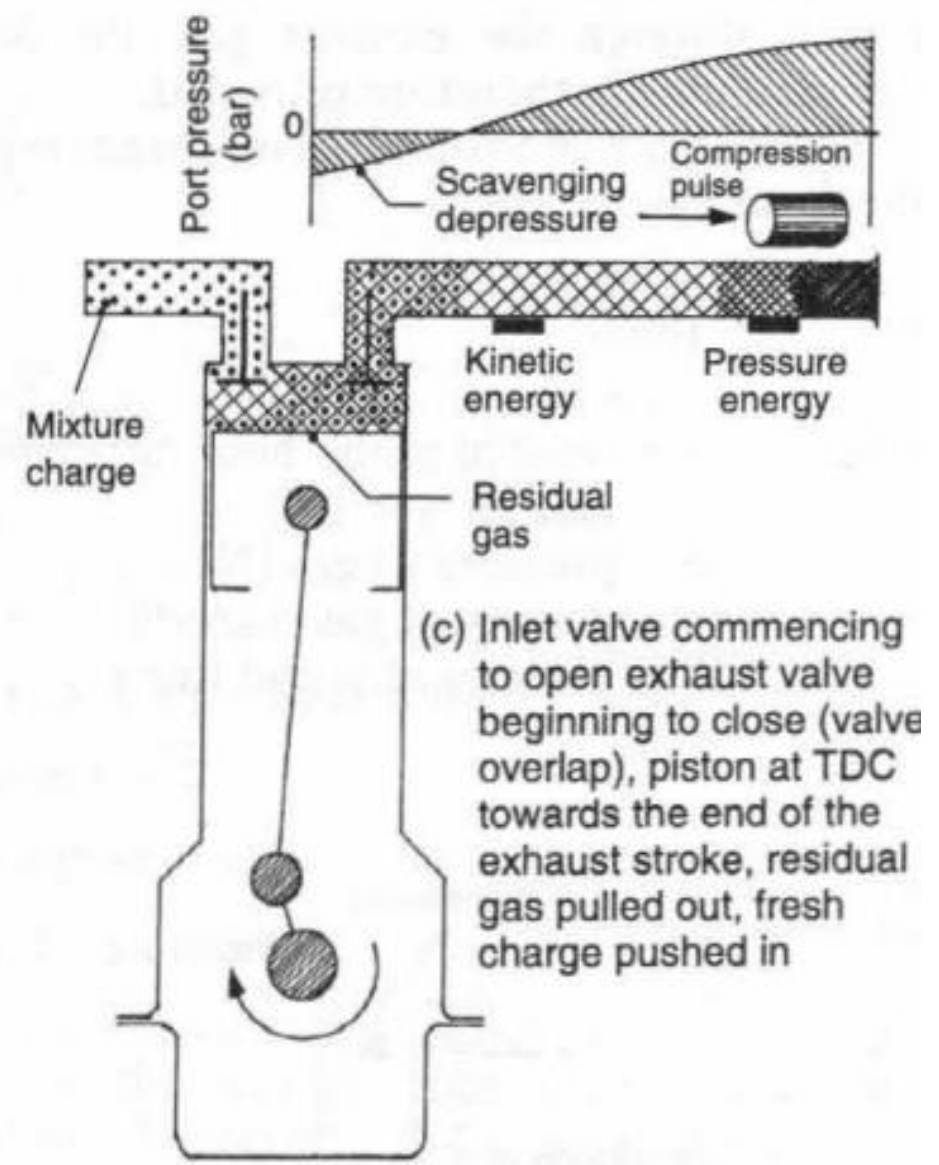

Fonte: Heisler, 1995.

Durante o período de sobreposição (overlap) a depressão formada pela extração dos gases ajuda introduzir maior quantidade de ar no duto de admissão e uma limpeza mais eficiente 
da câmara de combustão, uma vez que uma parte do ar passa direto pelo cilindro e sai pela válvula de exaustão. Este processo é chamado de scavenging.

Qualquer tipo de restrição que haja no duto ou no coletor de exaustão durante este processo pode atrapalhar a extração dos gases residuais e impedir a entrada da massa de ar fresca vindo da admissão. Isto pode ocorrer de diversas formas:

- O coletor de exaustão pode ser mal dimensionado, de forma que seu comprimento seja longo suficiente para não produzir os efeitos de onda necessários à extração;

- Pode haver ramificações do coletor que provoquem uma maior dificuldade do gás em percorrer o sistema;

- A aplicação de um turbocompressor pode causar uma restrição durante o percurso que resulte na reflexão da onda de pressão dos gases antes do momento desejado.

Para o uso da interferência dos gases de exaustão para melhora da limpeza do interior durante o período de abertura simultânea das válvulas (overlap), é necessário o entendimento do efeito de reflexão de onda quando há a liberação e propagação dos gases de exaustão.

Heisler (1995), utiliza de um exemplo didático para a explicação dos efeitos de compressão e rarefação através da Figura 20.

Figura 20 - Onda de pressão refletida em um tubo aberto

(a)

$$
\begin{aligned}
& C=\text { Compression } \\
& R=\text { Rarefaction (depression) }
\end{aligned}
$$

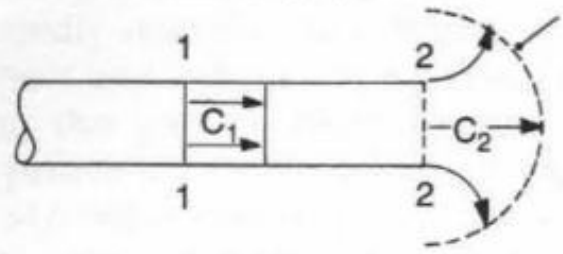

(c)

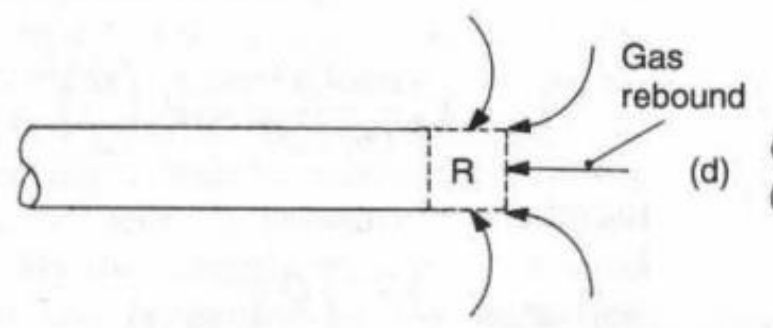

Compression spreading out

(b)

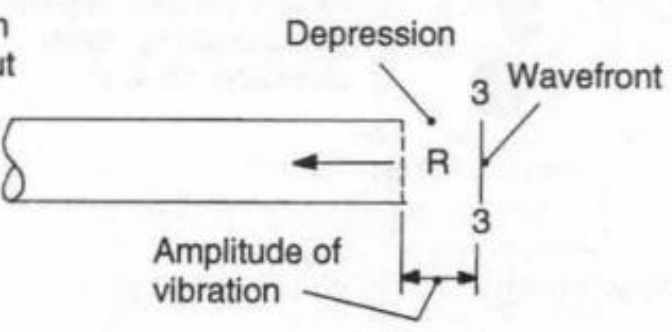

Reflected compression

Fonte: Heisler, 1995.

Imagina-se que uma onda de compressão $C_{2}$ chegando em uma abertura (Figura 20.a) e se espalhando em diversas direções, enquanto dentro do tubo $\mathrm{C}$ (1-1), uma onda $C_{1}$ de 
compressão, é impedida de se espalhar por estar confinada entre as paredes. No fim do tubo, o gás está sem restrição e na amplitude de oscilação, se espalha e reduz o gradiente de pressão, enquanto que a camada do gás (1-1) atrás da onda de compressão $\mathrm{C}$ é restringida pelo gás comprimido à sua frente. Sendo assim, a amplitude de vibração da camada (2-2) na saída será muito maior e se moverá para (3-3) devido a inércia (Figura 20.b), deixando uma região de depressão (rarefação) 'R' para trás.

A rarefação ' $R$ ' irá voltar ao longo do tubo, criando um efeito de reflexão, onde o valor de pressão assume um sinal negativo. Quando a onda refletida chega ao fim do tubo, encontrase com uma corrente de gás que vai em direção a região de baixa pressão. Portanto a rarefação (região de baixa pressão) é refletida novamente como uma onda de compressão 'C', movendose da esquerda para a direita.

Sendo assim, em resumo, a válvula de exaustão é aberta antes do fim do curso de potência do pistão, então é liberado uma onda de pressão positiva para o duto de exaustão. Esta onda positiva viaja até a saída do sistema de escapamento, onde encontra as condições de temperatura e pressão atmosférica, deixando para trás uma região de baixa pressão (rarefação). Neste instante ocorre a reflexão da onda, causando a propagação de um pulso de valor de pressão negativa que viaja de volta em direção a válvula. Quando o pulso chega à válvula, encontra o fluxo de gases com pressão positiva e novamente é refletida como onda de pressão positiva em direção a saída do sistema. Este ciclo se repete indefinidamente com o decaimento da amplitude, até a liberação do próximo pulso de pressão do cilindro.

Para se obter um bom resultado, o comprimento do coletor de exaustão deve ser selecionado ou dimensionado de forma que as ondas de pressão viagem a partir da válvula de exaustão até a saída do sistema e retornem durante um intervalo de $120^{\circ}$ de ângulo de rotação do virabrequim em uma determinada rotação de projeto Isto garante que a primeira reflexão de onda negativa esteja na região da válvula de exaustão no momento em que o pistão atinge o PMS, melhorando assim, a limpeza dos gases residuais. Este fenômeno é demonstrado na Figura 21. (HEISLER, 1995) 
Figura 21- Onda de pressão refletida dos gases de exaustão

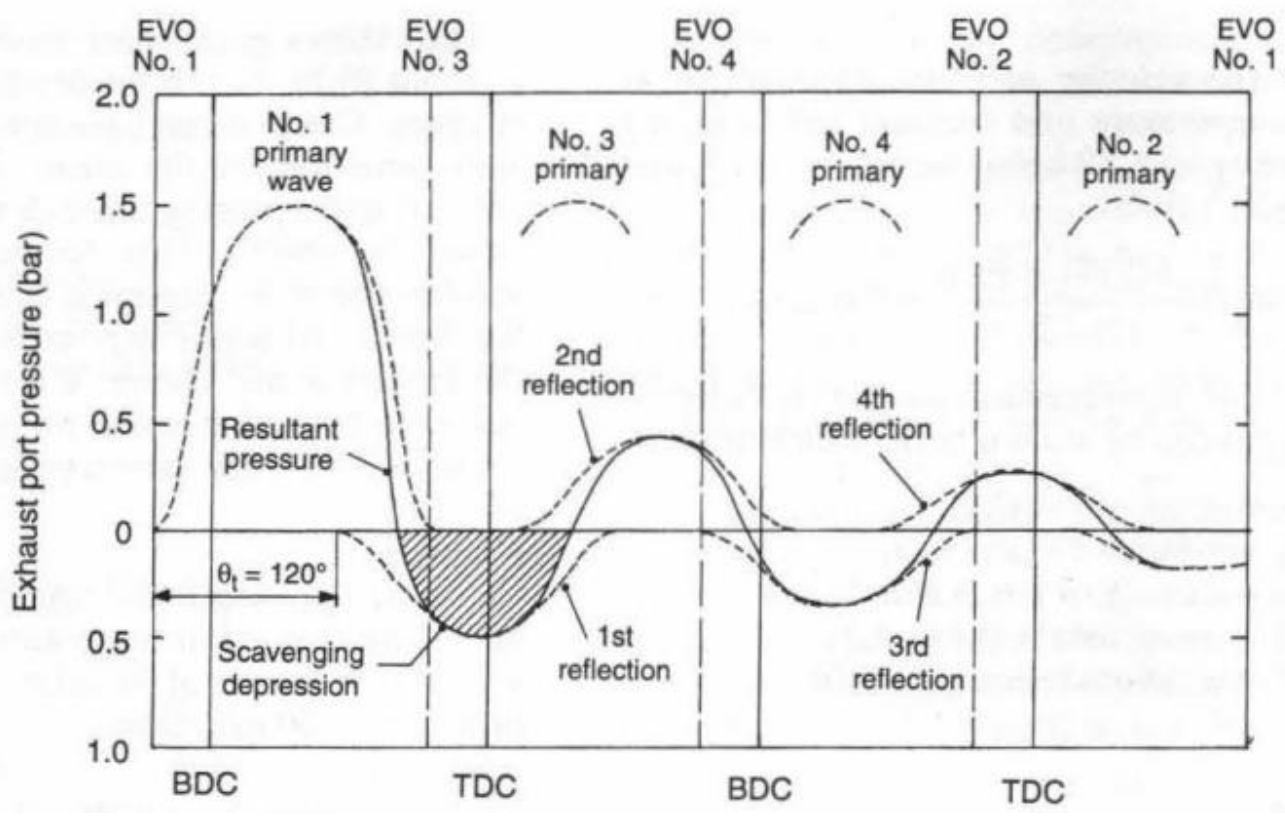

Fonte: Heisler, 1995.

As ondas de pressão são representadas na Figura 21 para um motor de quatro cilindros. A cada abertura das válvulas de exaustão (EVO) dos cilindros um pulso de pressão é liberado para o coletor de exaustão. $\mathrm{O}$ ângulo $\theta_{t}$ representa o período necessário para que a onda refletida retorne ao cilindro no momento em que o pistão atinge o PMS. A região hachurada demonstra a zona de baixa pressão que o processo de scavenging gera no momento em que as há o período de sobreposição das válvulas.

A especificação adequada de um turbocompressor, assim como o dimensionamento do coletor de exaustão, irão influenciar no modo como a reflexão de ondas irá ocorrer no momento da liberação dos gases. Durante o projeto, deseja-se que qualquer tipo de restrição que haja no coletor de exaustão seja previsto para que o retorno da onda de pressão não ocorra durante o movimento de subida do pistão. É desejável evitar que haja retorno dos gases de exaustão pelo coletor de admissão durante o período de overlap quando houver uma condição de baixa rotação do motor, fazendo com que a limpeza dos gases residuais dentro do cilindro seja maximizada, melhorando assim, a eficiência volumétrica e da combustão. 


\subsection{UTILIZAÇÃO DOS GASES DE EXAUSTÃO: PRESSÃO CONSTANTE E EFEITO PULSATIVO}

Cerca de 30 a $40 \%$ da energia disponibilizada pela queima do combustível é liberada através dos gases de exaustão. O desempenho de qualquer tipo de turbocompressor depende da habilidade da turbina de converter essa energia para impulsionar o compressor e gerar a sobrealimentação. A efetividade dessa operação pode ter um grande efeito no desempenho como um todo para a aplicação. (WATSON E JANOTA, 1982)

A Figura 22 demonstra o ciclo de um motor diesel naturalmente aspirado:

Figura 22 - Diagrama P-v de um ciclo Diesel

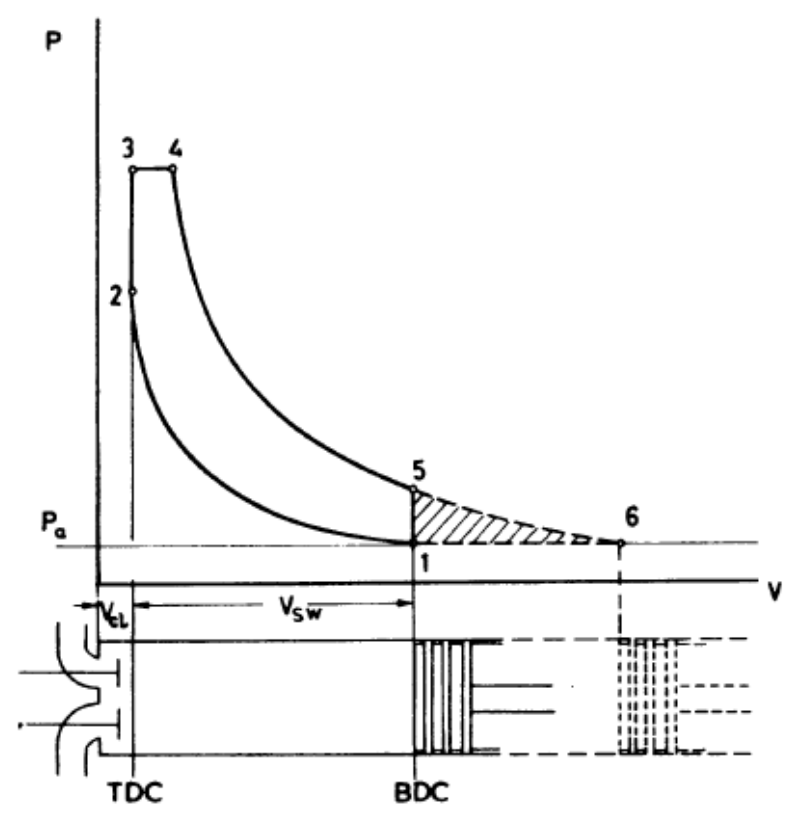

Fonte: Watson e Janota, 1982.

No fim da combustão (ponto 4) o pistão inicia o movimento em direção ao PMI (ponto 5) e neste instante as válvulas de exaustão se abrem. Como a pressão no interior do cilindro é maior que no coletor de exaustão (P1), o gás deixa o interior do cilindro se expandindo em direção a região de menor pressão. A expansão do gás que é liberado através das válvulas para o coletor de exaustão e posteriormente para o ambiente é uma oportunidade perdida de se gerar trabalho. Se, por algum motivo o movimento do pistão fosse capaz de exceder o ponto de PMI, a válvula de exaustão poderia permanecer fechada enquanto o gás se expandisse no interior do 
cilindro até atingir o menor valor possível (pressão ambiente) no ponto 6. Neste ponto a válvula de exaustão se abriria e o cilindro iria se esvaziar com o movimento do pistão, aproveitando assim toda a energia proveniente da expansão dos gases durante a queima. A área 5-6-1 então representa a máxima energia teórica disponível no sistema de exaustão.

Para um motor sobrealimentado, os autores afirmam que o diagrama que representa o processo pode ser demonstrado através da Figura 23:

Figura 23 - Diagrama P-v ciclo Diesel

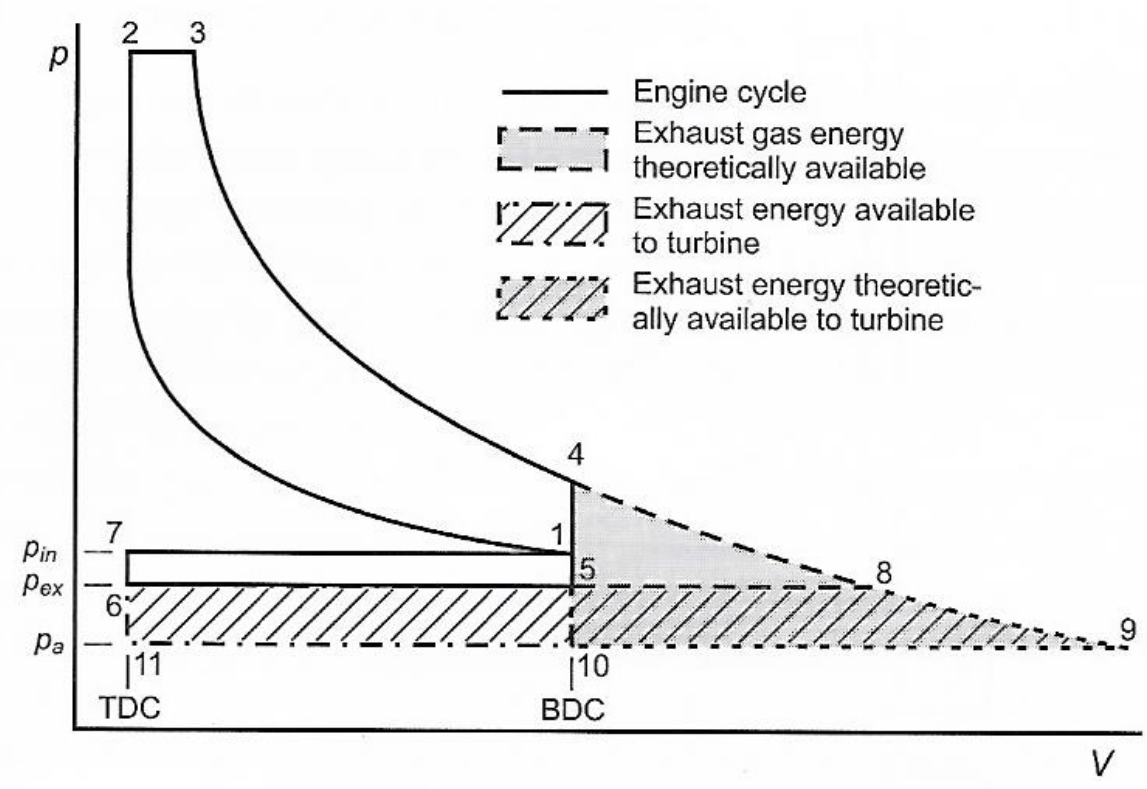

Fonte: Baines, 2005.

O processo de admissão pode ser representado pelos ponto 7-1, com pressão $p_{\text {in }}$ que é maior que o valor da pressão ambiente $\left(p_{a}\right)$. Após os processos de compressão, combustão e expansão, o pistão se encontra no ponto 4, no PMI, onde as válvulas de exaustão são abertas e então os gases se expandem para o interior do coletor de exaustão, na pressão $\left(p_{e x}\right)$. Este valor de pressão é menor que a pressão de admissão $p_{i n}$. No coletor de exaustão $p_{e x}$ é maior que a $p_{a}$, e assim é possível afirmar que existirá uma diferença de pressão entre a entrada e saída da turbina.

A Figura 24 representa um sistema com coletor que mantem a pressão constante na entrada da turbina: 
Figura 24 - Coletor de exaustão com grande volume

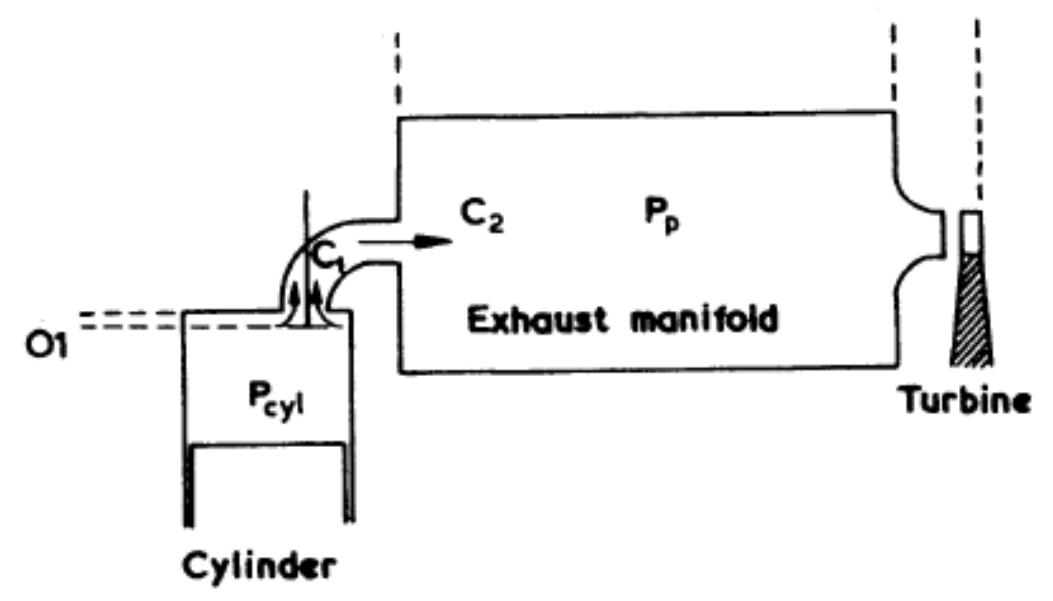

Fonte: Watson e Janota, 1982.

Admite-se que a pressão no coletor de exaustão é constante durante o ciclo, o que pode ser possível se seu volume for muito maior que o do cilindro. Sendo assim, isso agirá como um amortecedor para as vibrações provenientes dos efeitos pulsativos, causados quando as válvulas de abrem e fecham liberando o pulso dos gases.

Observa-se na Figura 24 que o gás no cilindro então se expande através das válvulas no ponto 5, e durante o curso de exaustão 5-6 a pressão no cilindro permanece constante e igual ao valor da pressão no coletor. Ao mesmo tempo, a turbina está recebendo os gases provenientes do coletor, que irão se expandir até atingir o valor de pressão atmosférico $\left(p_{a}\right)$, fazendo com que este trabalho seja convertido para o compressor. A área do diagrama 5-6-11-10 representa a energia disponível para a turbina. Durante o ciclo do motor, a pressão de entrada da turbina é constante e tem o mesmo valor que a do coletor de exaustão, enquanto na saída o valor também é constante e igual ao atmosférico, sendo assim é possível concluir que a turbina trabalha em regime permanente.

Somente para os motores aspirados a máxima energia teórica disponível é considerada maior que isso. Na condição ideal o curso de expansão poderia continuar até que a pressão do cilindro se igualasse ao do coletor de exaustão no ponto 8. A área 4-5-8 representa a energia adicional dos gases de exaustão que poderia estar disponível. 
No ciclo sobrealimentado, uma vez que o pistão começou o curso de exaustão, pode ser considerado que a pressão tende a cair para o valor ambiente enquanto os gases se expandem através da turbina. Durante este processo, a pressão na entrada da turbina cai de $p_{\text {ex }}$ no ponto 8 para $p_{a}$ no ponto 9. A área 5-8-9-10 representa a energia extra disponível em um processo de expansão completo na turbina.

Sendo assim, os autores citam que se torna evidente que mantendo a pressão constante de exaustão através dos ciclos leva a substancial perda da energia disponível proveniente dos gases de exaustão, representados por 4-9-10. A Figura 25 representa o diagrama dos gases de exaustão para um coletor que trabalha em pressão constante.

Figura 25 - Energia disponível nos gases de exaustão

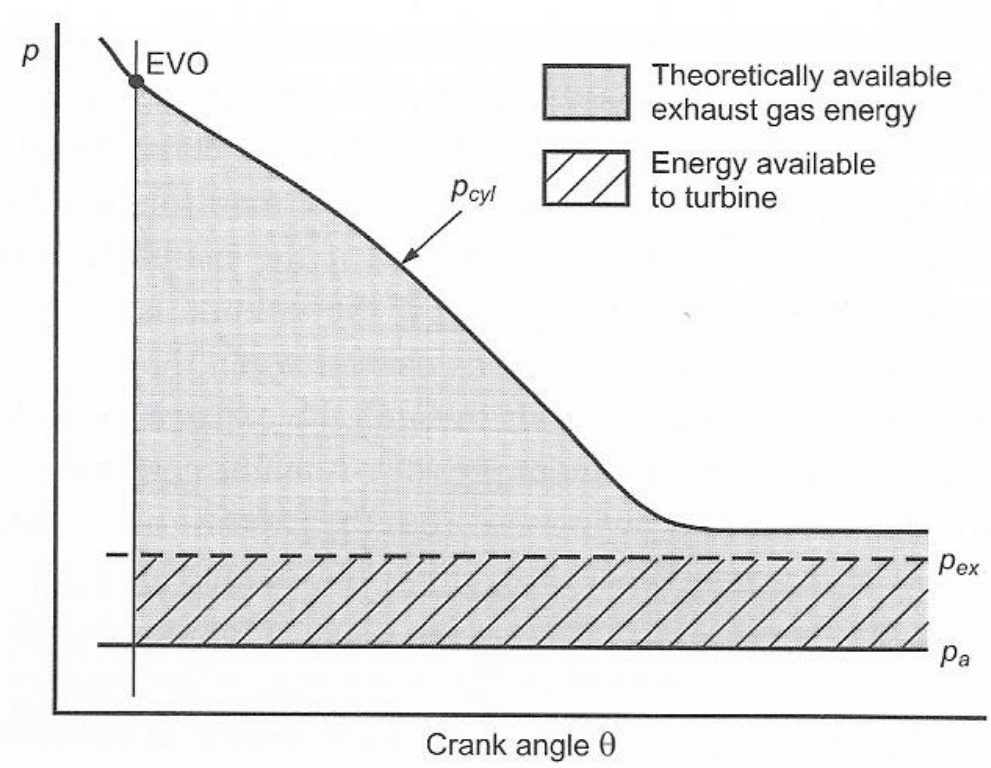

Fonte: Baines, 2005

Nota-se que o valor de energia disponível na turbina é pequeno em relação a energia teórica provenientes dos gases de exaustão disponibilizada pela queima do combustível, fazendo com que seja aproveitado uma quantidade relativamente pequena desta energia para se gerar trabalho.

Outra possibilidade apresentada é a restrição do volume do coletor de exaustão para um valor mínimo, ou seja, fazer com que a turbina esteja o mais próximo possível da válvula de exaustão. A Figura 26 demonstra o sistema. 
Figura 26 - Coletor de exaustão com volume mínimo

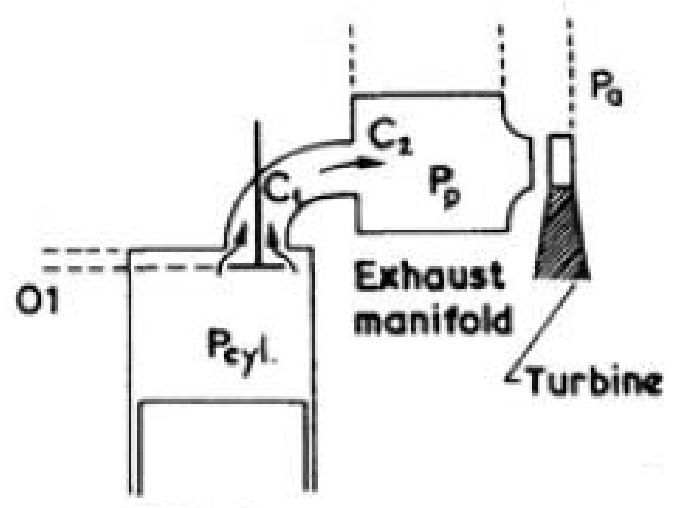

Cylinder

Fonte: Watson e Janota, 1982.

Na Figura 23 quando a válvula abrir no ponto 4, a pressão de entrada da turbina atingirá valores próximos da pressão no interior do cilindro, ou seja, a pressão cairá de 4 para 5, a entrada da turbina mudará de 4 para 8 e então continuará caindo para a pressão ambiente em 9 . Teoricamente toda a energia de blowdown estará disponível para a turbina. Para extrair-se toda a energia a pressão na entrada da turbina precisa-se aumentar instantaneamente no momento em que as válvulas se abrirem, saindo do valor $p_{a}$ e partindo para $p_{c y l}$. O início dá-se no ponto 4 e durante o processo de exaustão a pressão da turbina diminui gradualmente até atingir o valor ambiente. Entretanto, a pressão da turbina, assim como o fluxo de gases irão variar continuamente durante o ciclo do motor, e consequentemente, a potência transmitida para o compressor. A turbina irá operar momentaneamente no ponto ideal de operação durante o curso de exaustão e durante os cursos de admissão, compressão e expansão não produzirá nenhuma potência, caracterizando um efeito pulsativo no turbocompressor. A Figura 27 representa a energia proveniente dos gases de escape para um coletor agindo sob efeito pulsativo. 
Figura 27 -Energia disponível nos gases de exaustão coletor com pequeno volume

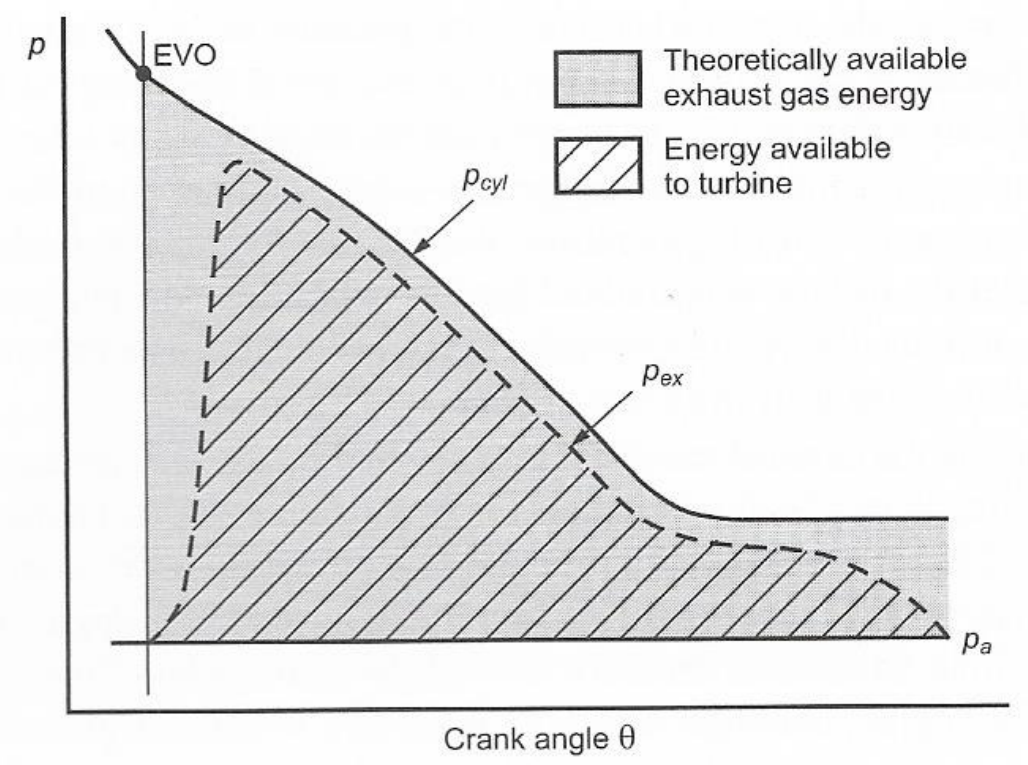

Fonte: Baines, 2005

Nota-se que o valor de energia disponível na turbina é maior quando comparado com o exemplo de pressão constante (Figura 25), fazendo com que seja aproveitado uma quantidade considerável para se gerar trabalho.

\subsection{APLICAÇÕES DE TURBOCOMPRESSORES EM MOTORES DE BAIXO DESLOCAMENTO}

Beach et al (2010) realizaram uma de aplicação de turbocompressor destinado há um veículo de fórmula SAE utilizando um Yamaha WR450F e um turbocompressor Garrett GT12. Com o projeto, atingiu-se um valor de potência de $53,7 \mathrm{~kW}$ e torque de $53 \mathrm{Nm}$. Os autores afirmam que em relação ao aspirado obteve-se um ganho de $10 \%$ em potência e $20 \%$ em torque. O trabalho de Beach et al. serve como referência por utilizar a mesma metodologia de cálculo de dimensionamento proposta por Hartman (2007). 
Griess et al. (2012) fizeram aplicação de um turbocompressor Honeywell GT15V em um motor monocilíndrico Yamaha WR450F, onde o objetivo era se atingir a potência de 44,7 kW e torque de $47 \mathrm{Nm}$.

Os autores avaliaram que o baixo peso do veículo é um ponto importante para o desempenho dinâmico, porém a relação entre peso e potência é o verdadeiro foco no projeto de veículos de competição, servindo como justificativa para buscar-se um aumento de potência do motor. Após esta aplicação e uma série de comparações com o desempenho do motor de 4 cilindros utilizado anteriormente, concluiu-se que o motor monocilíndrico apresentava uma melhor dirigibilidade devido a curva de torque, massa reduzida, viabilidade construtiva e singularidade.

Entretanto, a fabricante do turbocompressor fez um alerta para o efeito de pulsação causado devido ao menor número de cilindros do motor, que poderiam afetar o desempenho do turbocompressor. Estes efeitos de onda afetariam no modo como a potência da turbina é transferida para o compressor e, consequentemente, em como o ar seria comprimido. Sendo assim estudou-se três formas diferentes de geometria de coletores de exaustão: um coletor muito curto (com volume pequeno), múltiplos tubos e um com um volume de plenum muito grande.

A metodologia adotada foi a modelagem unidimensional do motor utilizando o software Ricardo Wave, onde se inseriu todas as características construtivas do motor de modo a representar algo próximo a realidade. Estudou-se o sistema de exaustão com os objetivos de minimizar a perda de energia entre motor e turbocompressor, encontrar um comprimento que maximizasse o desempenho em função dos efeitos acústicos, um material que suportasse as altas temperaturas pelas quais o sistema seria submetido e uma geometria que permitisse que o motor atingisse os valores de ruído impostos pelo regulamento.

O resultado obtido pela simulação foi de $43,3 \mathrm{~kW}$ e torque de $57 \mathrm{Nm}$ em uma rotação de 7200 rpm. Para validação do modelo, mediram o valor de potência no ponto de rotação de 7200 rpm, que resultou em um valor de $41,01 \mathrm{~kW}$. Como não havia tempo disponível para levantar todos os pontos da curva, os autores calibraram um ponto para determinar a correlação entre modelo e o real, e simularam os demais. A Figura 28 demonstra os resultados obtidos através da simulação. 
Figura 28 - Curvas de torque e potência obtidas na simulação

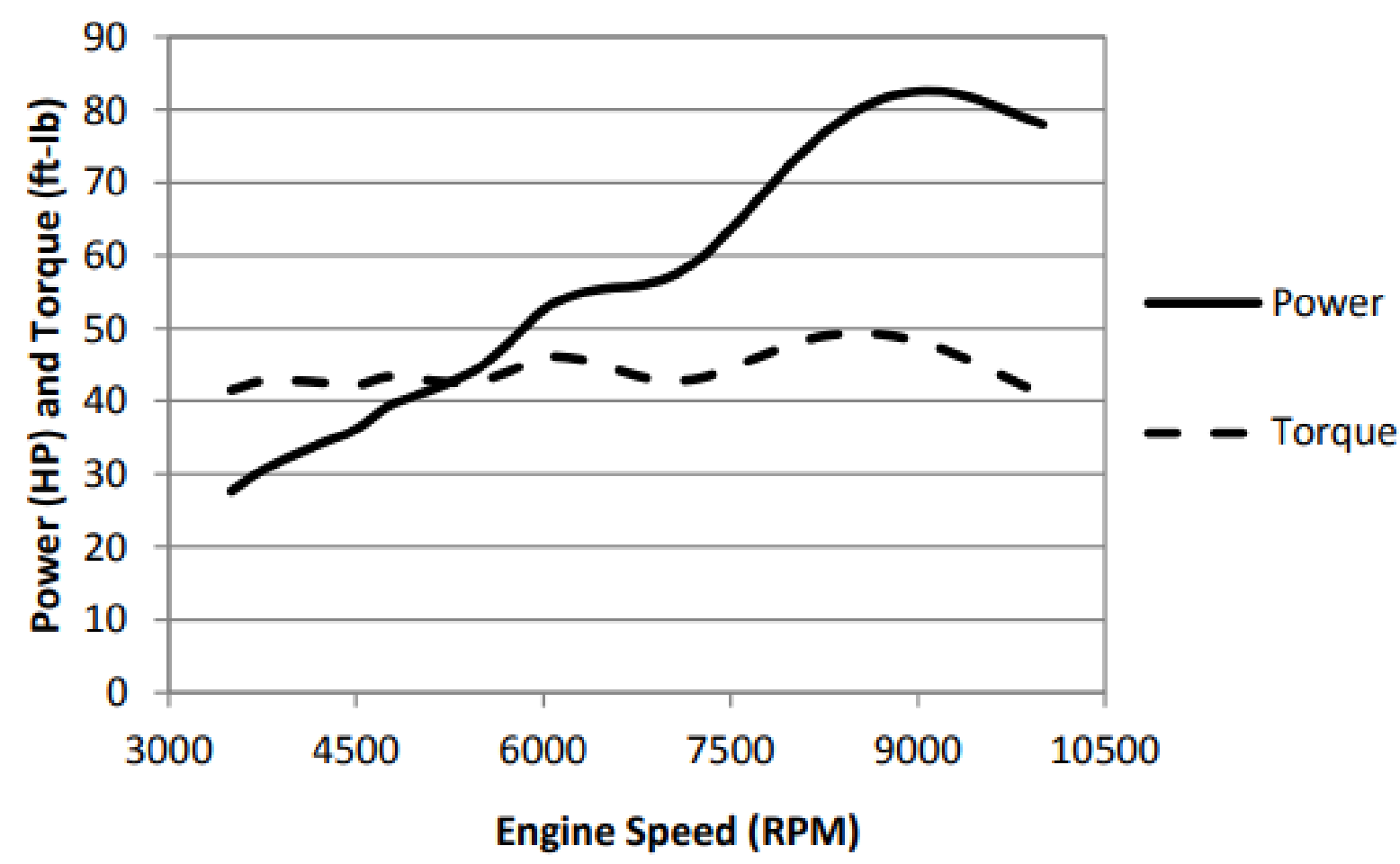

Fonte: Griess et al, 2012

Os autores, por fim, concluíram que a aplicação do turbocompressor apresentou um grande potencial de ganho no parâmetros e desempenho relacionado ao veículo, porém não foi possível obter todos os valores reais da curva de torque e potência para compará-los, sendo assim não se obteve uma conclusão efetiva sobre os resultados dos estudos sobre as geometrias de coletores de exaustão.

Pastorelli (2015) também elaborou um estudo numérico com o auxílio do software AVL Boost para avaliação de um motor de desempenho de um motor BMW G450X com a aplicação de dois diferentes tipos de turbocompressores: o Honeywell GT0632SZ e o MGT1238. Os objetivos principais do autor eram a avaliação da aplicação de um turbocompressor junto à um motor monocilíndrico de baixa cilindrada, utilizar como método a modelagem unidimensional para criar um modelo virtual que representasse o motor real e, a partir disso, selecionar a qual turbocompressor melhor se adequava a aplicação estudada.

Foram desenvolvidos três modelos: sendo um naturalmente aspirado sem restrição, um segundo com a restrição imposta pelo regulamento e, um modelo para o estudo da aplicação do turbocompressor. Os valores de torque em toda sua gama de rotações do modelo equivalente 
ao motor original aspirado quando comparado com os valores reais apresentaram um erro de aproximadamente $3 \%$, sendo assim, é possível dizer que o autor conseguiu desenvolver um modelo muito próximo do desempenho real, podendo ser utilizado nos estudos deste trabalho. A Figura 29 apresenta os valores de potência, torque e consumo específico obtidos através do modelo do motor naturalmente aspirado.

Figura 29 - Curvas de torque e potência obtidas através de simulação

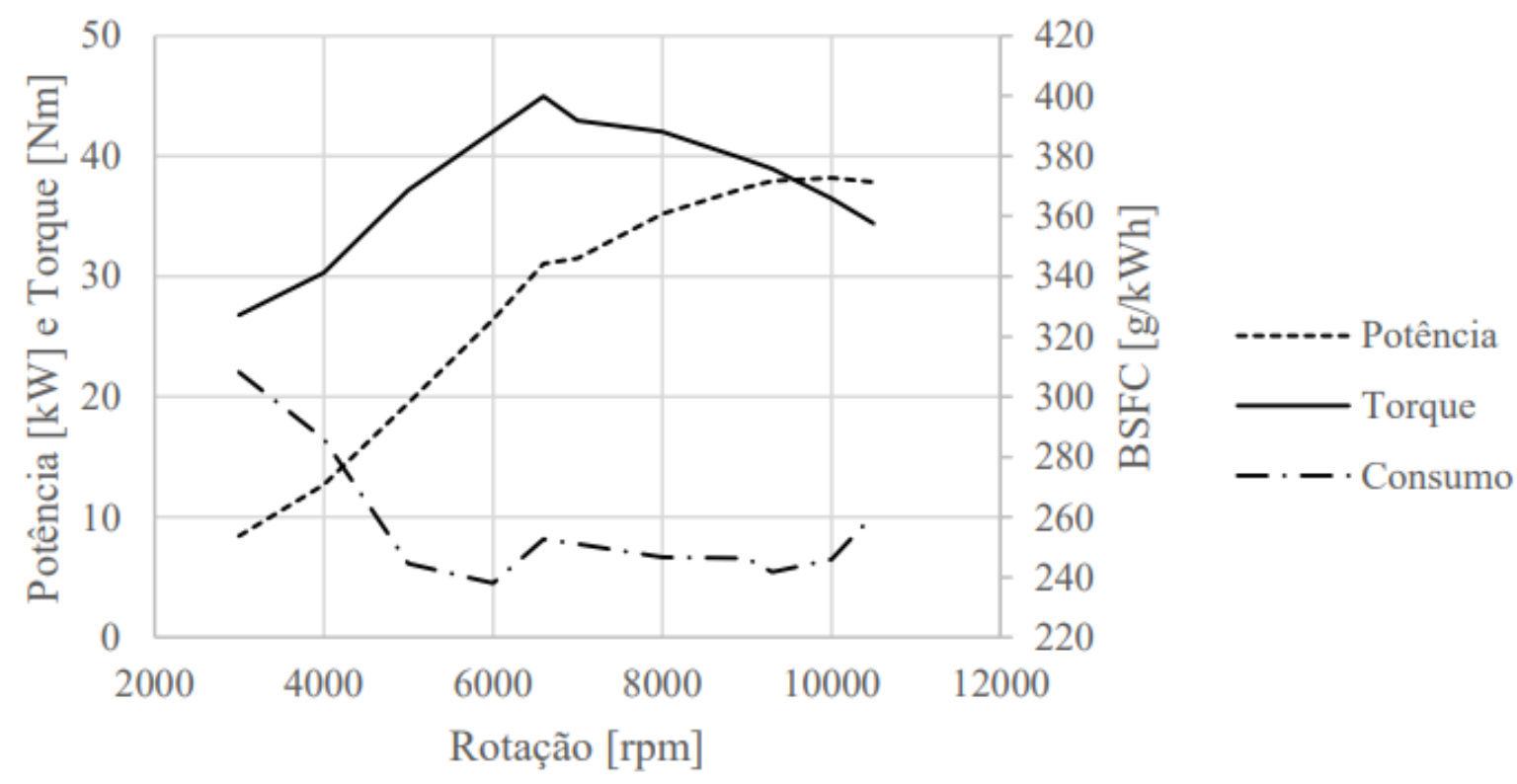

Fonte: Pastorelli, 2015

O modelo do motor com a restrição imposta pelo regulamento da competição na admissão desenvolvido apresentou uma redução considerável no desempenho, a curva de torque teve valor reduzido de 13,4 a 22,1\%, demonstrando como a alimentação do motor é afetada.

A partir do modelo aspirado com restrição, inseriu-se o turbocompressor para as simulações de desempenho. Observou-se que o turbocompressor GT0632SZ apresentou um ganho de torque em rotações mais baixas, devido a característica construtiva da turbina, onde a sua geometria favorece motores com menores valores de vazão mássica. Notou-se um ganho substancial em todas as faixas de rotação, superando os valores de torque do motor naturalmente aspirado sem restrição. O modelo MGT1238 apresentou um desempenho acima do obtido com o turbocompressor anterior, entretanto a geometria da turbina um pouco maior, projetada para um fluxo de exaustão de maior valor, proporciona em alguns momentos a operação do turbocompressor na região de surge, podendo causar falhas prematuras do mecanismo, fator 
que resultou na escolha do compressor GT0632SZ. A Figura 30 demonstra as curvas de torque obtidas pelas aplicações.

Figura 30 - Comparação entre resultados de curvas de torque

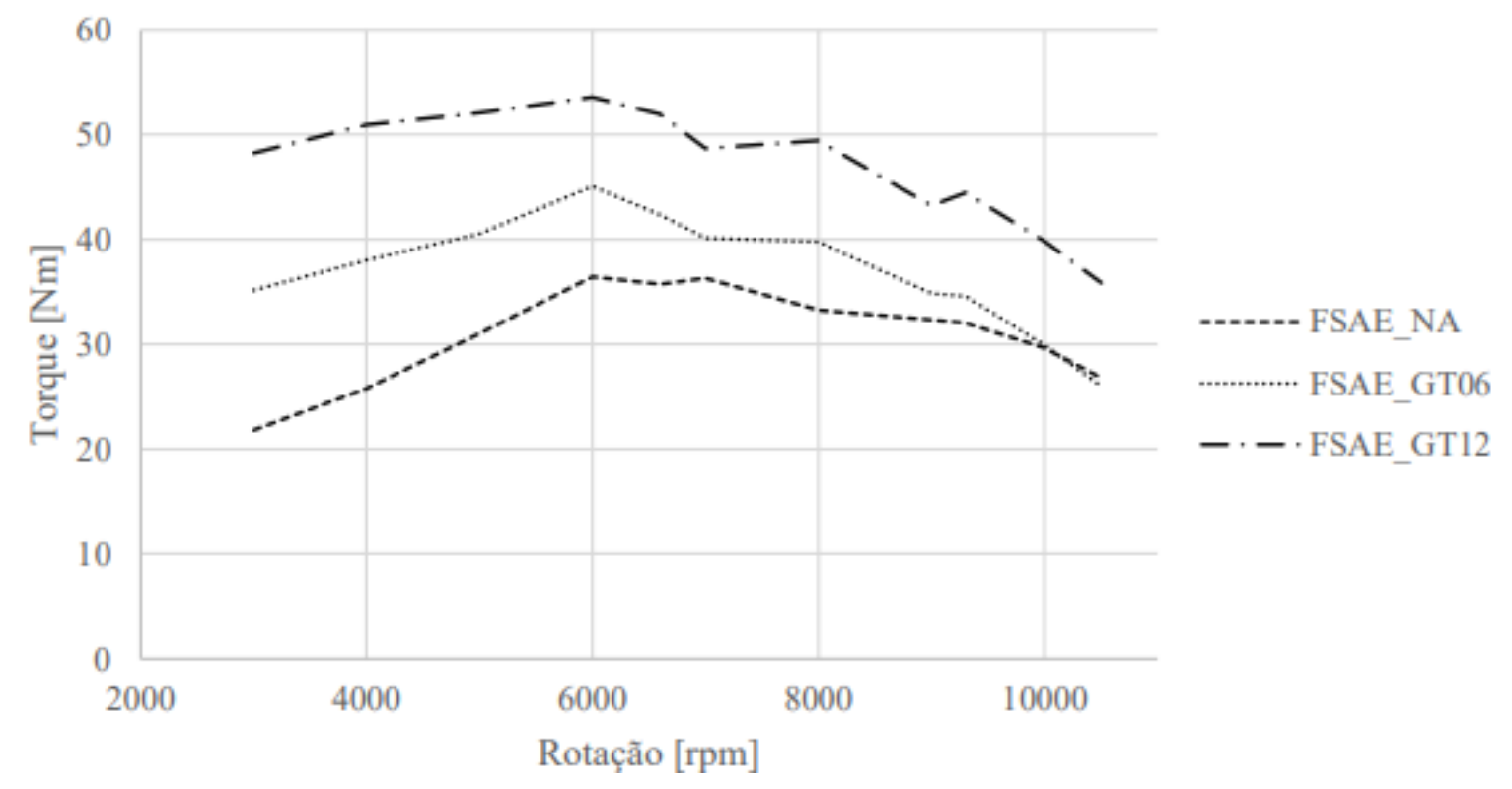

Fonte: Pastorelli, 2015

Attard et al (2007) desenvolveram uma pesquisa em uma aplicação de um motor bi cilíndrico de $430 \mathrm{~cm}^{3}$ com a aplicação de um turbocompressor Garrett GT-12. O objetivo foi desenvolver um motor turboalimentado de baixo deslocamento para equipar um veículo de fórmula SAE e investigar os feitos de pressão constante e efeito pulsativos discutidos por Watson e Janota (1982) e Baines (2005). No trabalho foi desenvolvido um modelo experimental para avaliação dos resultados.

Os testes se iniciaram pelo do motor naturalmente aspirado. Estudaram-se os limites do motor apenas com a sobrealimentação do coletor de admissão, fixando uma pressão de $15 \mathrm{kPa}$ com a ajuda de um compressor elétrico. O motor teria que suportar os altos valores de pressão impostos pelo turbocompressor na condição de plena carga.

Com a aplicação do turbocompressor, objetivou-se manter uma restrição que dificultasse a entrada de ar no compressor e estudar como isso poderia afetar o aumento de potência e a dirigibilidade do veículo. O limite esperado para o turbocompressor foi de um valor de pressão de admissão de $250 \mathrm{kPa}$, a partir daí a velocidade do ar na restrição afetaria o comportamento do fluxo de ar, devido aos efeitos acústicos. Outros limites impostos pelos 
autores aos testes foram o Knock Limit de 1\% do ciclo operar acima do Knock Amplitude de 4 bar (pressão na qual os efeitos de detonação começariam a ocorrer) e um Damage Limit de 1\% dos ciclos operarem acima de 20 bar.

O efeito pulsativo causado pela geometria do coletor teve impacto no desempenho da turbina, o que gerava flutuações na admissão de ar e anulava o efeito de scavenging no cilindro, prejudicando a queima de combustível.

Para investigar esse efeito, uma serie de geometrias de coletor de exaustão foram propostas, que foram estudadas com a utilização de um modelo unidimensional validado construído no software Ricardo Wave. Chegaram a duas configurações: um onde o comprimento do coletor foi calculado pensando no efeito pulsativo produzido e outra com um volume de plenum antes da turbina. $O$ fato de se aumentar a área superficial com o volume de plenum permite que o gás troque calor com as vizinhanças permitindo que os valores de entalpia na chegada da turbina sejam reduzidos, fazendo com que o seu rendimento seja prejudicado. Esta geometria foi profundamente analisada com o auxílio do software, onde foi possível variar o valor do volume do ressonador e avaliar seu impacto na curva de potência do veículo. A Figura 31 demonstra os resultados obtidos.

Figura 31 - Curva de potência com a variação de volume de plenum no coletor de exaustão

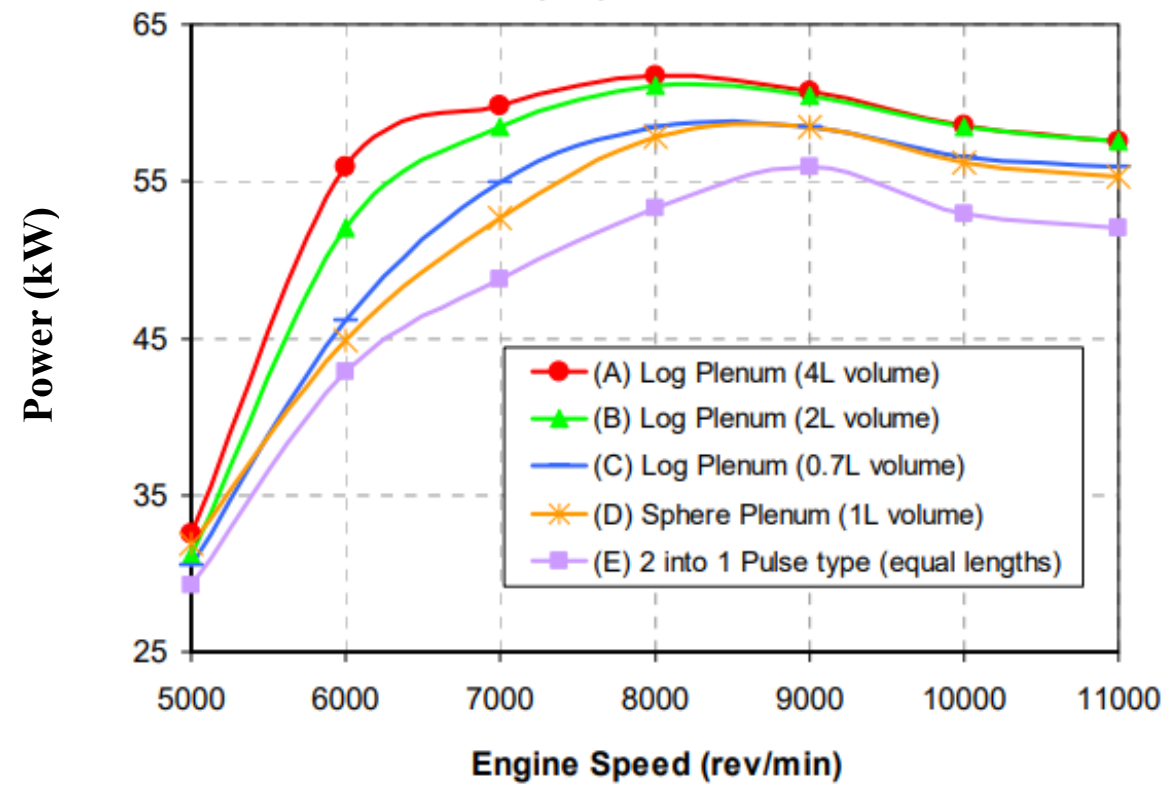

Fonte: Attard et al, 2007 
Nota-se que existe um aumento significativo de potência quando aplicado o volume de plenum com o objetivo de avaliar o funcionamento do turbocompressor trabalhando sob pressão constante. Os testes com modelo de coletor de comprimentos iguais dimensionado pelo método de efeito pulsativo apresentaram performance reduzida em todos os pontos de rotação, assim como o aumento dos gases residuais, indicando uma possível redução do consumo de ar.

O ganho de desempenho associa-se ao aumento do volume de plenum no coletor de exaustão, devido a redução do efeito pulsativo, agindo como uma forma de ressonador, fazendo com que as flutuações de velocidade da turbina fossem reduzidas. Este tipo de efeito foi dominante nas regiões de baixa rotação. Com o aumento da rotação, a frequência dos pulsos aumentava e o intervalo entre as ondas eram reduzidas, fazendo com que a rotação da turbina não fosse tão afetada. Os maiores volumes de plenum proporcionaram pequenos ganhos de desempenho, porém proporcionaram muita perda de calor, fazendo com que fossem descartados.

A geometria mais efetiva de volume seria a de um formato de esfera, onde a área superficial é reduzida ao mínimo, obtendo-se a melhor relação entre superfície e volume. Entretanto, as simulações demonstraram que o formato cilíndrico proporcionava pequenas perdas de calor para um volume similar, fazendo com que esta geometria fosse escolhida pela praticidade na fabricação. A Figura 32 demonstra as duas geometrias finais estudadas nos testes práticos.

Figura 32 - Coletores de exaustão utilizados nos testes em bancada

a) Coletor efeito pulsativo

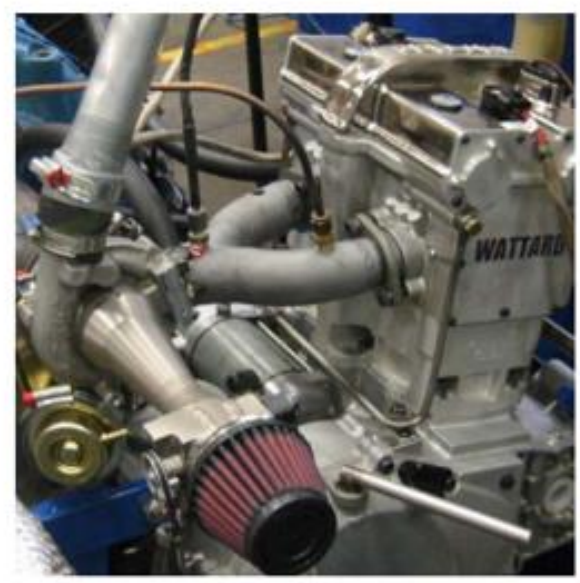

b) Coletor pressão constante

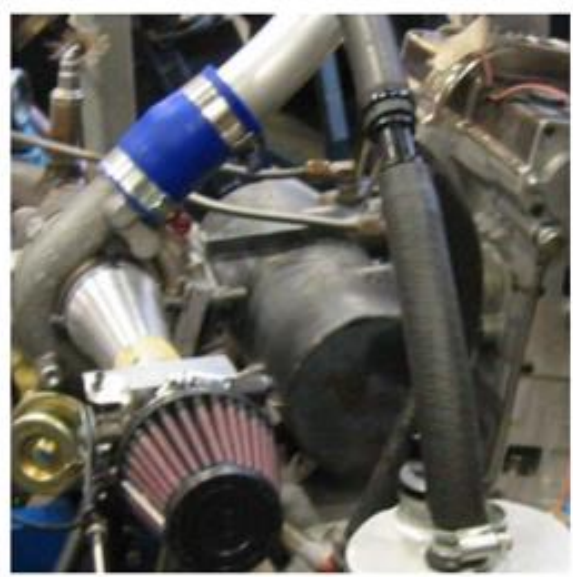


Durante os testes o coletor de exaustão com o volume de plenum foi substituído pelo coletor com comprimentos iguais. Nesta nova configuração, observou-se uma redução de torque de $30 \%$ e a ocorrência de problemas relacionados ao efeito de detonação com os valores de avanço determinados com a configuração anterior. A Figura 33 demonstra a diferença de resultados obtidos através da troca de geometrias.

Figura 33 - Curvas de pressão média efetiva (BMEP)

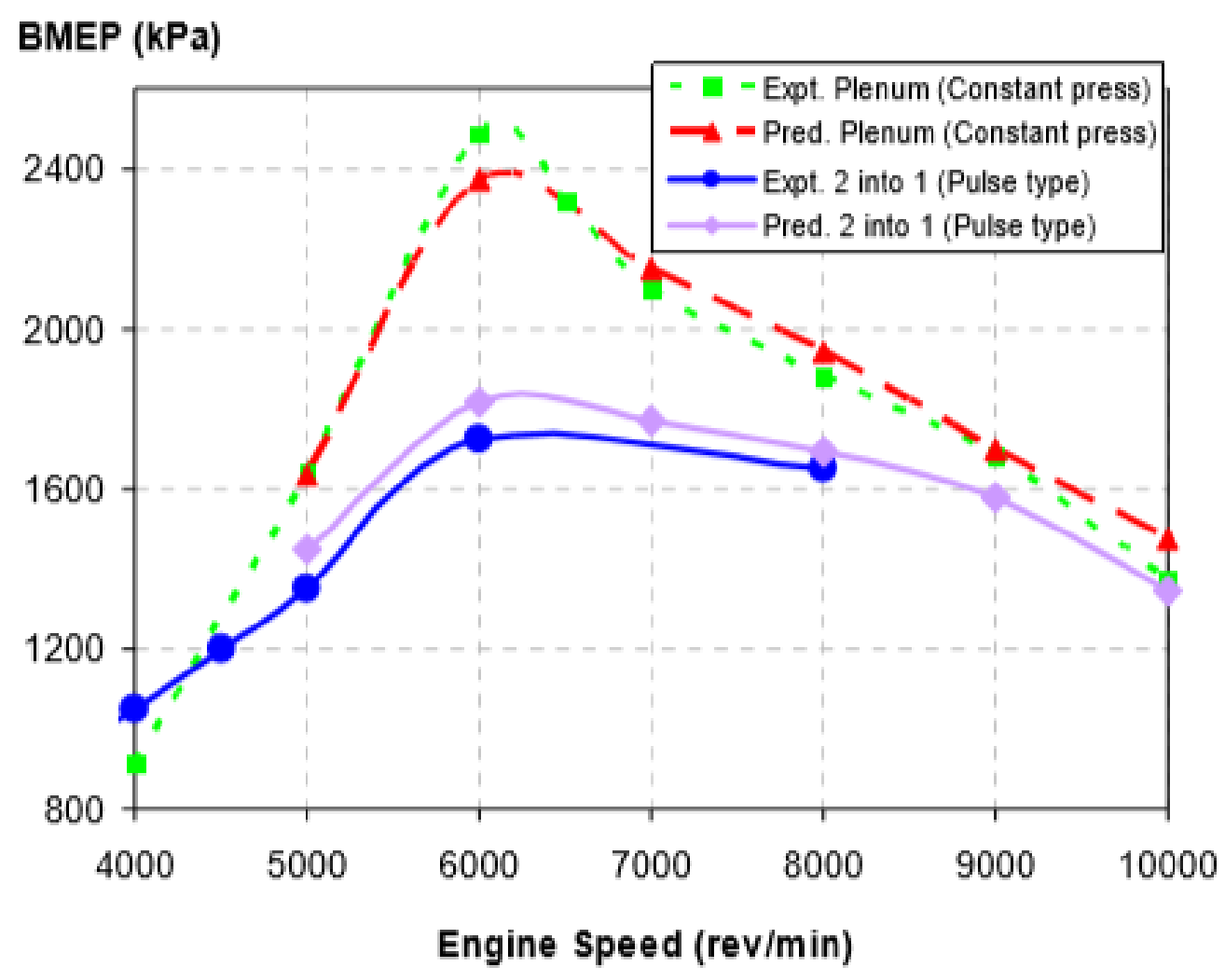

Fonte: Attard et al, 2007.

Com a finalidade de evitar danos ao motor, com a troca do coletor houve uma redução nos valores de avanço e pressão de admissão, como consequência o desempenho do motor foi prejudicado. A Figura 34 ilustra a diferença entres as configurações em um diagrama de pressão média efetiva (BMEP), avanço e pressão no coletor de admissão (MAP) para duas configurações diferentes de coletor de exaustão (pressão constante e efeito pulsativo) em uma rotação fixada de $5000 \mathrm{rpm}$. 
Figura 34 - BMEP e avanço de ignição versus MAP para coletores com pressão constante e efeito pulsativo no motor turboalimentado (50000 rev/min 10:1 CR)

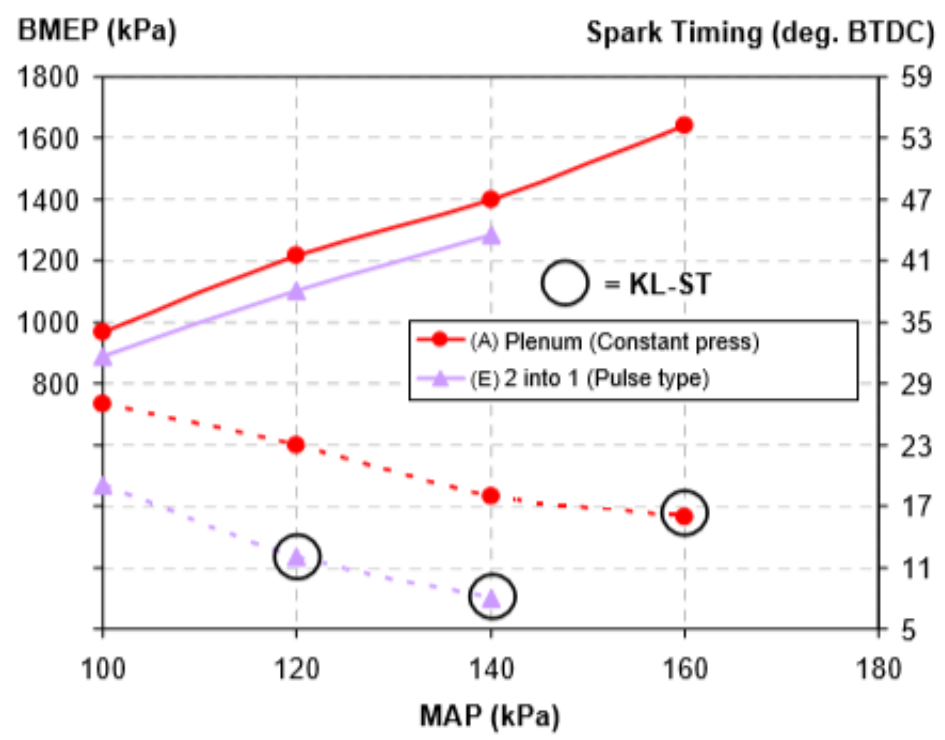

Fonte: Attard et al, 2007.

Por fim, compararam-se as curvas de potência resultantes do modelo e do experimental entre os motores motor bi cilíndrico turbocomprimido e o motor quatro cilindros de $600 \mathrm{~cm}^{3}$ naturalmente aspirado com a finalidade de demonstrar o ganho obtido e as diferenças entre as aplicações. Os resultados estão na Figura 35.

Figura 35 - Comparação de resultados nas curvas de torque e potência

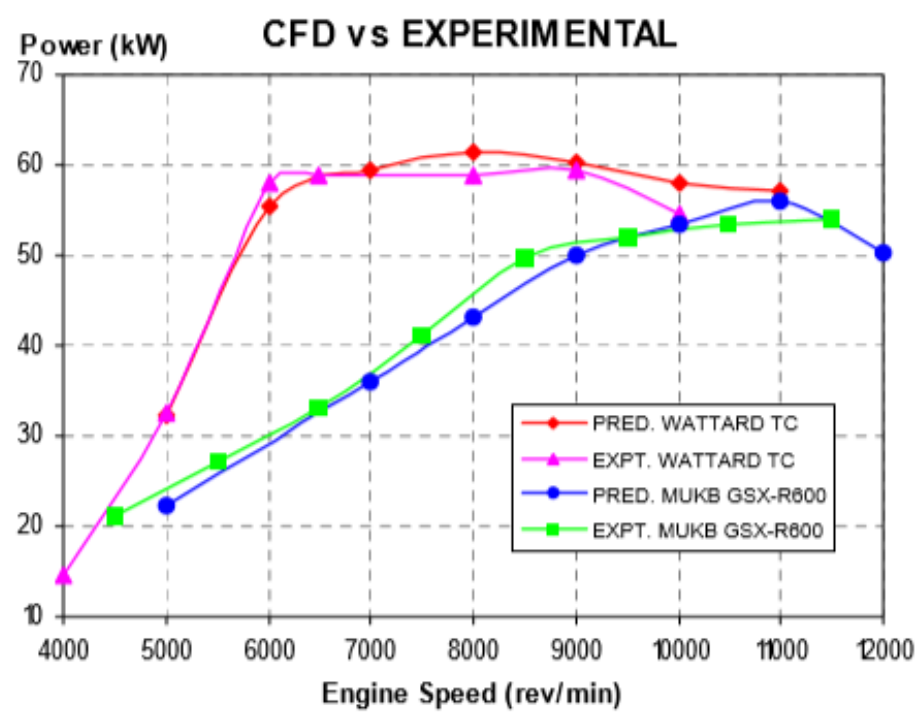

Fonte: Attard et al, 2007. 
Concluiu-se que para aplicação o uso da ferramenta de simulação foi extremamente importante para o rápido desenvolvimento do motor, ajudando no melhor entendimento do funcionamento do motor e na redução de custos de testes e peças.

Os efeitos acústicos no coletor de escape foram identificados em ambas configurações. Concluiu-se que o método de pressão constante se adequou melhor a aplicação do motor escolhido, resultando em um significativo aumento de potência e torque. Os autores ainda fazem um alerta para os efeitos de detonação, ressaltando ser um fator importante para definir os parâmetros de desempenho de motores com pequenos deslocamentos com a aplicação de turbocompressores.

\subsection{CALIBRAÇÃO COM UTILIZAÇÃO DE UMA VELA INSTRUMENTADA}

Custódio (2015) desenvolveu um trabalho em conjunto com a equipe formula FEI com a finalidade de abordar os princípios de funcionamento dos sensores de um sistema de injeção eletrônica e fazer as alterações necessárias para a instalação do sistema em um motor que previamente utilizava carburador, utilizando metodologia e recursos necessários para o desenvolvimento do processo de calibração. No estudo foi utilizado o motor Yamaha WR450F com uma central eletrônica programável Microsquirt para fazer o gerenciamento dos sensores.

Foi necessária a instrumentação de alguns pontos do motor para que durante o processo de construção dos mapas de injeção e ignição houvesse valores exatos de temperatura, pressão, tensão, corrente e etc. Definiram-se como pontos de instrumentação: pressão da câmara de combustão, corrente de sinal de ignição e injeção, sonda lambda e temperatura dos gases de exaustão.

Para a aquisição da pressão de combustão utilizou-se uma vela instrumentada, que possui um transdutor de pressão piezoelétrico que envia os sinais de cargas elétricas para um amplificador. O sinal condicionado enviado entra em um módulo (FlexiFem Indicom) que junto ao sinal proveniente do sensor de rotação, transmite ao software as informações do valor de pressão na câmara em função do ângulo de rotação do virabrequim. O modelo do sensor utilizado foi o AVL Z121_U3C. 
Para a verificação dos valores de corrente, foram utilizados dois alicates amperimétricos com a função de enviar o sinal de injeção e ignição para o modulo FlexiFem para que fosse verificado o momento exato do disparo da centelha e do pulso de injeção. Para a verificação dos valores de fator lambda utilizou-se um condicionador ETAS e uma sonda lambda Bosch LSU 4.9, para aquisitar os valores de temperatura dos gases de exaustão, foi utilizado um termopar tipo K, posicionado próximo a válvula de exaustão.

Para realização dos testes, o veículo foi instalado em um dinamômetro de chassi ativo, onde foi possível levantar as curvas necessárias ao processo. A Figura 36 demonstra o veículo instrumentado em dinamômetro durante os testes.

Figura 36 - Veículo fórmula FEI RS9 com instrumentação em dinamômetro

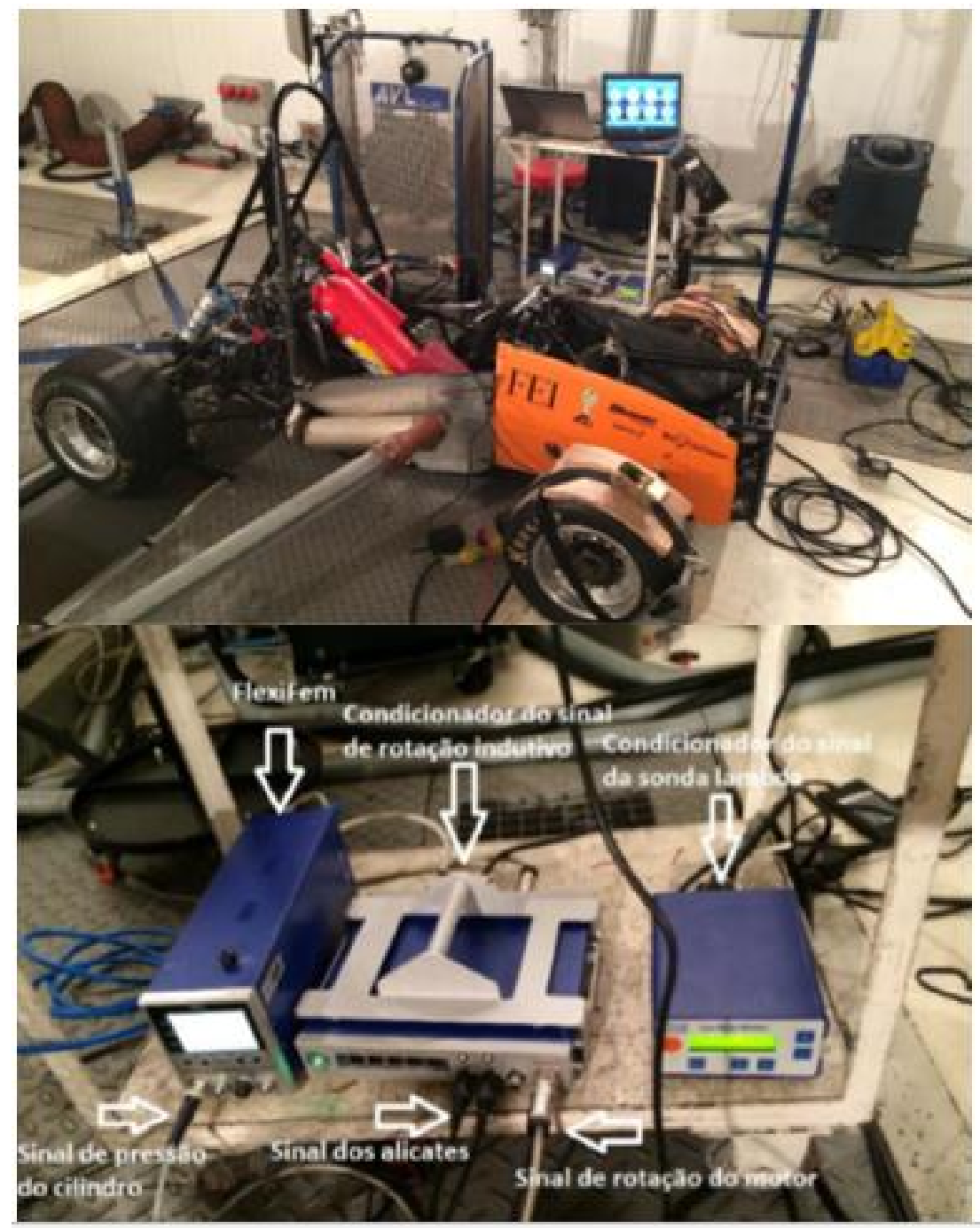

Fonte: Custódio, 2015 
A metodologia utilizada ajudou a compreender que com o sistema de injeção eletrônica podese ajustar de forma precisa os parâmetros de combustível e avanço de ignição. O uso do Indicom da AVL facilitou o processo de construção dos mapas de forma a monitorar a estabilidade da combustão. O dinamômetro ativo possibilitou a varredura completa do mapa para o máximo de condições de rotação e cargas nas quais o motor pode ser submetido, conseguindo assim melhorar a dirigibilidade do veículo. Por fim, obteve-se a curva de pressão media efetiva no cilindro (BMEP) do motor em função da rotação e dos valores de avanço de ignição. A Figura 37 ilustra os resultados obtidos.

Figura 37 - Curva de pressão média efetiva (BMEP) do motor Yamaha WR450F

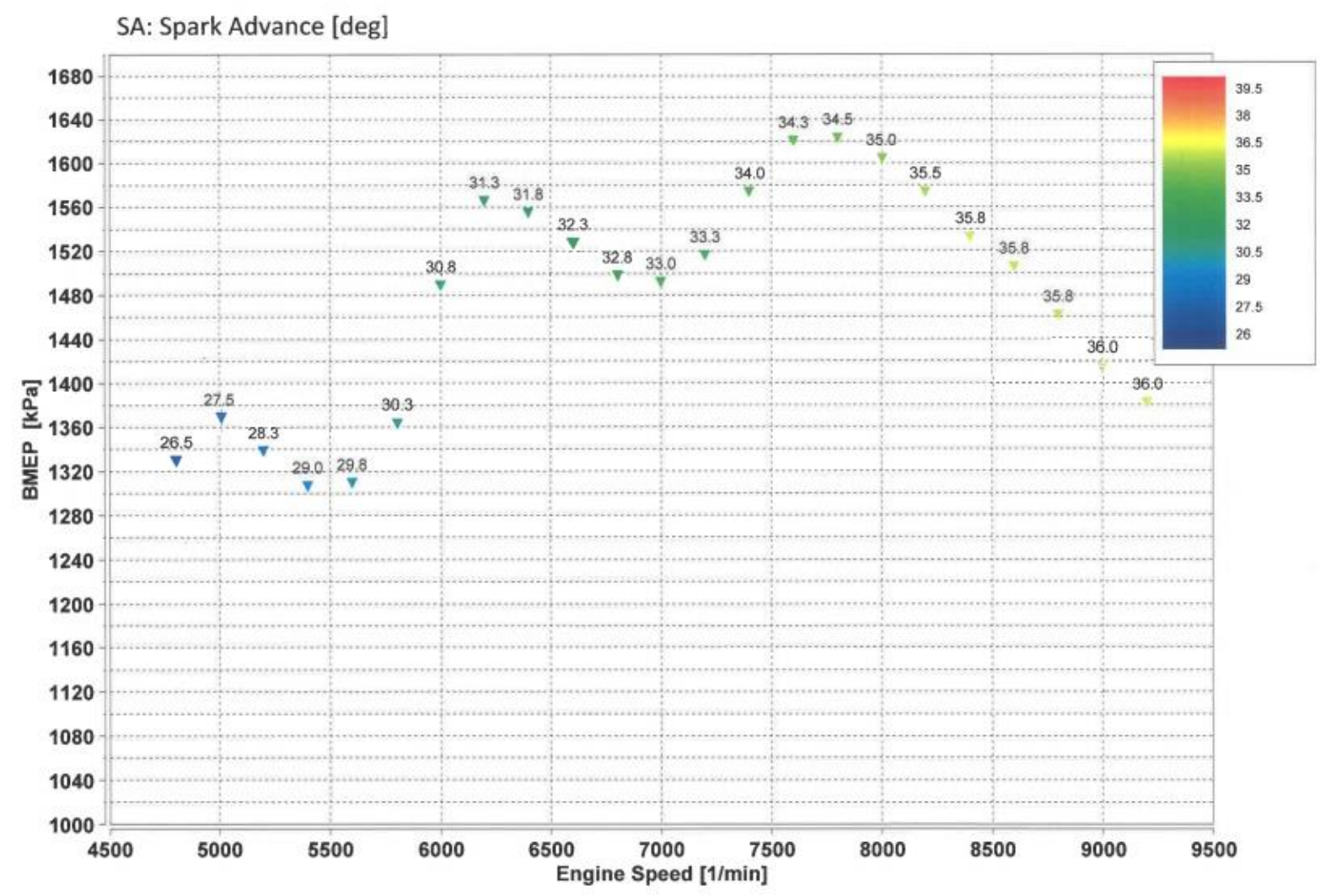

Fonte: Custódio, 2015

Os trabalhos mencionados servem como base para a elaboração da metodologia de desenvolvimento do modelo para estudo da influência do efeito pulsativo no desempenho de um motor com características parecidas com o objeto de estudo deste trabalho. Sendo assim, os pontos destacados e as análises citadas, conduzem o caminho que deseja-se traçar nos tópicos de metodologia e análise de resultados. 
As análises feitas por Attard et al. tem grande relevância no desenvolvimento da pesquisa, principalmente no comparativo entre as curvas de torque e potência resultantes das diferentes configurações de coletores. Um ponto a se destacar é a conclusão de que o coletor de grande volume pode proporcionar maior ganho em baixas rotações quando comparado ao coletor dimensionado por efeito pulsativo.

Gries et al., assim como Pastorelli, demonstra uma metodologia de desenvolvimento de modelo que será adotada para a definição do modelo naturalmente aspirado, e posteriormente, o comparativo com o modelo turboalimentado.

\section{METODOLOGIA}

Após a conclusão da revisão bibliográfica, formulação matemática, assim como apresentação dos trabalhos que serviram como referência para o projeto, serão abordados a metodologia, os recursos materiais utilizados e os cálculos referentes ao dimensionamento do projeto do motor turboalimentado.

\subsection{PROPOSTA}

Neste projeto tem-se como objetivo reproduzir a metodologia utilizada por Griess et al (2012) para construção e correlação de dois modelos unidimensionais com auxílio do software AVL Boost: um do motor naturalmente aspirado e outro com a utilização de turbocompressor. O procedimento adotado por Pastorelli (2015) servirá para dimensionar e avaliar a viabilidade de construção de um motor acoplado a um turbocompressor, permitindo o estudo de três peças diferentes.

Por fim, o trabalho realizado por Attard et al (2007) servirá como referência para estudo dos efeitos pulsativos no coletor de escape para avaliação de qual será a melhor geometria para aplicação.

O trabalho foi realizado em conjunto com a equipe formula FEI, que forneceu o motor Yamaha WR450F monocilíndrico de $450 \mathrm{~cm}^{3}$, assim como o veículo e todos os dados 
necessários para a construção do modelo. Dois turbocompressores foram estudados: dois protótipos exclusivos desenvolvidos pela empresa BorgWarner, para avaliação de qual atende melhor as necessidades e características da aplicação.

\subsection{SOFTWARE AVL BOOST}

A utilização do software AVL Boost para modelagem do motor naturalmente aspirado tem como objetivo representar o motor real em estudo. Este tipo de metodologia serve para aprofundar estudos de parâmetros e suas influências sem que seja necessário a realização de inúmeros testes de bancada, permitindo uma redução de custos e tempo de projeto.

O software AVL BOOST simula uma grande variedade de motores, podendo ser 4 tempos ou 2 tempos, com ignição espontânea ou faísca. As aplicações variam de acordo com a necessidade do estudo, podendo ser motores de pequeno volume para motocicletas e geradores, motores industriais e até motores para aplicação marítima.

Nessa plataforma é possível calcular a variação das propriedades termodinâmicas dos gases que compõe o fluido ativo de um ciclo em função do ângulo de rotação do virabrequim.

O pacote do programa consiste em um pré-processador interativo que auxilia na preparação dos dados de entrada para a lógica de cálculo principal. A análise dos resultados é suportada por um pós-processador.

A ferramenta de pré-processamento apresenta um editor de modelos e uma entrada dos dados necessários. O modelo de cálculo do motor é projetado selecionando os elementos necessários em uma arvores de componentes, que posteriormente são conectados por elementos de tubo. Desta forma, até mesmo configurações de motores muito complexas podem ser modeladas facilmente.

O software oferece algoritmos de simulação otimizados para cada componente disponível. O fluxo nas tubulações é tratado de maneira unidimensional. Isso significa que as pressões, temperaturas, velocidades entalpias, entropia e etc. são consideradas constantes ao $\operatorname{logo}$ da seção transversal do duto. As perdas devido aos efeitos tridimensionais são consideradas através da utilização de coeficientes de fluxo. Isto significa que a simulação 
multidimensional de peças críticas do motor deve ser feita com a utilização de outras ferramentas e combinadas com a análise unidimensional. (AVL, 2020)

A vantagem de se utilizar um simulador deste tipo é que as mudanças das grandezas geométricas não requerem uma descrição tão detalhada para cada simulação, tornando o estudo dos seus efeitos mais rápido e prático, podendo-se realizar cálculos de vários ciclos em um pequeno intervalo de tempo. (NETO, 2013; CAMPOS, 2015)

\subsubsection{Modelo de combustão}

Para o entendimento do processo de combustão de um motor real é necessário entender as principais diferenças entre o motor de combustão interna real e o motor de ciclo ideal Otto. No ciclo ideal admite-se que a queima ocorre em um instante onde o volume da câmara de combustão permanece constante, sendo o deslocamento do pistão durante o processo de combustão considerado desprezível. Nas aplicações reais o combustível precisa de um tempo determinado para completar o processo de queima, sendo inevitável a movimentação do pistão enquanto o processo ocorre, tornando este conceito prático inaplicável em condições reais. (NETO, 2013)

Existem métodos matemáticos que preveem o cálculo da taxa de queima do combustível de forma adequada. Desta forma, é possível determinar a taxa de fornecimento de energia do sistema, impactando diretamente no gradiente de pressão e temperatura no interior do cilindro e na eficiência térmica, afetando o trabalho produzido e a transferência de calor com as paredes do cilindro. (NETO, 2013)

A função Viebe é um modelo zero-dimensional normalmente usados para desenvolvimento de motores de ignição por centelha. Esse é um método relativamente simples de aproximar a fração de massa queimada durante o processo de combustão comparado com os demais modelos existentes. (Dumitrescu e Liu, 2019)

A equação que define a função padrão do cálculo do modelo Viebe é definida como:

$$
x_{b}(\theta)=1-\exp \left[-a\left(\frac{\theta-\theta_{0}}{\Delta \theta}\right)^{m+1}\right]
$$


Onde $x_{b}(\theta)$ é a fração em massa do combustível queimado, $\theta$ é o ângulo do virabrequim, $\theta_{0}$ é o ângulo onde a se inicia a combustão, $\Delta \theta$ é a duração do processo de combustão, $m$ é o fator de forma ( isso determina o comportamento da curva do processo) e $a$ é determinado como o parâmetro de eficiência ( responsável pela duração).

O comparativo entre os resultados obtidos pelo cálculo e os valores reais medidos são demonstrados na Figura 39:

Figura 38 - Aproximação da taxa de liberação de Calor

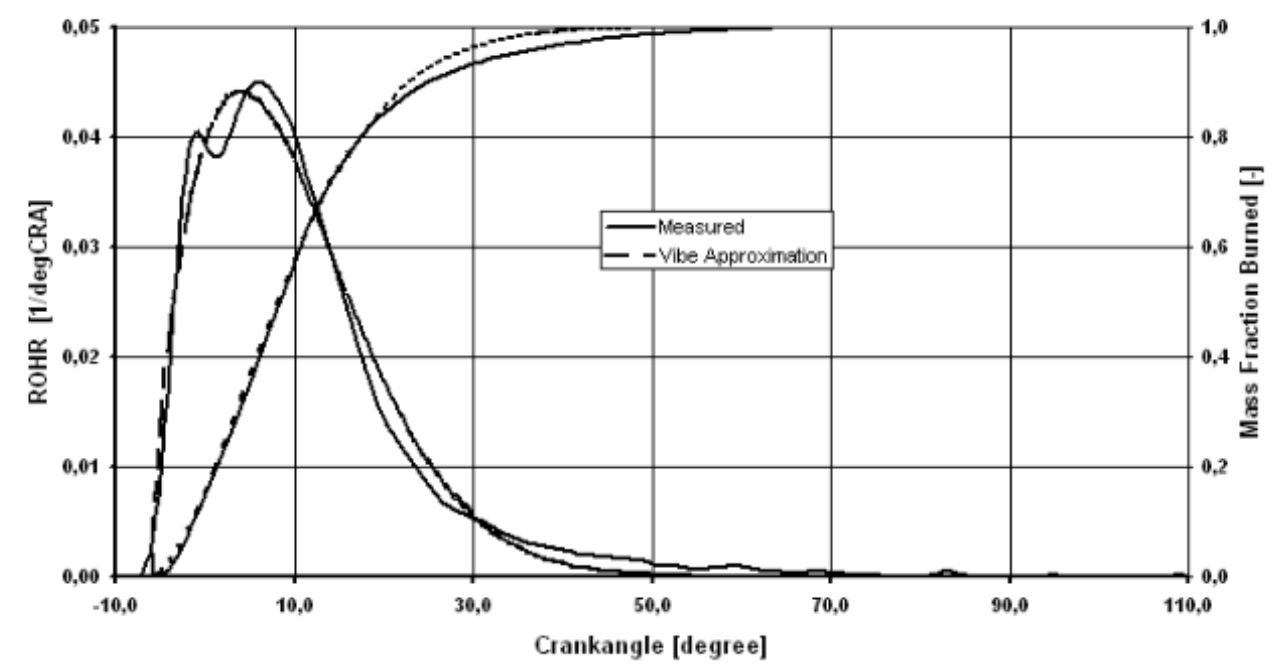

Fonte: AVL BOOST theory, 2020.

As curvas demonstram a aproximação da taxa de liberação de calor (ROHR) da combustão de um motor Diesel de injeção direta modelado utilizando o cálculo da função Wiebe e valores experimentais. Observa-se que os resultados têm comportamento muito próximos dos valores modelados, indicando uma aproximação aceitável para utilização em um modelo.

A AVL também fornece um diagrama demonstrado a influência do valor do fator de forma $(m)$ na duração do processo de combustão, demonstrado na Figura 40: 
Figura 39 - Influencia do fator de forma na taxa de liberação de calor da combustão

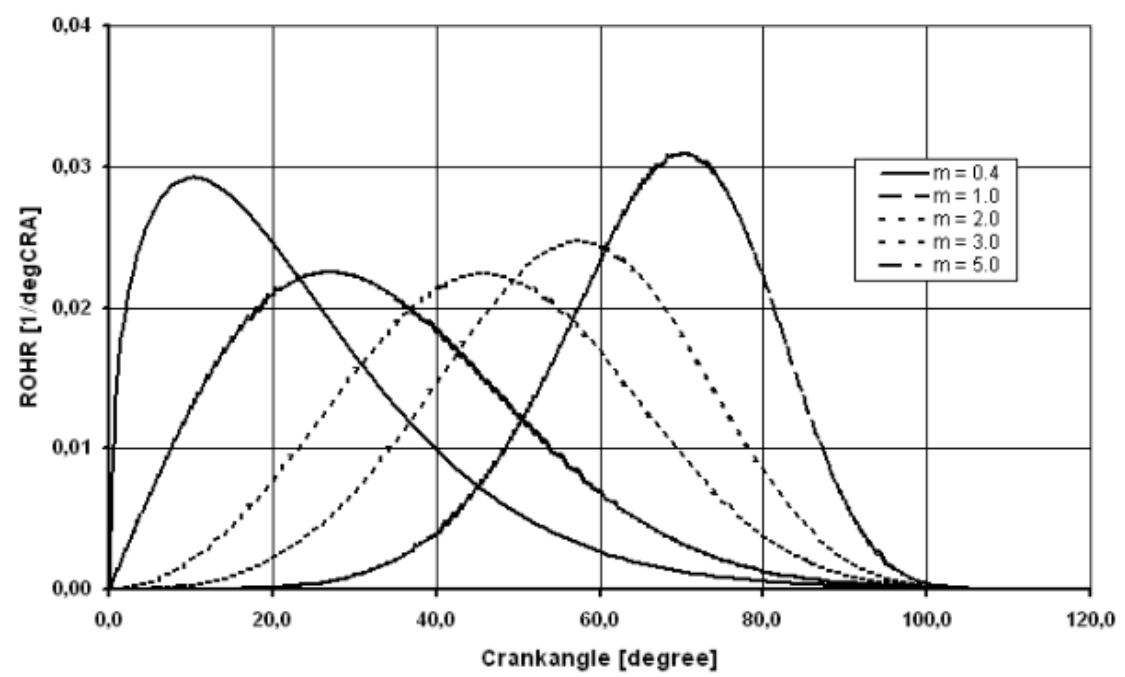

Fonte: AVL BOOST theory, 2020.

O software recomenda uma série de valores para o parâmetro de forma em diferentes aplicações de motores. As categorias são divididas em motores a gasolina, carros de passeio ciclo Otto de injeção indireta, carros de passeio ciclo Diesel com injeção direta, veículos pesados de ciclo Diesel e motores de velocidades médias. O principal ponto de interesse para simulação são os valores apresentados na Figura 41, referentes a motores de ciclo Otto com aplicação de gasolina.

Figura 40 Parâmetro de forma para diferentes aplicações

\begin{tabular}{|c|c|c|c|}
\hline & Operating Point & Comb. Duration & Par. $\mathrm{m}$ \\
\hline \multirow[t]{9}{*}{ Gasoline Engine } & \multicolumn{3}{|c|}{ Standard Combustion System (2-Valve Engine) } \\
\hline & $1500 \mathrm{rpm}$ WOT & 60 degrees CRA & 2.3 \\
\hline & $5000 \mathrm{rpm}$ WOT & 65 degrees CRA & 1.9 \\
\hline & \multicolumn{3}{|c|}{ Standard Combustion System (4-Valve Engine) } \\
\hline & $1500 \mathrm{rpm}$ WOT & 50 degrees CRA & 2.5 \\
\hline & $5000 \mathrm{rpm}$ WOT & 55 degrees CRA & 2.1 \\
\hline & \multicolumn{3}{|c|}{ Fast Burn Concepts } \\
\hline & $1500 \mathrm{rpm}$ WOT & 45 degrees CRA & 2.6 \\
\hline & $5000 \mathrm{rpm}$ WOT & 50 degrees CRA & 2.6 \\
\hline
\end{tabular}

Fonte: AVL BOOST theory, 2020. 
O modelo adota o valor do parâmetro de eficiência $(a)$ como sendo 6.9, admitindo assim que a combustão é completa durante as simulações.

Sendo assim, a Tabela 2 apresenta os valores adotados para o modelo da combustão para o motor Yamaha WR450F aspirado.

Tabela 2 - Parâmetros de entrada do modelo Wiebe

\section{Parâmetros Wiebe}

\begin{tabular}{c|c}
\hline Parâmetro de forma $(m)$ & 2.6 \\
Parâmetro de eficiência $(a)$ & 6.9 \\
Duração da combustão $\left(^{\circ}\right)$ & 50 \\
\hline
\end{tabular}

Fonte: Autor, 2020

\subsubsection{Modelo de transferência de calor}

O software AVL BOOST apresenta cinco modelos de transferência de calor que podem ser adotados para o modelamento dos processos internos ao cilindro

- Woschini 1978 e 1990

- Hohenberg

- $\quad$ Lorenz 1978 e 1990

- AVL 2000

- Bargende

O coeficiente de transferência pode ser calculado através dos valores de pressão no cilindro, velocidade média do pistão, swirl e etc. A taxa de troca térmica depende do coeficiente de convecção, das dimensões das áreas superficiais do pistão, cilindro e câmara de combustão, assim como suas temperaturas médias na superfície.

No geral, é comum se adotar para a transferência de calor nos motores de combustão interna o modelo de resfriamento de Newton para o cálculo da taxa de transferência de calor. A equação é conhecida como: (NETO, 2013) 


$$
Q_{p}=h_{c} A\left(T-T_{p}\right)
$$

Onde $Q_{p}$ é a taxa de transferência de calor, $h_{c}$ é o coeficiente de transferência de calor por convecção, $A$ é a área pela qual o calor é trocado e $T-T_{p}$ o gradiente de temperatura entre o gás e as paredes ao redor. A área de troca engloba todas as superfícies da câmara de combustão, pistão e do cilindro que estão nas redondezas da região onde o gás está se expandindo.

Para modelagem do cálculo do coeficiente de convecção, admitiu-se o modelo de Woschini, representado pela equação:

$$
a_{w}=130 D^{-0.2} p_{c}^{0.8} T_{c}^{-0.53}\left[C_{1} c_{m}+C_{2} \frac{V_{D} T_{c, 1}}{p_{c, 1} V_{c, 1}}\left(p_{c}-p_{c, 0}\right)\right]^{0.8}
$$

Onde:

$C_{1}=2,28+0,308 c_{u} / c_{m}$

$C_{2}=0,00622$ para motores de injeção indireta

$D=$ Diâmetro do cilindro [mm]

$c_{u}=$ velocidade circunferencial $[\mathrm{rad} / \mathrm{s}]$

$c_{m}=$ velocidade media do pistão $[\mathrm{m} / \mathrm{s}]$

$V_{D}=$ deslocamento por cilindro $[\mathrm{m} / \mathrm{s}]$

$p_{c, 0}=$ pressão no interior do cilindro [ $\left.\mathrm{MPa}\right]$

$T_{c, 1}=$ temperatura no cilindro no momento em que as válvulas de admissão são fechadas (IVC) $\left[{ }^{\circ} \mathrm{C}\right]$

$p_{c, 1}=$ Pressão no cilindro no momento em que as válvulas de admissão são fechadas (IVC) $[\mathrm{MPa}]$

A correlação entre o coeficiente de convecção real e o teórico não é algo trivial. Apesar de todas as expressões possuírem coeficientes de ajuste empíricos, apenas o resultado 
experimental poderia ser empregado para o ajuste dos parâmetros ou verificação da melhor correlação se adaptaria para o motor de aplicação. (NETO, 2013)

Para alimentação do modelo utilizado no software, introduziu-se os dados da Tabela 3 Tabela 3 - Variáveis para cálculo do modelo de transferência de calor

\begin{tabular}{l|c}
\hline \multicolumn{1}{c|}{ Variável } & Valores \\
\hline Área superficial do pistão & $7620 \mathrm{~mm}^{2}$ \\
Temperatura da superfície do pistão & $246,85^{\circ} \mathrm{C}$ \\
Área superficial da câmara de combustão & $7600 \mathrm{~mm}^{2}$ \\
Temperatura da parede da câmara de combustão & $186,85^{\circ} \mathrm{C}$ \\
Área superficial da lateral do cilindro no PMS & $223 \mathrm{~mm}^{2}$ \\
Temperatura da superfície lateral do cilindro no PMS & $24,85^{\circ} \mathrm{C}$ \\
Temperatura da superfície lateral do cilindro no PMI & $146,85^{\circ} \mathrm{C}$ \\
\hline
\end{tabular}

Fonte: Autor, 2020

\subsubsection{Modelo de atrito}

O atrito presente no contanto com os componentes do motor pode ser modelado através da pressão média efetiva de atrito (FMEP) para que seja possível estimar o trabalho útil resultante dos processos de combustão do motor. O software apresenta três formas para o modelamento da potência de atrito:

- $\quad$ Modelo de Patton, Nitschke e Heywood (1989)

- Modelo de Shayler, Leong e Murphy (2005)

- Potência de atrito medida em dinamômetro (valores reais de potência de atrito em função da rotação do motor)

O modelo de Patton, Nitschke e Heywood (PNH) foi desenvolvido para associar as perdas por atrito devido aos rolamentos, trem de válvulas, componentes do pistão e outros componentes associados. Originalmente o modelo foi desenvolvido para motores em condições totalmente aquecidas e seu cálculo pode ser estimado pela equação 17: (AVL, 2020) 


$$
F M E P_{T O T}=\left(F M E P_{C S}+F M E P_{P}+F M E P_{V T}+F M E P_{A U X}+F E M P_{I P}\right) \cdot\left(\frac{v_{T o i l}}{v_{T o i l=90^{\circ} \mathrm{C}}}\right)^{0,24}
$$

Onde $F M E P_{C S}$ são as perdas por atrito no virabrequim, $F M E P_{P}$ perdas no pistão e seus componentes, $F M E P_{V T}$ perdas nos componentes do trem de válvulas, $F M E P_{A U X}$ perdas de componentes auxiliares, $F M E P_{I P}$ perdas devido a bomba injetoras ( no caso de motores com aplicação de bombas mecânicas), $v_{\text {Toil }}$ viscosidade do óleo na temperatura de trabalho e $v_{T o i l}=90^{\circ} \mathrm{C}$ viscosidade do óleo na temperatura de $90^{\circ} \mathrm{C}$.

Shayler, Leong e Murphy (SLM) acrescentou o último termo da formulação da equação leva em consideração a mudança de viscosidade em função da temperatura, para que assim fosse possível o estudo de motores Diesel 4 cilindros. Seu grande propósito é analisar as perdas por atrito em baixas rotações e em condições frias, fazendo conexões em estudos de condições de partida a frio. (AVL,2020)

A Tabela 4 apresenta as grandezas levadas em consideração para o cálculo das perdas por atrito.

Tabela 4 - Parâmetros de entrada do modelo de atrito

\section{Variáveis}

Tipo de construção do motor (Em linha/ V6/V8)

Tipo de trem de válvulas (SOHC/DOHC/OHV)

Número de eixos de comando de válvulas

Máximo curso das válvulas [mm]

Tipo de contanto do came (Contato direto ou com rolamentos)

Tipo de óleo

Temperatura do óleo $\left[{ }^{\circ} \mathrm{C}\right]$

Presença de bomba injetora

Fonte: Autor, 2020 


\subsection{DETERMINAÇÃO DOS PARÂMETROS DE ENTRADA DO MODELO NATURALMENTE ASPIRADO}

Para a otimização de desempenho não se faz necessário a utilização de métodos de cálculos de CFD multidimensionais, tornando possível utilizar uma representação unidimensional de baixa complexidade, porém de extrema importância para a realização do projeto. A Figura 41 representa o modelo do motor Yamaha WR450F naturalmente aspirado reproduzido com o auxílio do software.

Figura 41 - Modelo unidimensional aspirado WR450 F

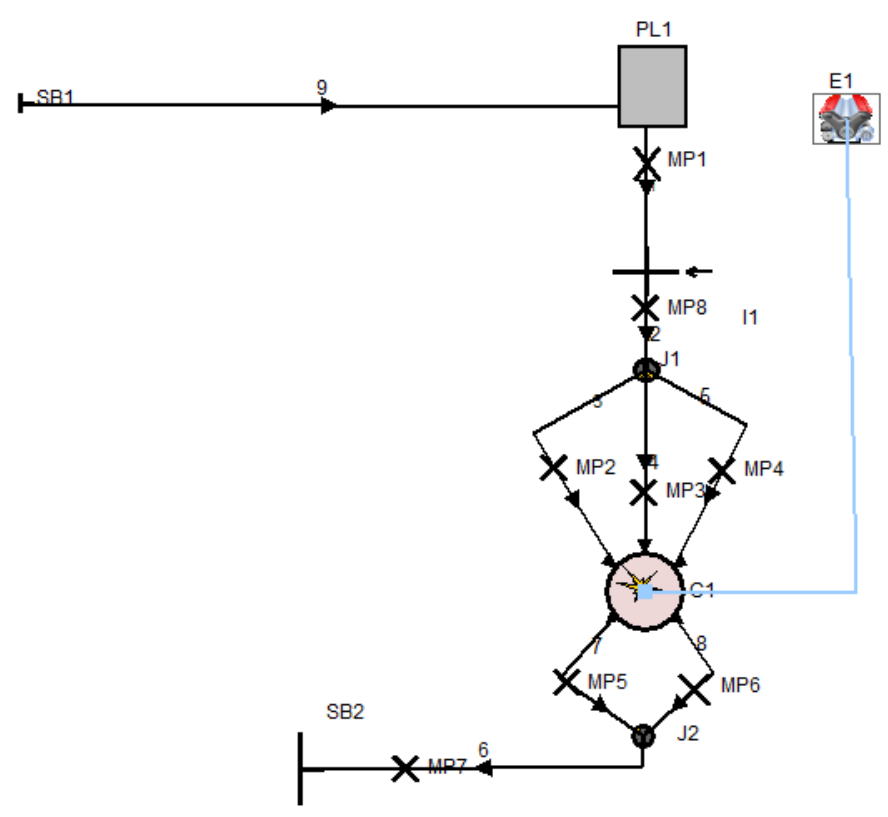

Fonte: Autor, 2018

O modelo foi construído com informações dos componentes:

- Cilindro (C1): dimensões superficiais dos dutos de admissão e exaustão, câmara de combustão e pistão, diâmetro das válvulas, assim como o diagrama de abertura, diâmetro do pistão, curso, taxa de compressão geométrica, comprimento de biela, folga de válvulas, modelo de combustão, modelo de transferência de calor, valores de temperatura e pressão do ar, coeficiente de descarga das válvulas e etc. 
- Motor (E1): valores de rotação, ordem de ignição, modelos de atrito, tipo de óleo lubrificante, controle de pressão média efetiva e etc.

- Válvula injetora de combustível (I1): parâmetros referentes a mistura de combustível e comportamento da válvula injetora.

- Fronteiras do sistema (SB1/SB2): as condições de entrada e saída dos gases no volume de controle que se deseja estudar.

- Junções (J): características geométricas das uniões dos dutos e a respectiva perda de carga

- Plenum (PL1): representa o volume e as características geométricas do volume de plenum

- Pontos de medidas (MP): pontos onde o software demonstra os valores das grandezas do fluido naquele instante.

\subsection{CONSTRUÇÃO DO MODELO TURBOALIMENTADO}

A desvantagem dos motores com reduzido número de cilindro e um longo período entre os instantes da ordem de ignição é a geração de pulso de pressão no coletor de exaustão com uma frequência menor. Esse efeito associado ao fluxo de gases podem influenciar na eficiência do turbocompressor. Para o sistema, é mais interessante e eficiente o trabalho sobre condições de pressões de entrada e saída com valores constante. (KELLERMAYR et al, 2019)

Para a simulação e modelo do turbocompressor, utilizou-se a metodologia de Kellermayr et al (2019), onde que para cada modelo, adotou-se a mesma geometria de cilindro e deslocamento, mantendo as características do motor idênticas. Com essa abordagem, os efeitos do cilindro e dutos podem ser excluídos da análise durante o comparativo entre os modelos que serão abordados neste tópico. Somado a esse fato, os efeitos de rejeição térmica são idênticos para os pontos de operação simulados.

Para modelo do turbocompressor adotado foi simplificado de modo que a eficiência do turbocompressor seja constante e não dependa da relação de compressão do compressor. O acionamento da válvula wastegate foi ajustado para que a relação de compressão fosse mantida no valor determinado através dos cálculos apresentados no tópico 5. 
Utilizou-se os dados do modelo unidimensional da Figura 41 construído para a elaboração de um novo modelo com a introdução de um turbocompressor. A Figura 42 ilustra do modelo.

Figura 42 - Modelo unidimensional com aplicação de turbocompressor

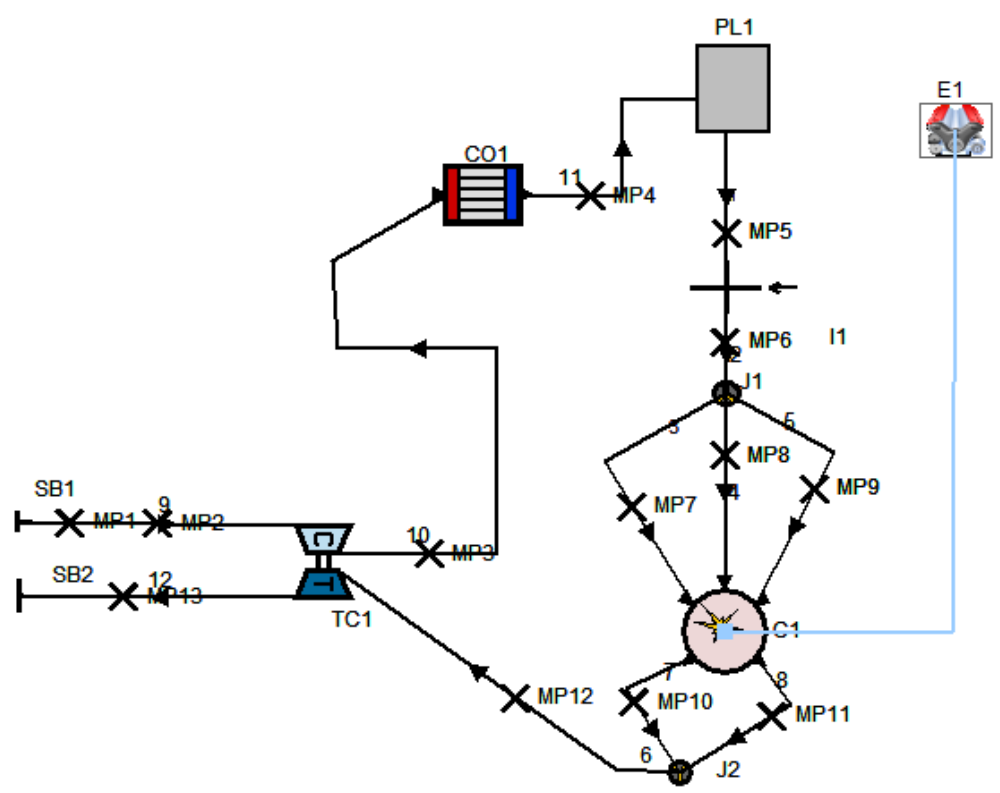

Fonte: Autor, 2019

O modelo foi construído com a mesma estrutura do modelo naturalmente aspirado da Figura 41, adicionando apenas os novos componentes:

- Plenum (PL1): representa o volume e as características geométricas do volume de plenum

- Turbocompressor (TC1): valores de relação de compressão, expansão e eficiências da turbina e do compressor.

- Intercooler (CO1): valores de vazão de massa de ar, temperatura de entrada e saída e volume do trocador de calor.

Um outro modelo foi construído para o estudo da influência do volume de plenum no coletor de exaustão. Um plenum foi adicionado ao modelo e nele foram inseridos diferentes valores, para que assim fosse possível determinar a partir de qual momento os efeitos começam a gerar ganhos ou perdas. Assim o modelo da Figura 43 utilizará o menor comprimento de coletor de exaustão possível na tentativa de que não haja um efeito de contrapressão devido à 
restrição da turbina e aproveite o efeito acústico dos gases para gerar potência no eixo, enquanto que o modelo em discussão servirá para analisar os feitos de pressão constante. A Figura 43 apresenta o segundo modelo estudado.

Figura 43 - Modelo unidimensional turbocomprimido com adição de um plenum no coletor de escape

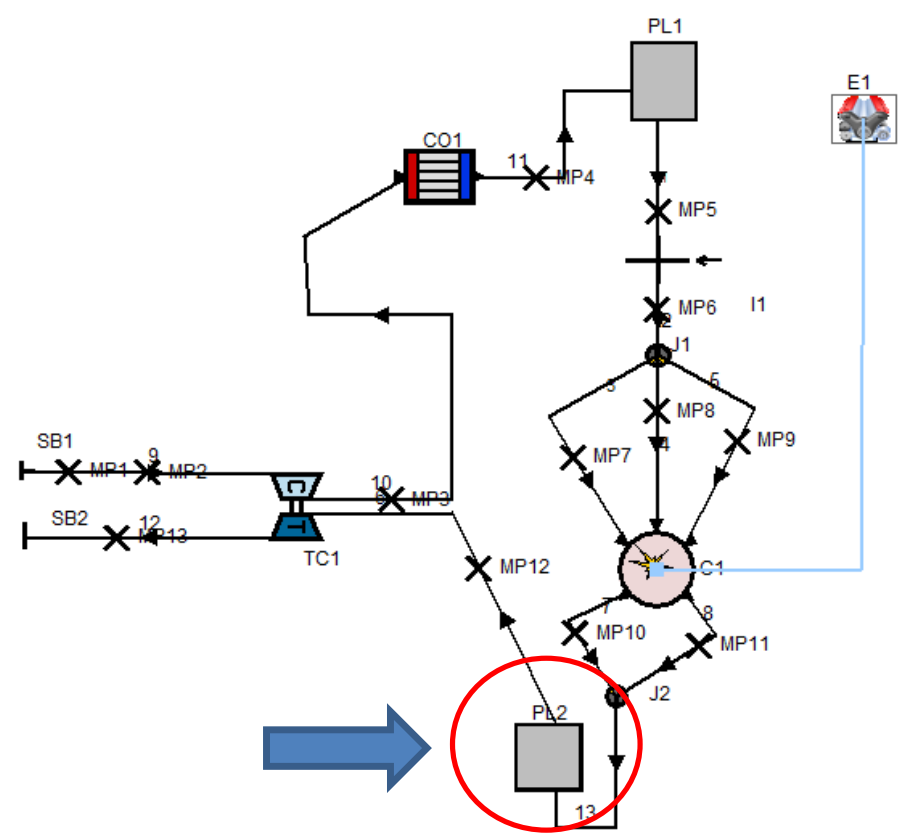

Fonte: Autor, 2019

\section{PROCEDIMENTO EXPERIMENTAL}

Para a análise do mapa de compressor adequado à aplicação utilizou-se como método a medição dos coeficientes de escoamento em função do levantamento das válvulas em um coletor de admissão com a restrição imposta pelo regulamento. Para isso utilizou-se os materiais citados.

- Banco de fluxo Servitec modelo BS400X

- Cabeçote Yamaha WR450F com válvulas montadas

- Coletor de admissão do veículo RS11

- Relógio comparador 20mm (precisão de 0,01mm)

A Figura 44 demonstra a montagem do experimento para a medição da vazão máxima admissível no motor. 
Figura 44 - Cabeçote Yamaha WR450F montado em bancada de fluxo

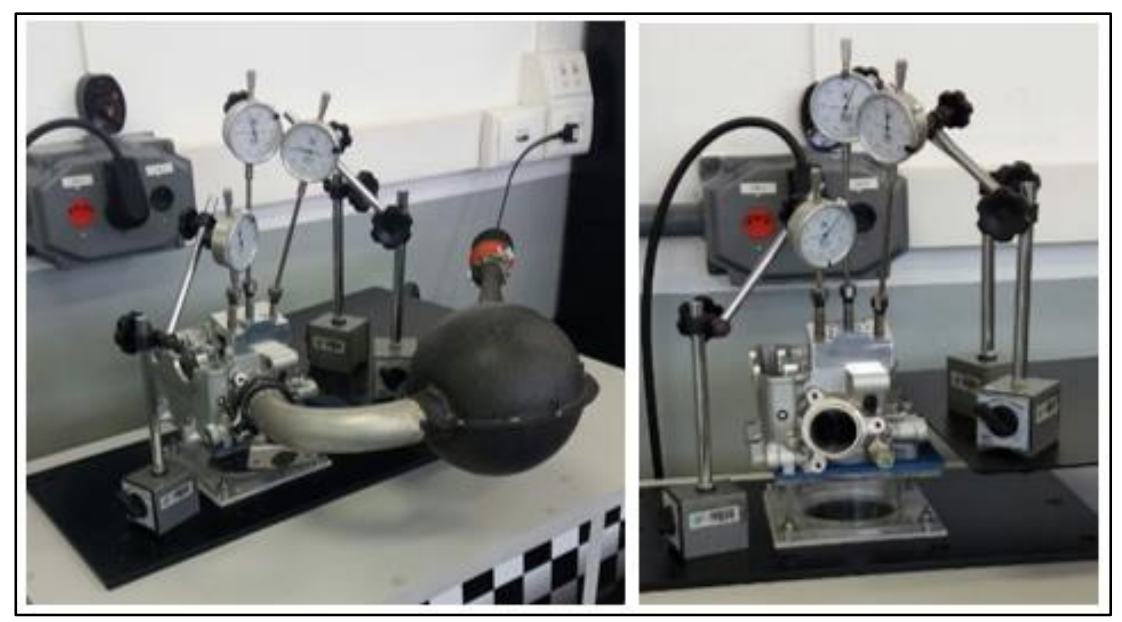

Fonte: Autor, 2018

Cada relógio comparador foi devidamente posicionado acima das válvulas de admissão. Com o auxílio de um fuso pressionou-se as válvulas ao passo de $1 \mathrm{~mm}$ até que fosse atingido o máximo curso medido através do procedimento de medição do diagrama de levantamento das válvulas. Posicionou-se o corpo de aceleração de forma que este apresentasse a máxima abertura possível. Foram aquisitados os dados de fluxo em função do deslocamento das válvulas em apenas um sentido, que é o de fluxo normal.

Figura 45 - Diagrama de tempo de válvulas Yamaha WR450F

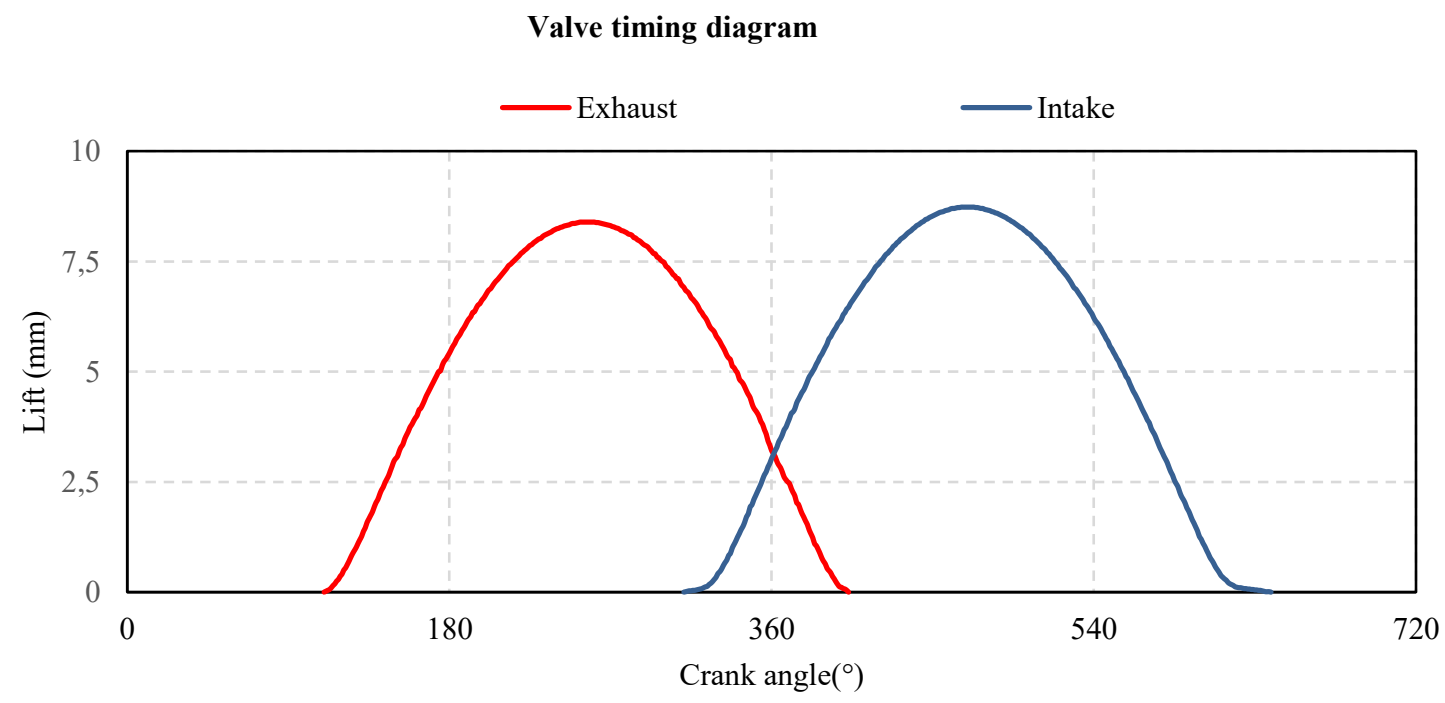

Fonte: Autor, 2018 
Outras geometrias do motor foram analisadas e medidas, tais como: volume de câmara de combustão, geometria dos dutos de admissão e exaustão, área superficial da coroa do pistão, geometria do coletor de admissão e do coletor de exaustão etc. todas estas grandezas foram determinadas através do processo de metrologia ótica. Os volumes foram modelados a partir da utilização de moldes de silicone para obter-se os moldes dos espaços interiores ao cabeçote, onde torna-se difícil a utilização de outros instrumentos de medição. Após o processo, os modelos puderam ser digitalizados de forma a obter os valore de áreas e volumes de maneira precisa. As Figuras 46 e 47 demonstram o procedimento.

Figura 46 - Processo de medição de componentes do motor Yamaha WR450F

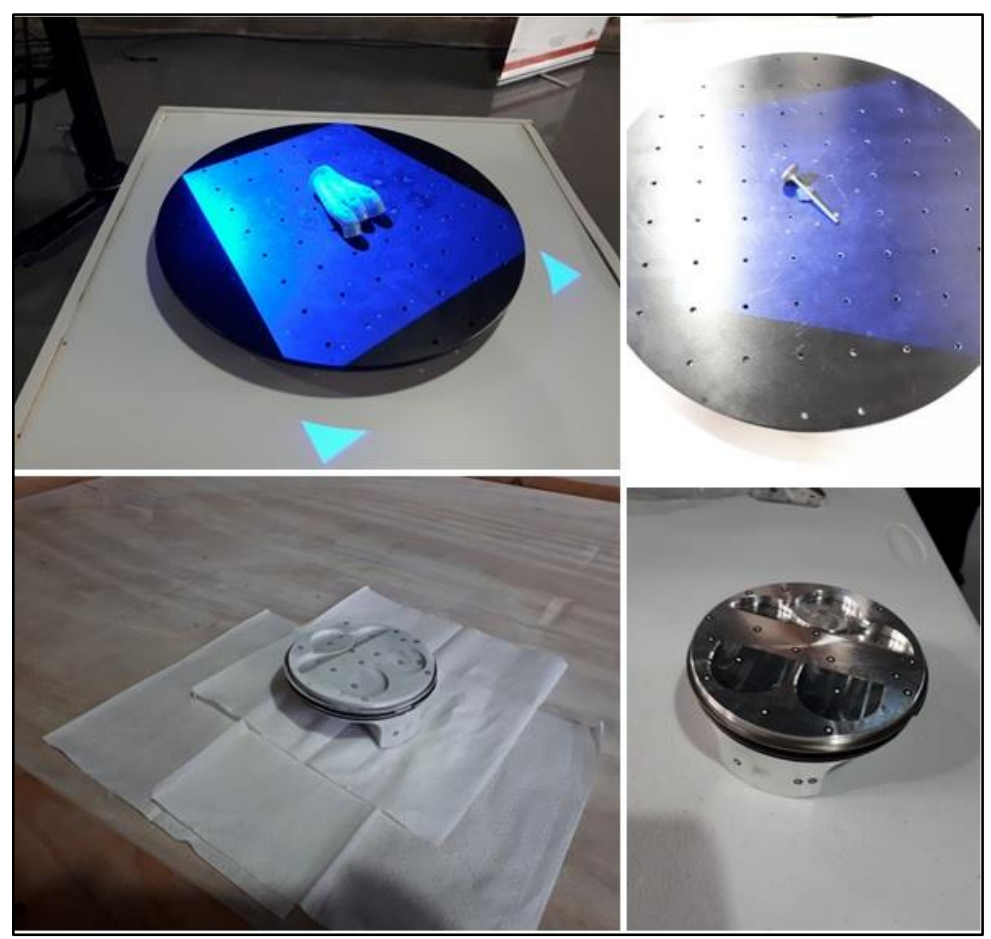

Fonte: Autor, 2018

Figura 47 - Dutos de admissão digitalizados

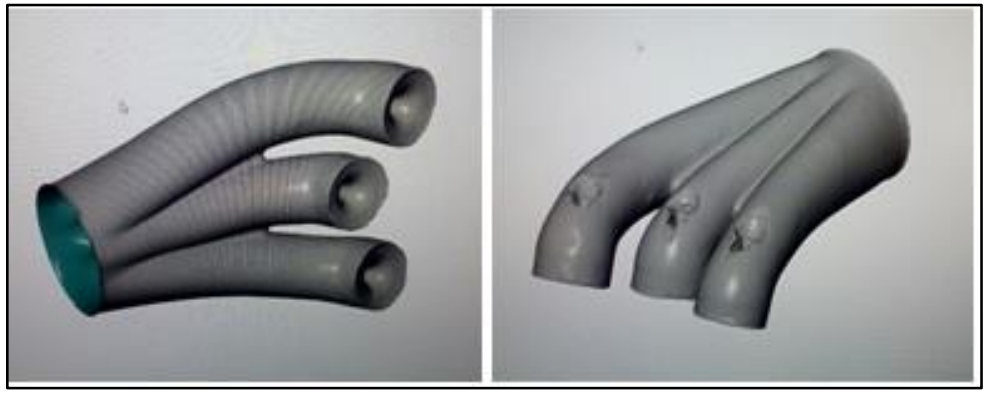

Fonte: Autor, 2018 


\section{ANÁLISE DOS RESULTADOS}

Neste tópico serão abordados todos os resultados dos cálculos e medições necessários para dimensionamento e alimentação dos modelos aspirado e turboalimentados.

\subsection{ANÁLISE DE DADOS DO MOTOR ASPIRADO}

Iniciaram-se alguns estudos com o objetivo de estimar um ponto de operação em regime permanente para o qual fosse possível calcular parâmetros do funcionamento do motor e assim construir um modelo unidimensional. Portanto, através dos dados aquisitados do veículo em pista, gerou-se um histograma de rotação, temperatura do ar de admissão e temperatura dos gases de exaustão para determinar em quais faixas o veículo opera durante as provas. A Figura 48 demonstra o histograma de rotação levantado com auxílio do software Motec i2 pro.

Figura 48 - Histograma de rotação da prova de enduro

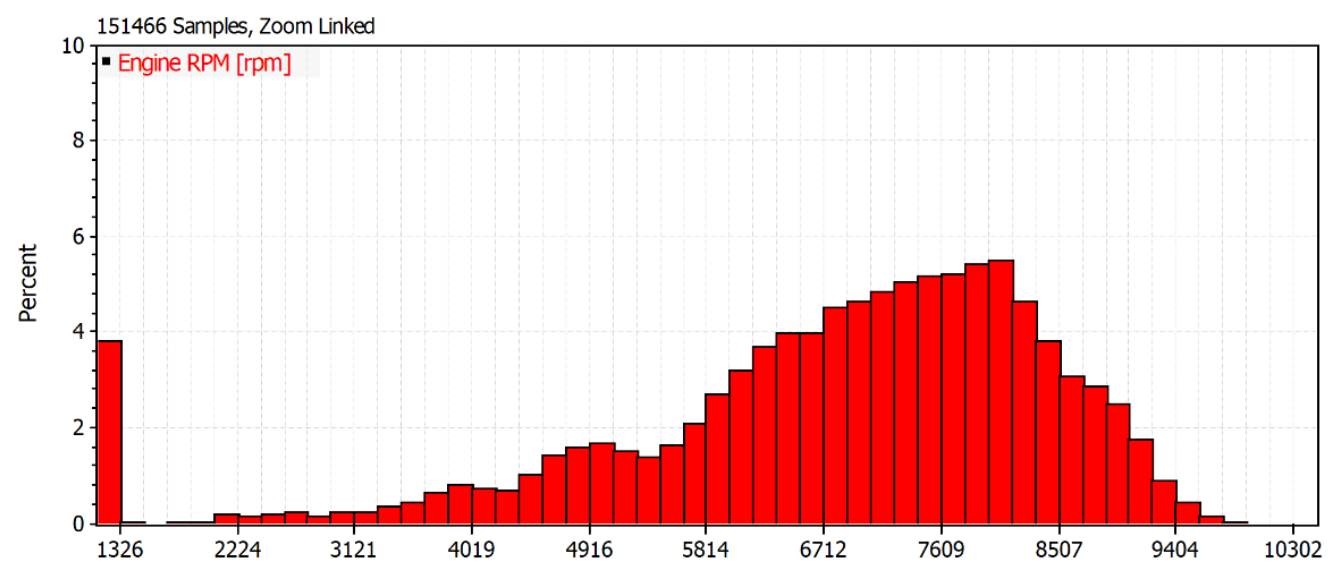

Fonte: Autor, 2018

O maior número de amostras aquisitados demonstra uma concentração entre a faixa de rotação de 7789 rpm e 8148 rpm. Objetivando-se uma rotação média desta região, utilizou-se 8000 rpm como a rotação de trabalho para os cálculos em regime permanente. A mesma metodologia foi utilizada para os valores de temperatura do ar de admissão e gases de exaustão. Os resultados das temperaturas dos gases de escapamento estão mostrados na Figura 49. 
Figura 49 - Histograma de temperatura dos gases de exaustão da prova de enduro

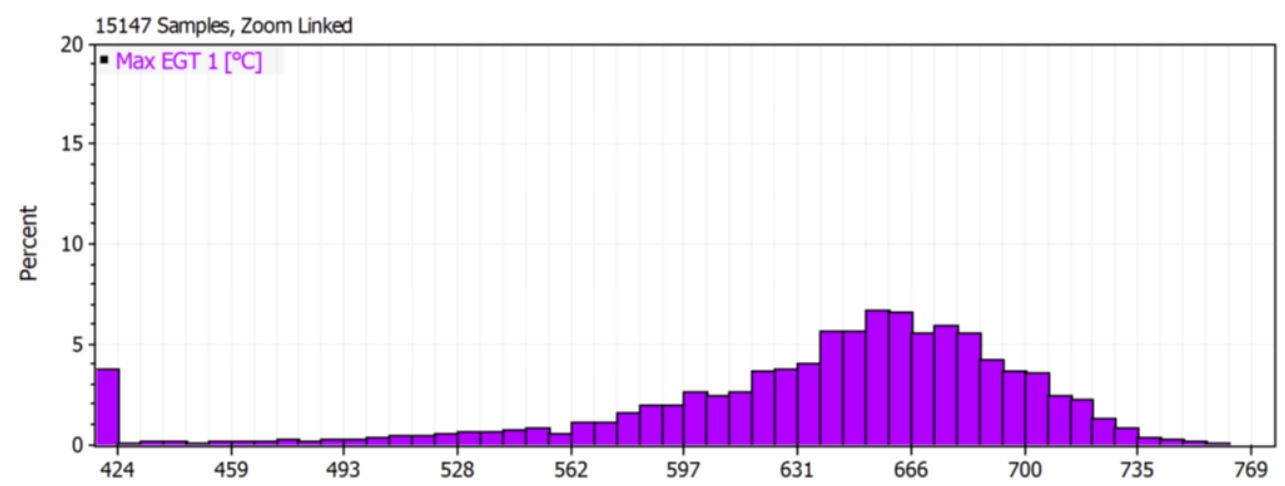

Fonte: Autor, 2018

Baseado nos resultados obtidos utilizou-se como temperatura do ar de referência o valor de $44^{\circ}$ C. Os resultados de temperatura de admissão estão demonstrados na Figura 50.

Figura 50 - Histograma de temperatura de admissão da prova de enduro

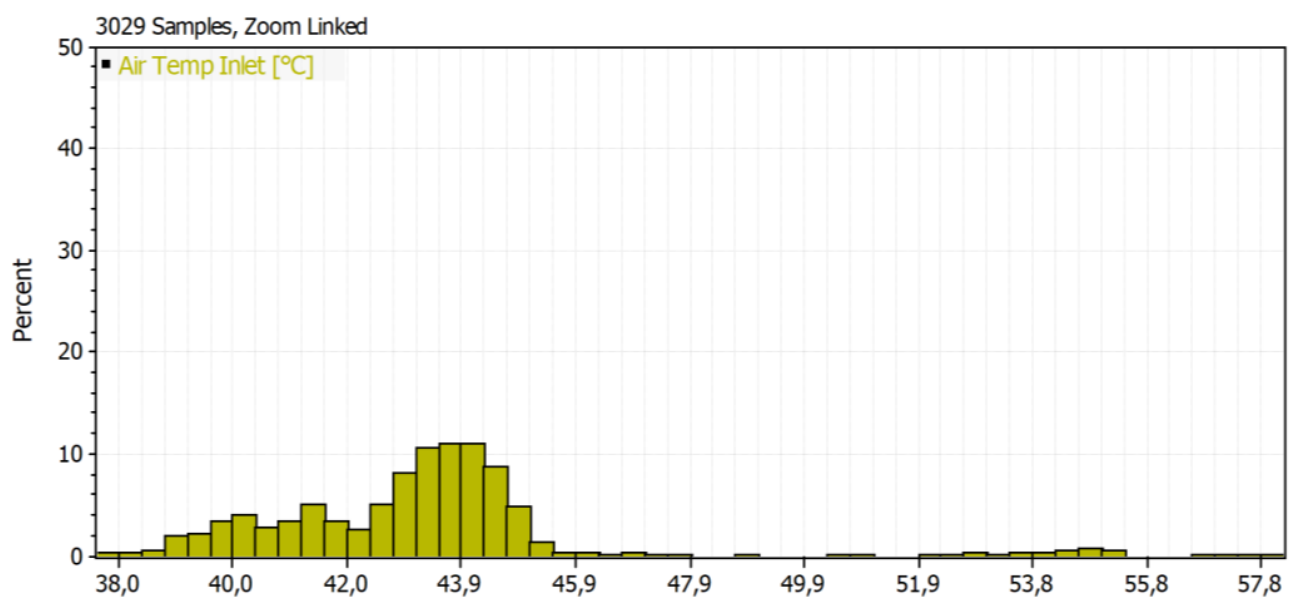

Fonte: Autor, 2018

A análise demonstra um maior número de amostras entre a faixa de $652^{\circ} \mathrm{C}$ e $666^{\circ} \mathrm{C}$. Portanto utilizou-se como referência o valor médio de $660^{\circ} \mathrm{C}$.

Para determinação dos coeficientes de fluxo, utilizou-se como método a medição da vazão de ar em bancada de fluxo.

Cada relógio comparador foi devidamente posicionado acima das válvulas de admissão. Com o auxílio de um fuso pressionou-se as válvulas com passos de $1 \mathrm{~mm}$ até que fosse atingido o máximo curso medido através do procedimento de levantamento do diagrama de tempo de 
válvulas. Feito isso, posicionou-se o corpo de aceleração de forma que este apresentasse a máxima abertura possível. Por fim, iniciou-se o software do banco de fluxo de modo que fosse simulado a admissão do ar. A Figura 51 demonstra o diagrama do fluxo de ar através das válvulas.

Figura 51 - Fluxo de admissão de ar

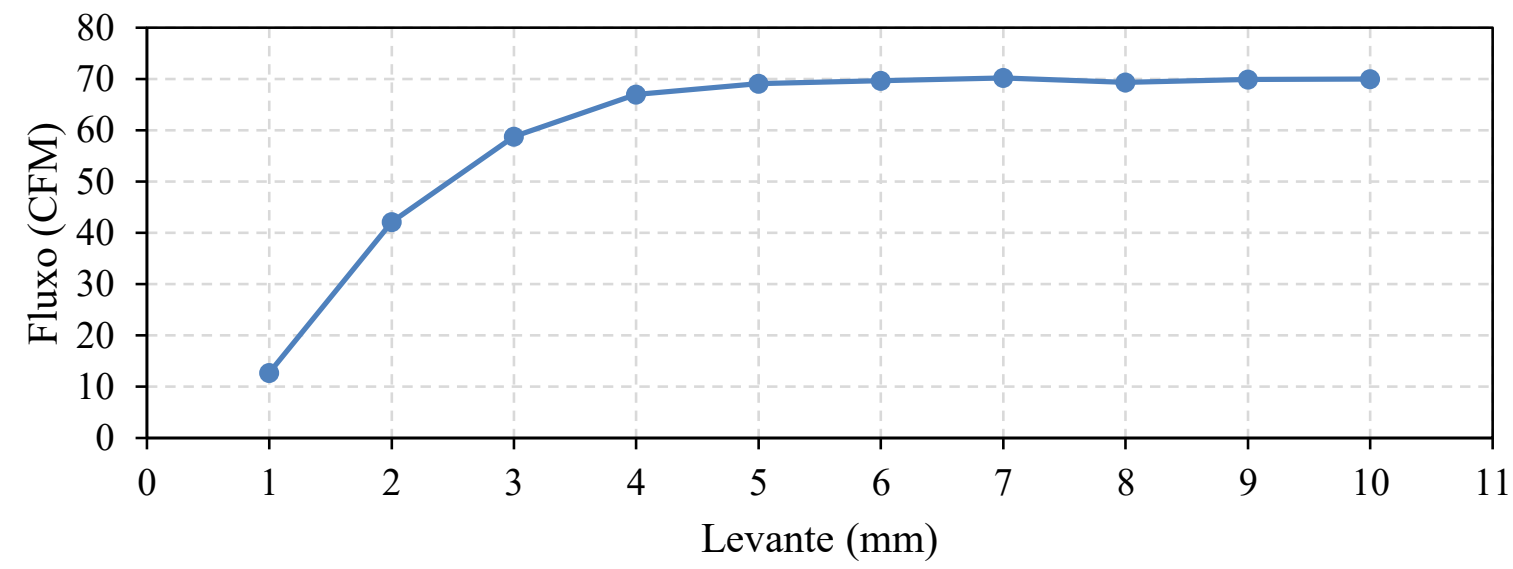

\subsection{DIMENSIONAMENTO DO TURBOCOMPRESSOR}

A construção do modelo turboalimentado iniciou-se através do dimensionamento do motor. Utilizando a metodologia proposta por Hartman (2007), utilizou-se a Equação 6 para determinação da massa de ar que é necessária para a obtenção dos $52 \mathrm{~kW}$ de potência (valor posto como objetivo pela equipe). Sendo assim tem-se:

$$
W_{a}=0,0575 \mathrm{~kg} / \mathrm{s}
$$

A pressão necessária para a produção da vazão de ar calculada pela equação 6 é definida pela equação 7. Sendo assim, calcula-se:

$$
M A P_{r e q}=198,886 \mathrm{kPa}
$$

Admite-se um valor de pressão atmosférica de 14,7 psi, ou seja, 101,3529 kPa. Portanto a relação de pressão necessária ao turbocompressor é obtida pela equação 8 . 


$$
\frac{P_{2}}{P_{1}}=1,96
$$

A partir do valor de vazão obtido é possível estimar-se, em uma condição de plena carga em regime permanente, qual seria o aumento de vazão com a mudança de massa específica. Sendo assim, utiliza-se a equação 11 para obtenção da relação de massa específica para diferentes relações de pressão. Iniciou-se os cálculos a partir de um valor de 1,2.

$$
\frac{\rho_{2}}{\rho_{1}}=1,117
$$

Portanto a vazão em massa deste ponto é obtida pela equação:

$$
m_{\text {ar2 }}=m_{\text {ar1 }} \frac{\rho_{2}}{\rho_{1}}=0,03305.1,117=0,0369 \mathrm{~kg} / \mathrm{s}
$$

O mesmo cálculo foi realizado até a relação de pressão máxima de $\frac{P_{2}}{P_{1}}=2,2$, com passo de 0,2 entre os intervalos. A Tabela 5 apresenta os resultados.

Tabela 5 - Valores de vazão mássica com aumento de pressão

\begin{tabular}{c|c|c}
\hline $\mathbf{p 2} / \mathbf{p} 1$ & $\mathbf{\rho 2} / \mathbf{\rho 1}$ & $\mathbf{M a r 2}\left(\mathbf{m}^{\mathbf{3}} \mathbf{s}\right)$ \\
\hline 1 & 1,000 & 0,0331 \\
1,2 & 1,117 & 0,0369 \\
1,4 & 1,228 & 0,0406 \\
1,6 & 1,334 & 0,0441 \\
1,8 & 1,435 & 0,0474 \\
2 & 1,534 & 0,0507 \\
2,2 & 1,629 & 0,0538 \\
\hline
\end{tabular}

Fonte: Autor, 2019 
Figura 52 - Mapa de eficiência do compressor com curva de plena carga e rotação constante

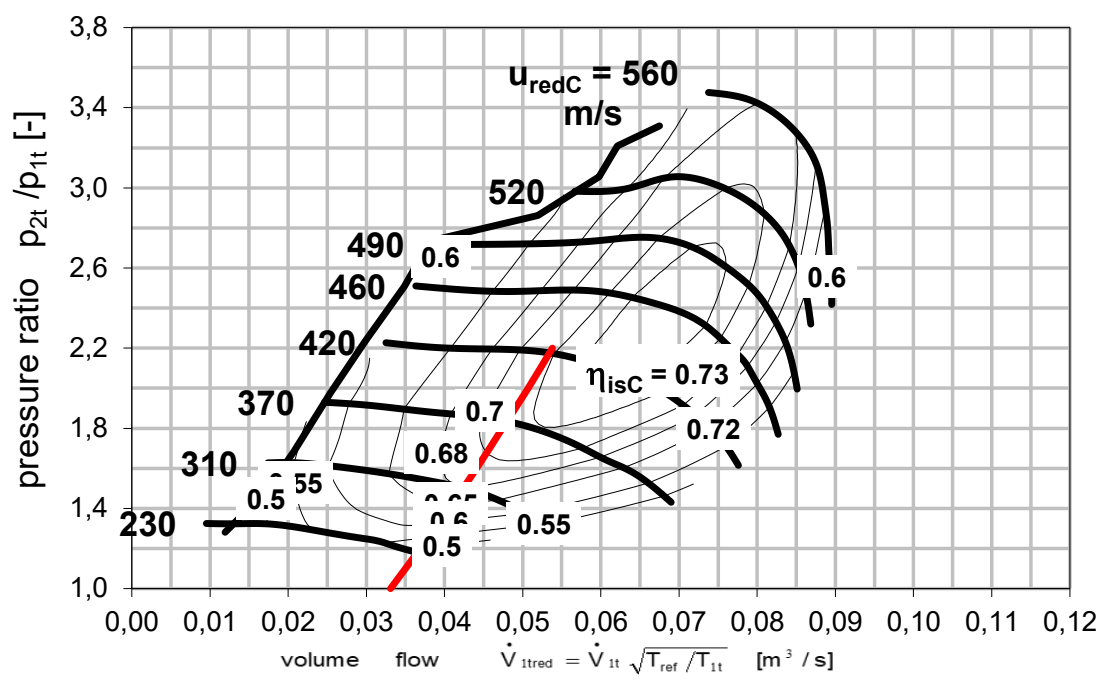

Fonte: Borgwarner do Brasil

A Tabela 5 permite fazer a análise do compressor proposta por Watson e Janota (1982), onde os pontos de operação do motor são colocados no diagrama para análise da região de trabalho do motor. A avaliação partindo do valor de massa de ar obtido em bancada, sugere um motor em plena carga em regime constante e sem alteração de rotação. Sendo assim, a Figura 53 mostra o resultado.

Observa-se que em uma condição de carga constante, onde haja o máximo fluxo de ar o compressor utilizado para a aplicação apresenta um desempenho aceitável para uma aplicação onde o motor tem um deslocamento volumétrico inferior ao de um veículo convencional onde ele é aplicado. Entretanto, esta analise não permite avaliar se o motor em baixas condições de carga e rotação trabalha em regiões próximas a região de surge. Sendo assim, optou-se por expandir os cálculos e determinar uma região ainda maior. A tabela 6 apresenta os valores de vazão para condições onde a rotação e pressão são alteradas, utilizando a mesma a equação 11 como base para o cálculo. 
Tabela 6 - Vazão mássica para diferentes tipos de carga e rotação

\begin{tabular}{|c|c|c|c|c|c|c|c|c|c|}
\hline \multicolumn{5}{|c|}{ Pressão 2 bar } & \multicolumn{5}{|c|}{$\mathrm{n}[\mathrm{rpm}]=4000$} \\
\hline n[rpm] & $\mathbf{H v}$ & p2/p2 & $\rho 2 / \rho 1$ & $\operatorname{Mar} 2\left(\mathbf{m}^{3} / \mathbf{s}\right)$ & $\mathbf{n}[\mathbf{r p m}]$ & $\eta \mathbf{v}$ & $\mathrm{p} 2 / \mathrm{p} 2$ & $\rho 2 / \rho 1$ & $\operatorname{Mar} 2\left(\mathrm{~m}^{3} / \mathrm{s}\right)$ \\
\hline 2500 & 1,3686 & 2 & 1,534 & 0,0209 & 4000 & 1,3971 & 1,2 & 1,117 & 0,0249 \\
\hline 4000 & 1,3971 & 2 & 1,534 & 0,0342 & 4000 & 1,3971 & 1,4 & 1,228 & 0,0273 \\
\hline 6000 & 1,4131 & 2 & 1,534 & 0,0518 & 4000 & 1,3971 & 1,6 & 1,334 & 0,0297 \\
\hline 8000 & 1,3061 & 2 & 1,534 & 0,0639 & 4000 & 1,3971 & 1,8 & 1,435 & 0,0320 \\
\hline 10000 & 1 & 2 & 1,534 & 0,0611 & 4000 & 1,3971 & 2 & 1,534 & 0,0342 \\
\hline \multicolumn{5}{|c|}{ Pressão 1,8 bar } & \multicolumn{5}{|c|}{$\mathrm{n}[\mathrm{rpm}]=6000$} \\
\hline n[rpm] & $\mathbf{H v}$ & p2/p2 & $\rho 2 / \rho 1$ & $\operatorname{Mar} 2\left(\mathrm{~m}^{3} / \mathrm{s}\right)$ & $\mathrm{n}$ [rpm] & $\eta \mathbf{v}$ & $\mathrm{p} 2 / \mathrm{p} 2$ & $\rho 2 / \rho 1$ & $\operatorname{Mar2}\left(\mathrm{m}^{3} / \mathrm{s}\right)$ \\
\hline 2500 & 1,3686 & 1,8 & 1,435 & 0,0196 & 6000 & 1,4131 & 1,2 & 1,117 & 0,0377 \\
\hline 4000 & 1,3971 & 1,8 & 1,435 & 0,0320 & 6000 & 1,4131 & 1,4 & 1,228 & 0,0415 \\
\hline 6000 & 1,4131 & 1,8 & 1,435 & 0,0485 & 6000 & 1,4131 & 1,6 & 1,334 & 0,0451 \\
\hline 8000 & 1,3061 & 1,8 & 1,435 & 0,0598 & 6000 & 1,4131 & 1,8 & 1,435 & 0,0485 \\
\hline 10000 & 1 & 1,8 & 1,435 & 0,0572 & 6000 & 1,4131 & 2 & 1,534 & 0,0518 \\
\hline \multicolumn{5}{|c|}{ Pressão 1,6 bar } & \multicolumn{5}{|c|}{$\mathrm{n}[\mathrm{rpm}]=\mathbf{8 0 0 0}$} \\
\hline n[rpm] & $\mathbf{H v}$ & p2/p2 & $\rho 2 / \rho 1$ & $\operatorname{Mar} 2\left(\mathbf{m}^{3} / \mathbf{s}\right)$ & $\mathbf{n}[\mathbf{r p m}]$ & $\eta \mathbf{v}$ & p2/p2 & $\rho 2 / \rho 1$ & $\operatorname{Mar} 2\left(\mathrm{~m}^{3} / \mathrm{s}\right)$ \\
\hline 2500 & 1,3686 & 1,6 & 1,334 & 0,0182 & 8000 & 1,3061 & 1,2 & 1,117 & 0,0465 \\
\hline 4000 & 1,3971 & 1,6 & 1,334 & 0,0297 & 8000 & 1,3061 & 1,4 & 1,228 & 0,0511 \\
\hline 6000 & 1,4131 & 1,6 & 1,334 & 0,0451 & 8000 & 1,3061 & 1,6 & 1,334 & 0,0555 \\
\hline 8000 & 1,3061 & 1,6 & 1,334 & 0,0555 & 8000 & 1,3061 & 1,8 & 1,435 & 0,0598 \\
\hline 10000 & 1 & 1,6 & 1,334 & 0,0532 & 8000 & 1,3061 & 2 & 1,534 & 0,0639 \\
\hline \multicolumn{5}{|c|}{ Pressão 1,4 bar } & \multicolumn{5}{|c|}{$\mathrm{n}[\mathrm{rpm}]=10000$} \\
\hline n[rpm] & $\mathbf{H v}$ & p2/p2 & $\rho 2 / \rho 1$ & $\operatorname{Mar2}\left(\mathrm{m}^{3} / \mathrm{s}\right)$ & $\mathrm{n}$ [rpm] & $\eta \mathbf{v}$ & p2/p2 & $\rho 2 / \rho 1$ & $\operatorname{Mar2}\left(\mathrm{m}^{3} / \mathrm{s}\right)$ \\
\hline 2500 & 1,3686 & 1,4 & 1,228 & 0,0167 & 10000 & 1 & 1,2 & 1,117 & 0,0445 \\
\hline 4000 & 1,3971 & 1,4 & 1,228 & 0,0273 & 10000 & 1 & 1,4 & 1,228 & 0,0489 \\
\hline 6000 & 1,4131 & 1,4 & 1,228 & 0,0415 & 10000 & 1 & 1,6 & 1,334 & 0,0532 \\
\hline 8000 & 1,3061 & 1,4 & 1,228 & 0,0511 & 10000 & 1 & 1,8 & 1,435 & 0,0572 \\
\hline 10000 & 1 & 1,4 & 1,228 & 0,0489 & 10000 & 1 & 2 & 1,534 & 0,0611 \\
\hline
\end{tabular}

Fonte: Autor, 2019

Com os valores obtidos, é possível fazer uma análise mais detalhada do compressor demonstrada na Figura 53. 
Figura 53 -Mapa de eficiência do compressor com região de operação do motor

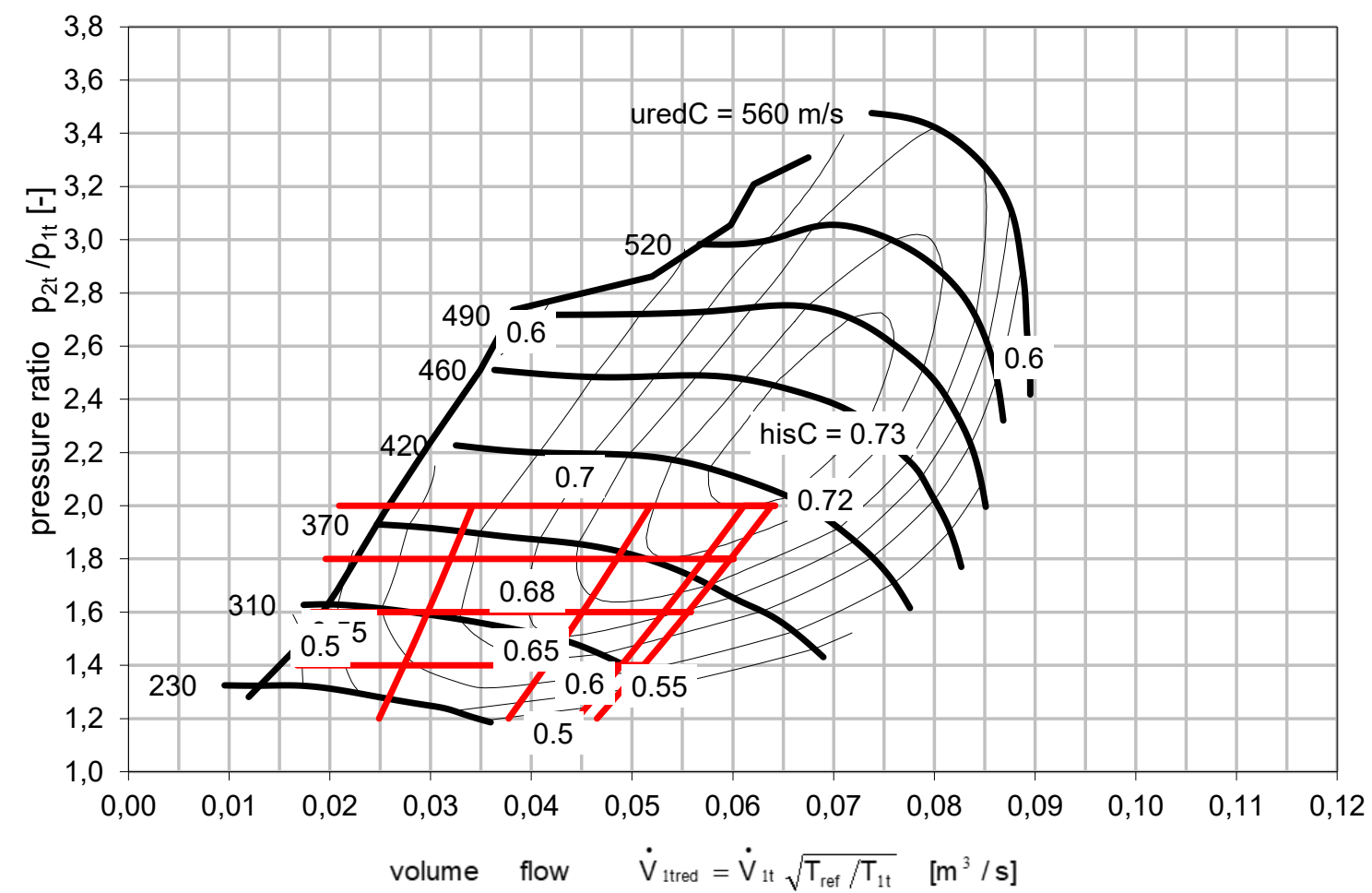

Fonte: Autor “adaptado de” Borgwarner do Brasil

Para determinação da rotação mínima na qual o veículo se submete durante uma prova, analisou-se os valores de rotação provenientes dos dados aquisitados durante uma volta da prova de enduro.

A análise dos dados demonstrou que o veículo não trabalha sob rotações inferiores a $4500 \mathrm{rpm}$, sendo assim, os pontos referentes a rotação de $2500 \mathrm{rpm}$ utilizados para cálculo foram excluídos da análise. Portanto, as linhas verticais da Figura 53 representam as condições de rotação constante, sendo a curva mais à esquerda a de rotação de 4000 rpm e a última mais a direta a de $10000 \mathrm{rpm}$. Nota-se que os valores mínimos de rotação se posicionam longe da linha de surge, proporcionando valores de vazão suficiente para que a aplicação do turbo compressor não apresente maiores problemas com efeitos causados pelo surge. Conclui-se então, que o compressor pode ser utilizado para aplicação.

Após a avaliação do compressor, calcula-se a temperatura do ar após o compressor utilizando a equação 10 . Sendo assim, tem-se:

$$
T_{2}=137,519^{\circ} \mathrm{C}
$$


Devido ao valor elevado da temperatura do ar de admissão é recomendável a utilização de um aftercooler. A temperatura do ar elevada poderia provocar problemas ao motor devido ao fenômeno de pré-ignição. Watson e Janota (1982) indicam para um cálculo inicial um valor de efetividade do trocador de calor de 70\%. Desta forma, através da equação 13 , tem-se.

$$
T_{3}=345 K=72^{\circ} \mathrm{C}
$$

\subsection{RESULTADOS SIMULAÇÃO MODELO ASPIRADO}

O estudo feito através da análise de dados do veículo e medições de componentes permitiu estimar de forma mais precisa os valores dos para alimentação do modelo, de forma a buscar resultados próximos aos valores reais obtidos em dinamômetro. As curvas de torque e potência utilizadas como referência, foram obtidas durante o processo de calibração do sistema de injeção eletrônica do veículo durante a temporada de 2019, com a utilização de um dinamômetro de chassi. Os valores das perdas entre motor e o freio dinamômetro foram estimados, fazendo assim que haja um erro entre o valor medido e calculado. Estima-se que as perdas totais entre os engrenamentos da transmissão, corrente de transmissão, diferencial, trizetas e contato entre pneu e solo sejam de um valor de $28,45 \%$.

A curva de torque e potência foram obtidas através do teste em dinamômetro de chassi e medidos no freio dinamométrico, ou seja, os valores reais foram medidos de acordo com o que o pneu descarrega no rolo. Posteriormente, foram utilizados os valores das perdas na transmissão para estimar os valores de potência e torque no eixo do motor. Por fim, os valores de pressão média efetiva foram calculados para comparação com os do modelo. 
Figura 54 - Curva de torque e potência do motor obtidas em dinamômetro de chassi

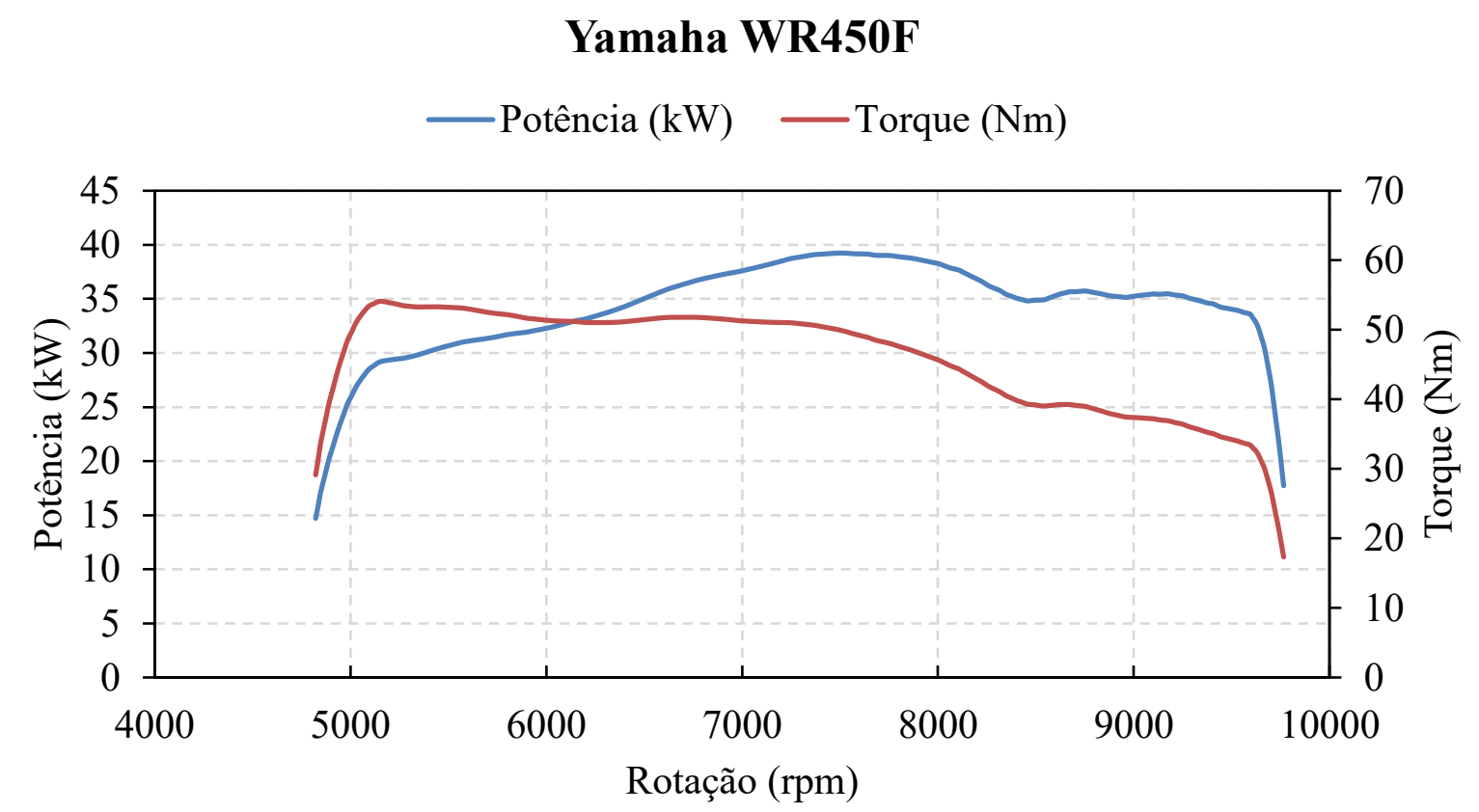

Fonte: Autor

As medições obtiveram como resultados valores máximos de potência de $27,77 \mathrm{~kW}$ em uma rotação de $7510 \mathrm{rpm}$ e torque de $39 \mathrm{Nm}$ a uma rotação de $5170 \mathrm{rpm}$. Desta forma, estimase que o valor obtido no motor seja de $38,85 \mathrm{~kW}$ na rotação de $5710 \mathrm{rpm}$ e torque de $54,54 \mathrm{Nm}$ na rotação de $5170 \mathrm{rpm}$.

Com base nestes valores é possível fazer uma comparação com os resultados obtidos pela simulação, em busca de uma correlação entre o modelo real e o teórico. A Figura 55 faz a comparação entre os resultados da simulação e o experimento real. 
Figura 55 - Curva de potência Yamaha WR450F

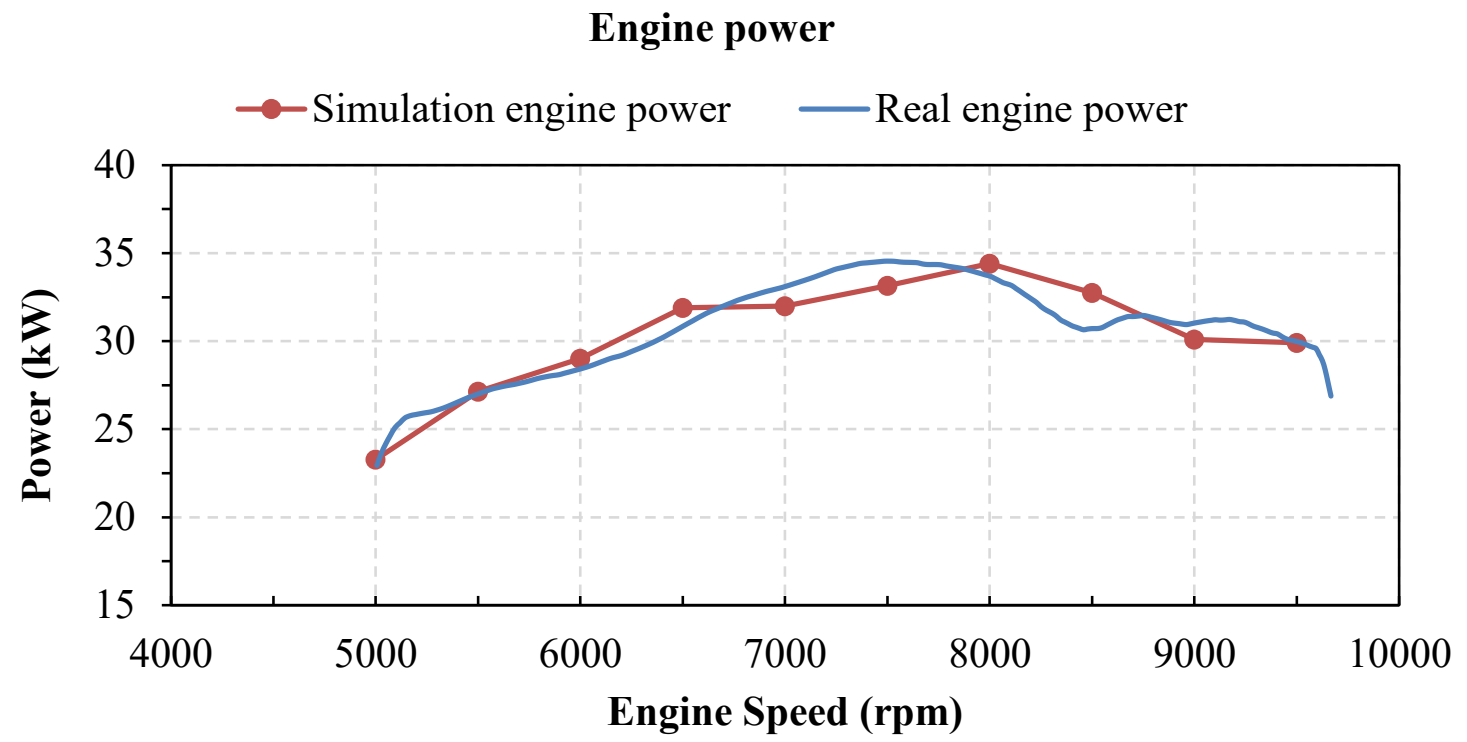

Fonte: Autor

O ponto de máxima potência da curva simulada desloca-se para a rotação de $8000 \mathrm{rpm}$, ou seja, uma diferença de $490 \mathrm{rpm}$ resultando em um erro de $6,1 \%$ no valor de rotação. $O$ valor de potência de $34,41 \mathrm{~kW}$, carrega erro de $0,4 \%$ no valor de potência máxima.

O mesmo processo foi realizado para as curvas de torque e pressão media efetiva (BMEP). Os resultados, assim como os erros obtidos nos pontos são demonstrados na Figuras 56 e 57.

Figura 56 - Curva de torque Yamaha WR450F

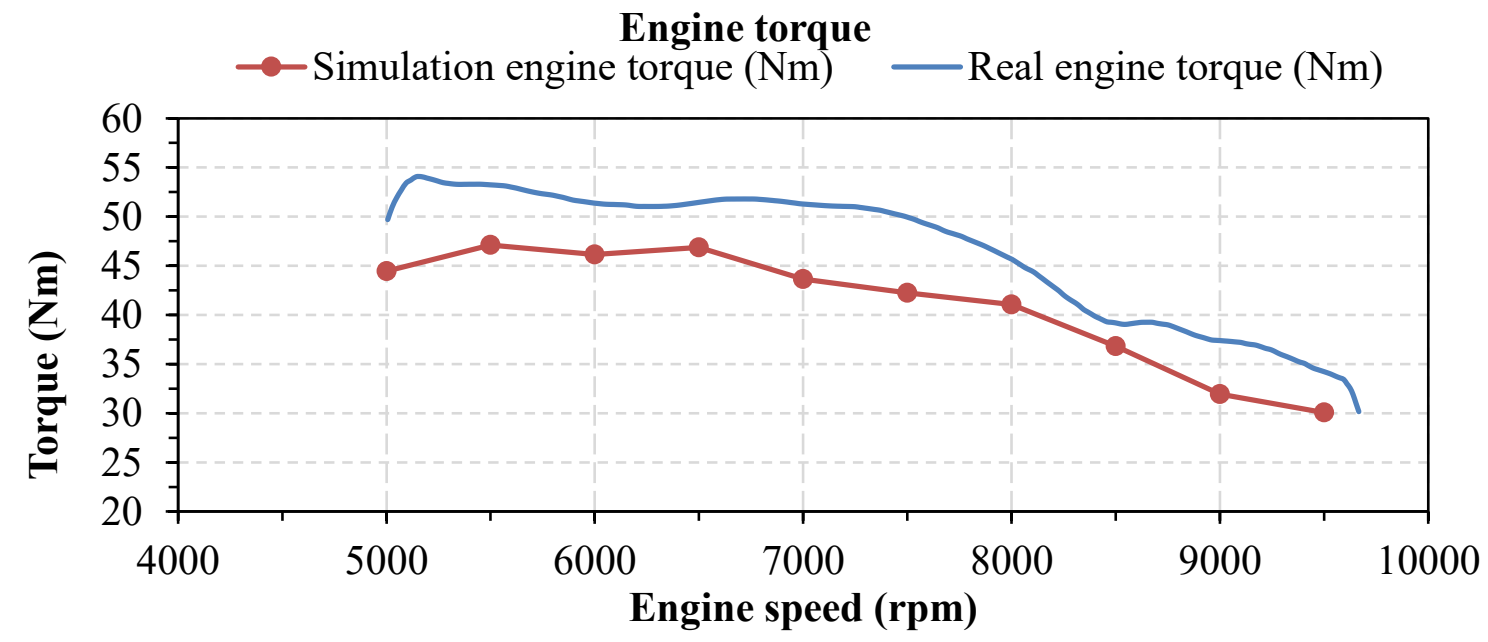


A curva de torque apresentada mostra um valor de torque máximo do modelo simulado de 47,11 Nm na rotação de $5500 \mathrm{rpm}$, diferenciando-se em 13,64 \% no valor de torque máximo e $6 \%$ no valor da rotação.

Na curva de pressão média efetiva há comportamento semelhante a curva de torque e potência.

Figura 57 - Curva de BMEP Yamaha WR450F

Engine BMEP (bar)

$\longrightarrow$ BMEP simulation engine (bar) $\quad$ BMEP Real engine (bar)

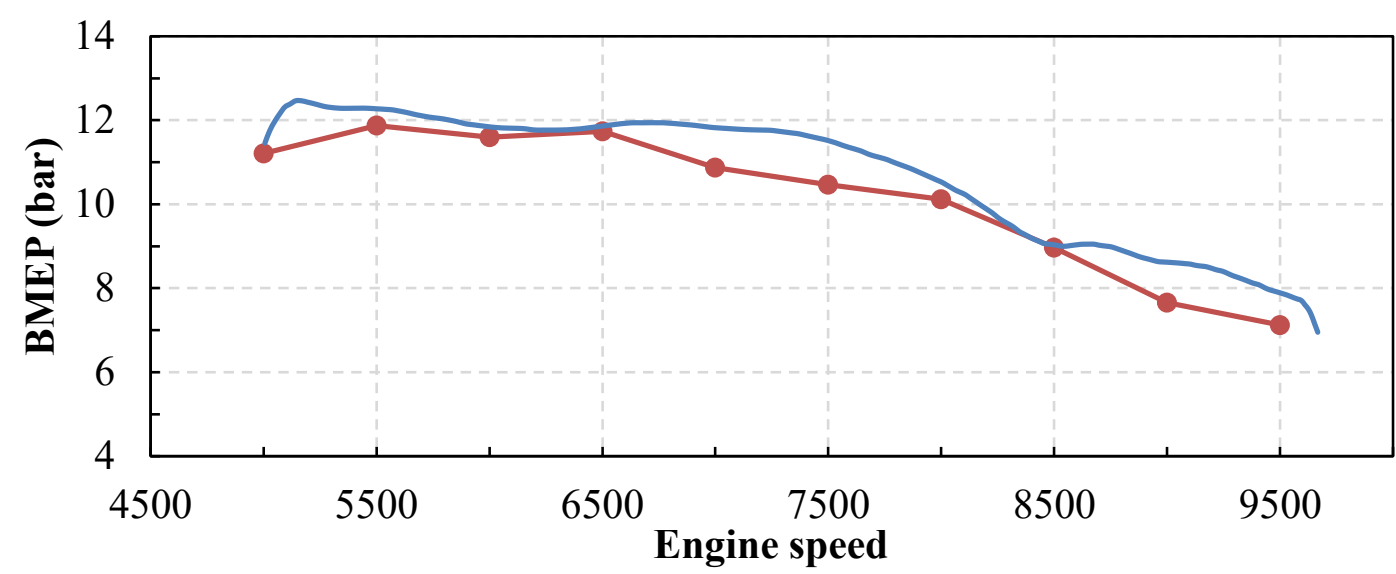

Fonte: Autor

O valor máximo de pressão média efetiva calculado baseado na curva obtida em dinamômetro resultou em 12, 27 bar na rotação de $5170 \mathrm{rpm}$. Na simulação o máximo valor obtido foi de 11,87 na mesma rotação, totalizando uma diferença de 3,26\%.

\subsection{RESULTADOS MODELO TURBOALIMENTADO}

A Figura 58 demonstra os resultados obtidos pelo o modelo para a curva de plena carga do motor, com o objetivo de comprar os cálculos com o modelo matemático do software. 
Figura 58 - Resultados dos pontos de operação do motor em plena carga obtidos em simulação

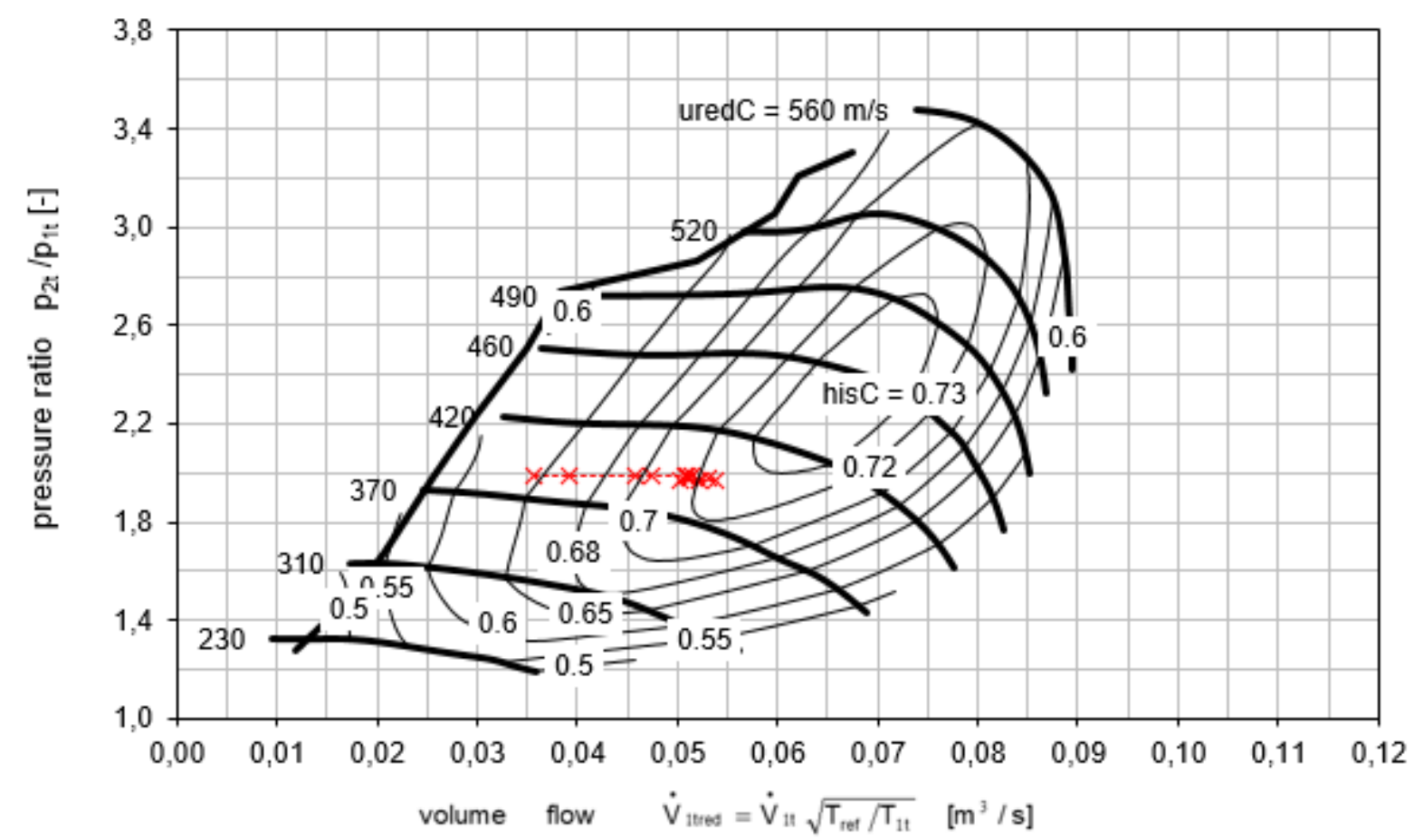

Fonte: Autor "adaptado de" Borgwarner do Brasil.

A simulação demonstra que o motor opera grande parte do tempo na região de eficiência entre $70 \%$ e $72 \%$, com vazões entre 0,035 e $0,055 \mathrm{~m}^{3} / \mathrm{s}$.

Os resultados da aplicação do turbocompressor em comparação ao modelo aspirado demonstra um significativo aumento de potência e torque em todas as faixas de rotação. Em um primeiro momento foram analisados os ganhos com aplicação pelo método pulsativo, posicionando o turbocompressor o mais próximo possível da saída dos gases de exaustão durante a abertura das válvulas, com uma distância de 100 mm. As Figuras 59, 60 e 61 demonstram as novas curvas de potência, torque e IMEP comparando os valores dos modelos aspirado e turboalimentado. 
Figura 59 - Comparativo das curvas de torque entre os modelos do motor naturalmente aspirado e turbocomprimido

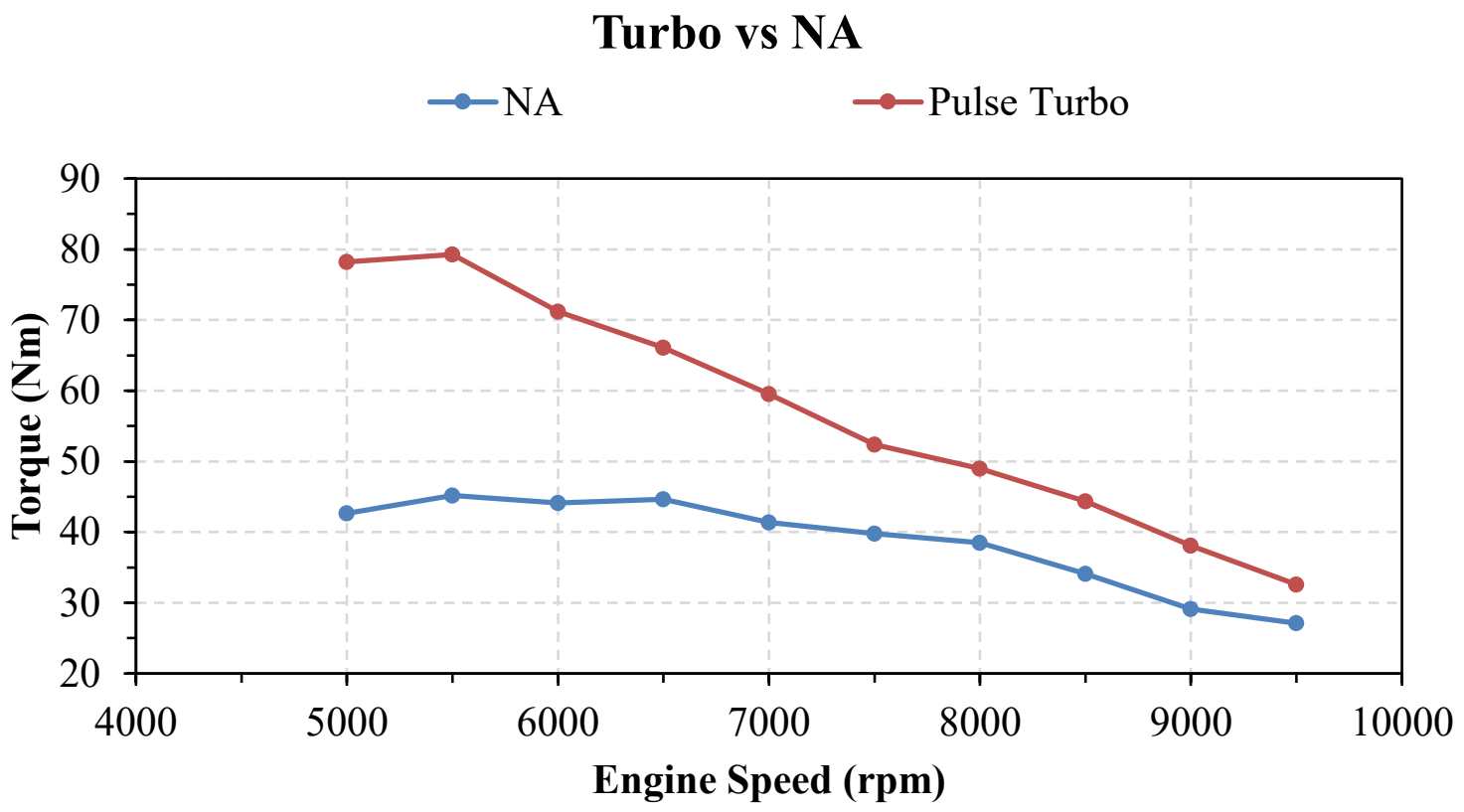

Fonte: Autor

Figura 60 - Comparativo da curva de potência entre os modelos do motor naturalmente aspirado e turbocomprimido

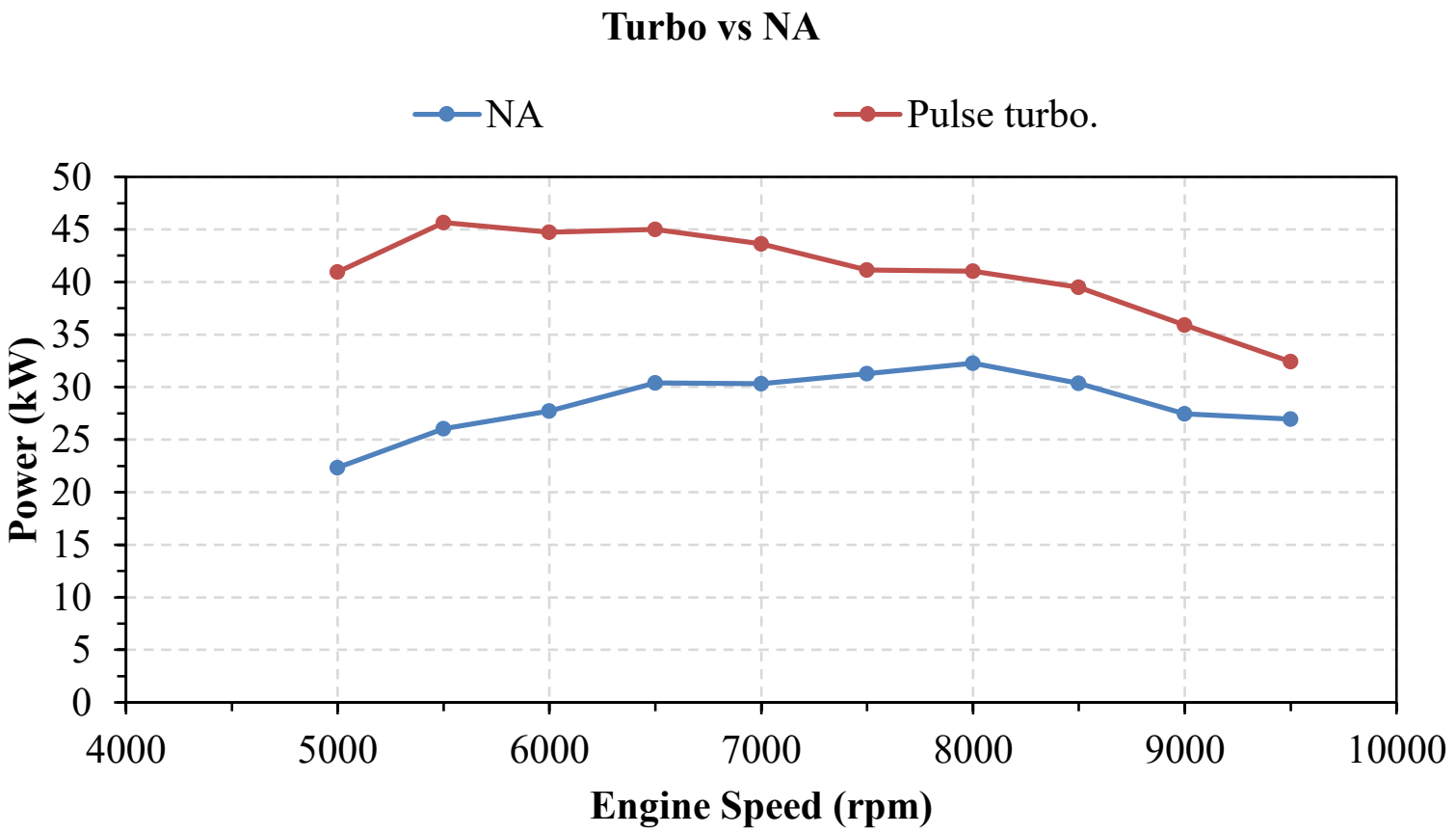


Figura 61 - Comparativo das curvas de IMEP entre os modelos do motor naturalmente aspirado e turbocomprimido

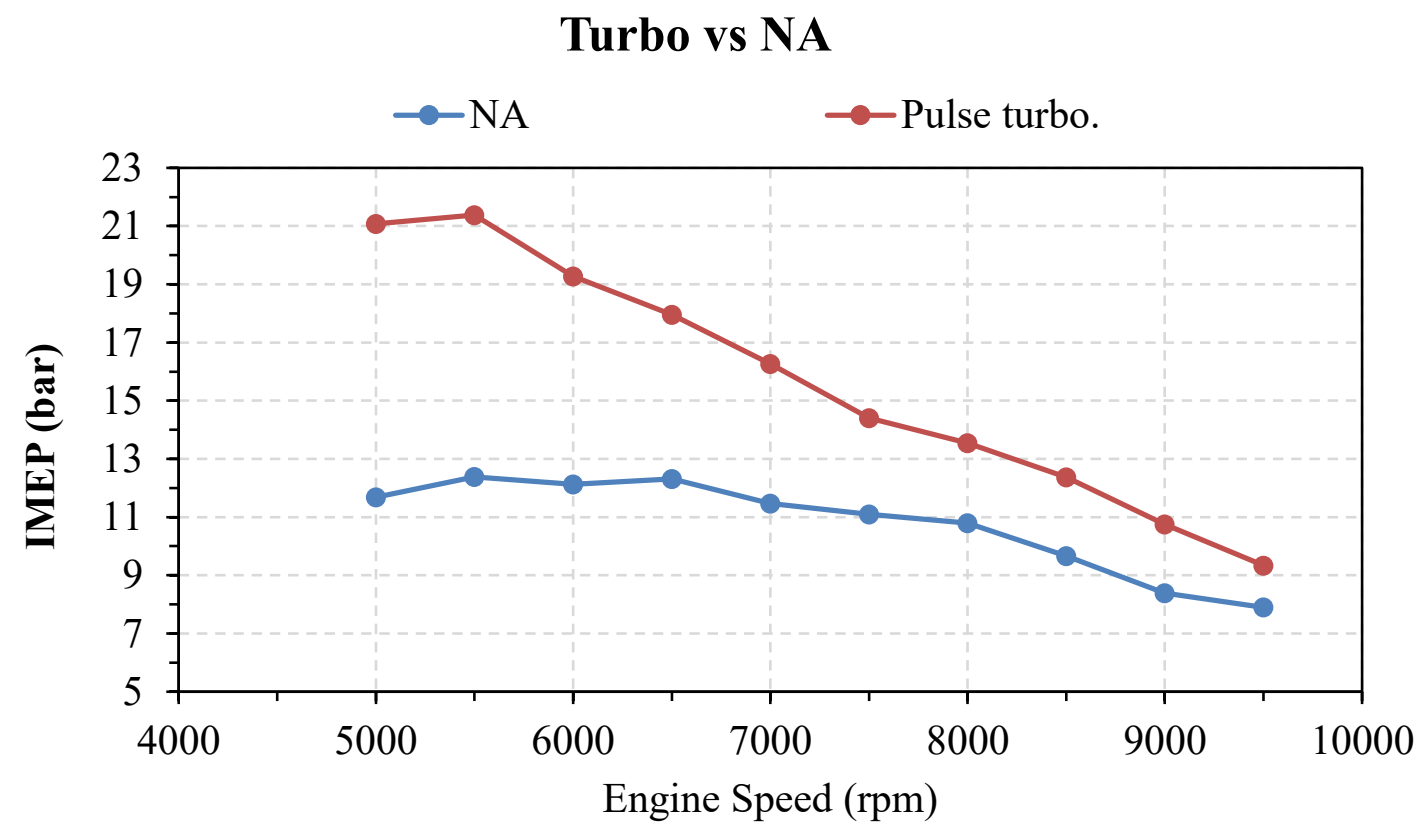

Fonte: Autor

A aplicação desta configuração de coletor de exaustão proporcionou um valor máximo indicado de torque de 79,27 Nm e potência de $45,65 \mathrm{~kW}$, um ganho de $43 \%$ na mesma faixa de rotação de $5500 \mathrm{rpm}$. Entretanto, o comportamento da curva indica uma grande perda de potência e torque a medida que aumenta o regime de rotação do motor.

Com a finalidade de melhorar ainda mais a faixa de torque e potência para as regiões de rotação mais elevadas, principalmente para a faixa de $7500-8000 \mathrm{rpm}$, foram estudados diferente volumes de coletor de exaustão: 1L, 2L, 3L e 4L. As Figuras 62, 63 e 64 representam os resultados obtidos nas curvas com a alteração. 
Figura 62 - Análise do impacto da alteração do volume do coletor de exaustão na curva de torque do motor.

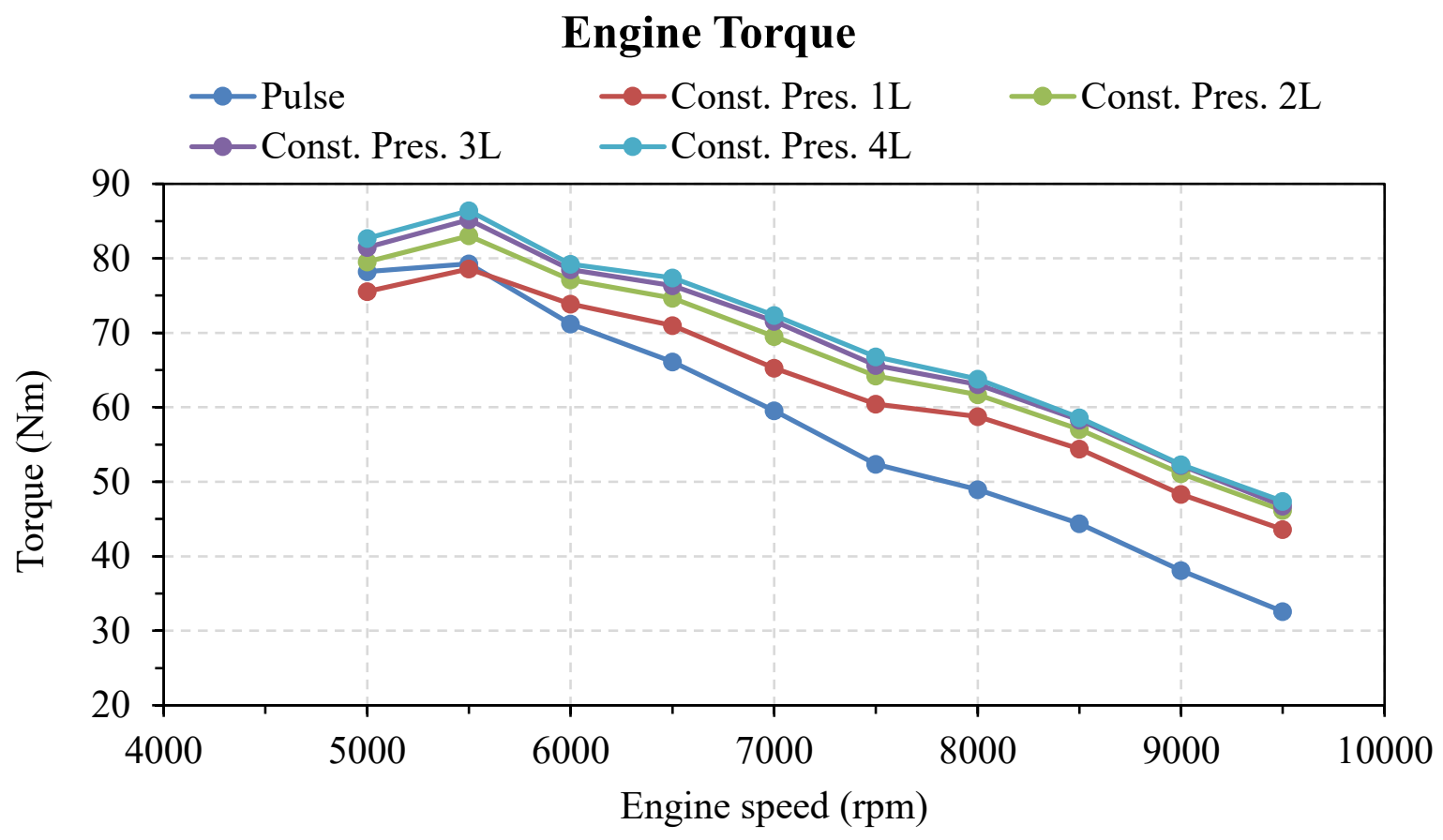

Fonte: Autor

Figura 63 - Análise do impacto da alteração do volume do coletor de exaustão na curva de potência do motor.

\section{Engine Power}

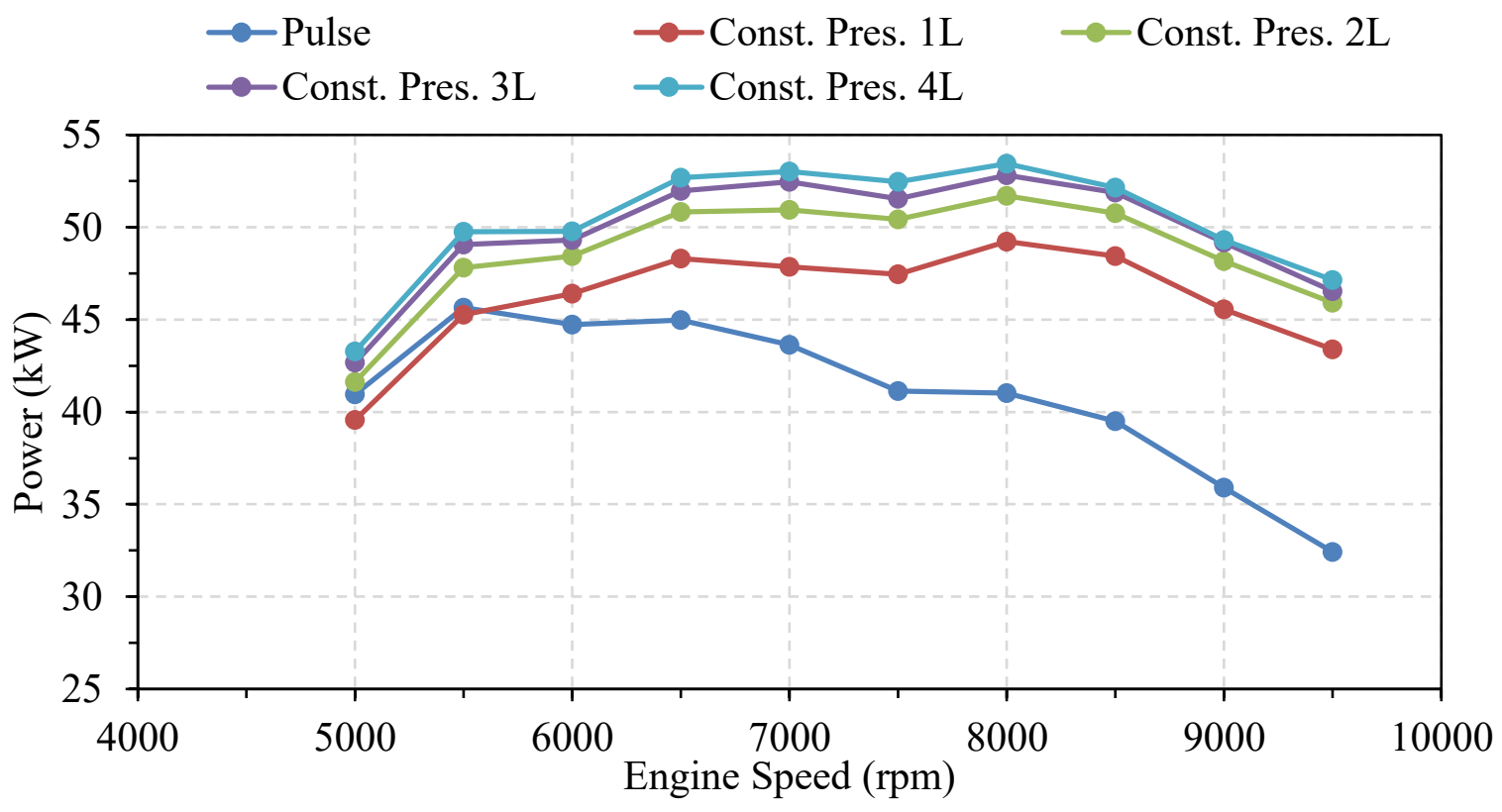


Figura 64 - Análise do impacto da alteração do volume do coletor de exaustão na curva de IMEP do motor.

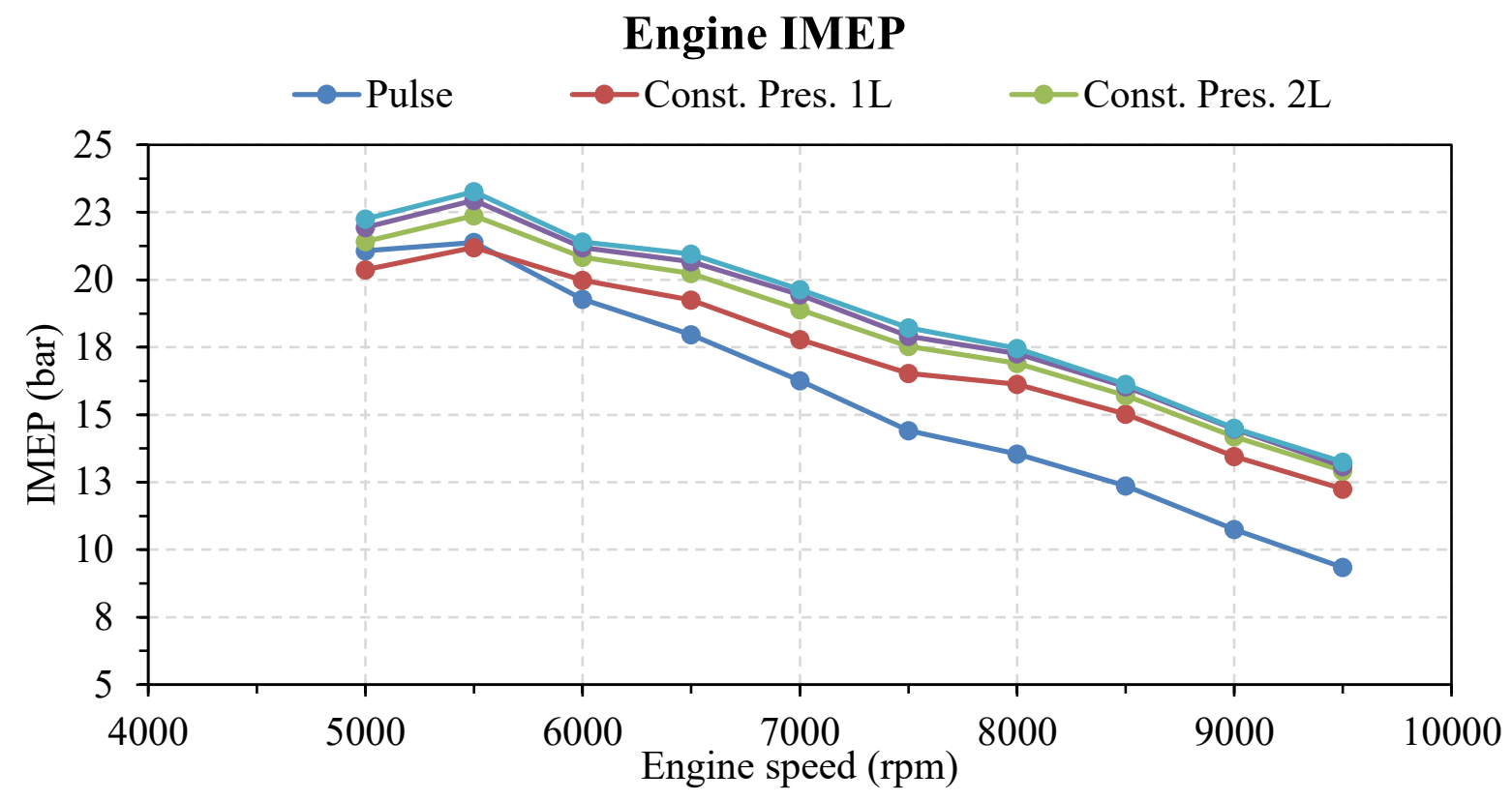

Fonte: Autor

O modelo demonstra que a medida em que aumenta o volume do coletor de exaustão há um ganho expressivo de potência, torque e pressão média efetiva indicada. Isso deve-se ao fato do grande volume servir como um ressonador e amortecer o efeito pulsativo das ondas provenientes dos gases de exaustão.

A pressão presente no coletor cai de forma significativa com o aumento do volume e o plenum faz com que o valor seja mantido de forma praticamente constante. Esse fenômeno proporciona uma alimentação constante de fluxo à turbina, fazendo com que ela trabalhe praticamente em regime permanente. Com isso, com o aumento da rotação, maior será a demanda de gases que vão para o coletor de escape e alimentam o rotor da turbina, e assim, maior é o trabalho gerado.

Observando o ponto de rotação de 8000 rpm é possível calcular um ganho de 20\% para torque, potência e IMEP com a aplicação de $1 \mathrm{~L}$ de volume. Com o aumento para $2 \mathrm{~L}$, as grandezas sofreram um aumento de apenas $26,04 \%$ nos valores em relação a curva inicial do motor, ou seja, uma diferença de 6,04\%. O ganho nos valores vai diminuindo, levando a entender que o sistema está próximo do seu desempenho máximo. 
O coletor de escapamento com uma área superficial muito grande irá proporcionar uma maior taxa de troca de calor entre o gás e as paredes do turbo, fazendo com que ocorram perdas consideráveis de temperatura dos gases que estão alimentando a turbina, prejudicando assim sua eficiência. Considerando esse fato, uma vez que o ganho de desempenho em termos de torque, potência e IMEP para volumes muito grandes não é muito vantajoso, combinado com a dificuldade de projetar um pacote do motor com uma geometria que ocupe muito espaço. Portanto, optou-se pela utilização de um volume máximo de 2L.

O conceito discutido sobre a atenuação dos pulsos pode ser observado quando é analisada a pressão no coletor de exaustão durante a realização de um ciclo. Os pontos escolhidos para comparação são o MP12 da Figura 43 e o PL2 da Figura 44, para o volume selecionado de 2L. Sendo assim, os resultados são demonstrados na Figura 65.

Figura 65 - Pressão dos gases no coletor de exaustão ao longo de 1 ciclo de operação do motor.

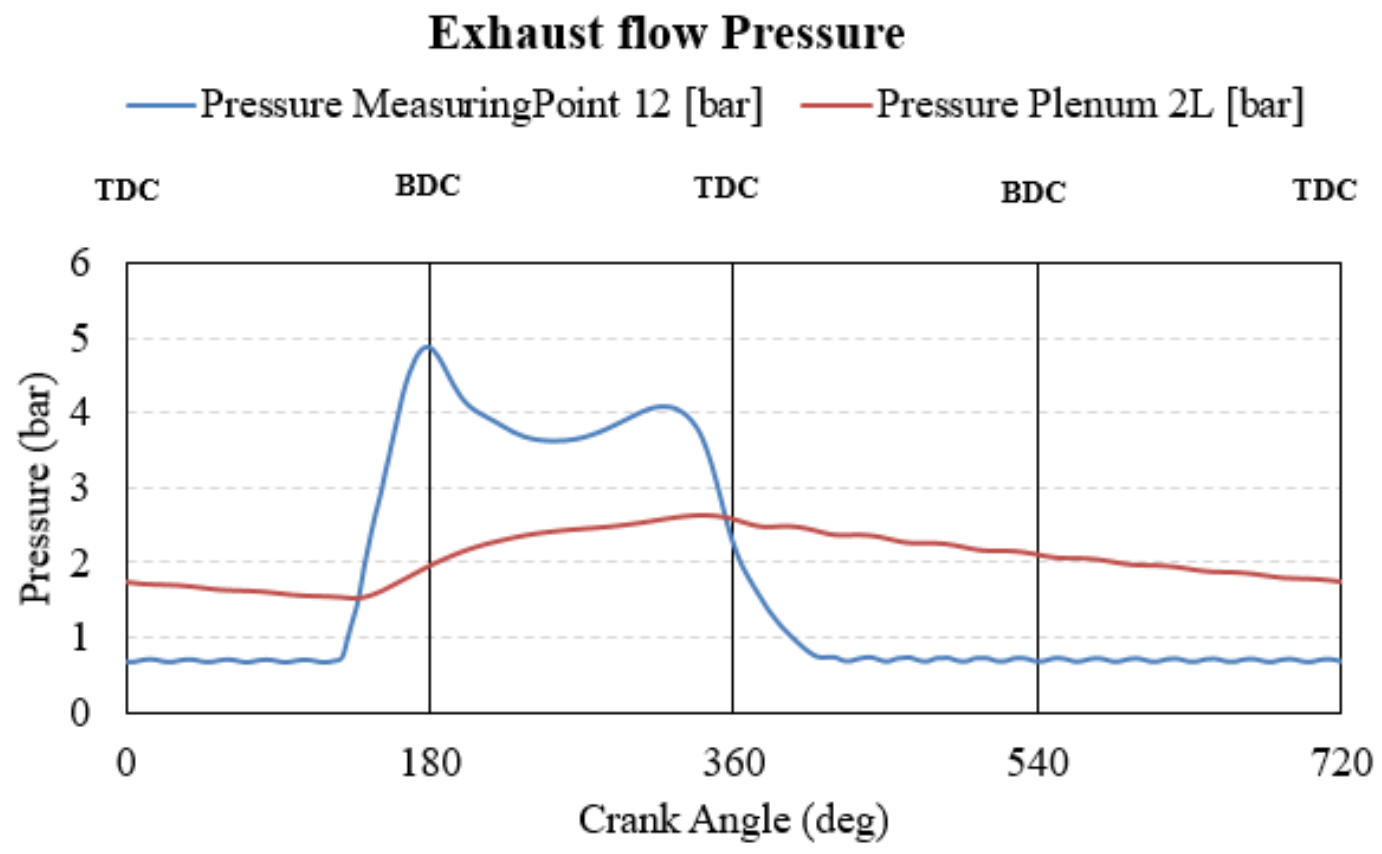

Fonte: Autor

O grande volume atenua o pulso de pressão dos gases com a abertura da válvula de exaustão, fazendo com que o pico de pressão obtenha um valor menor e que não haja uma grande variação ao longo do ciclo. Deste modo, devido a estes conceitos, é possível notar o ganho de torque e potência de forma mais acentuada em rotações acima $6000 \mathrm{rpm}$. 
Por fim o comparativo entre as curvas do motor naturalmente aspirado, turboalimentado com coletor dimensionado por efeito pulsativo e por pressão constante com a aplicação de um volume de 2L, podem ser observados nas Figuras 66, 67 e 68.

Figura 66 - Comparativo entre curvas de torque do motor aspirado, turboalimentado com coletor de exaustão dimensionado por efeito pulsativo e pressão constante.

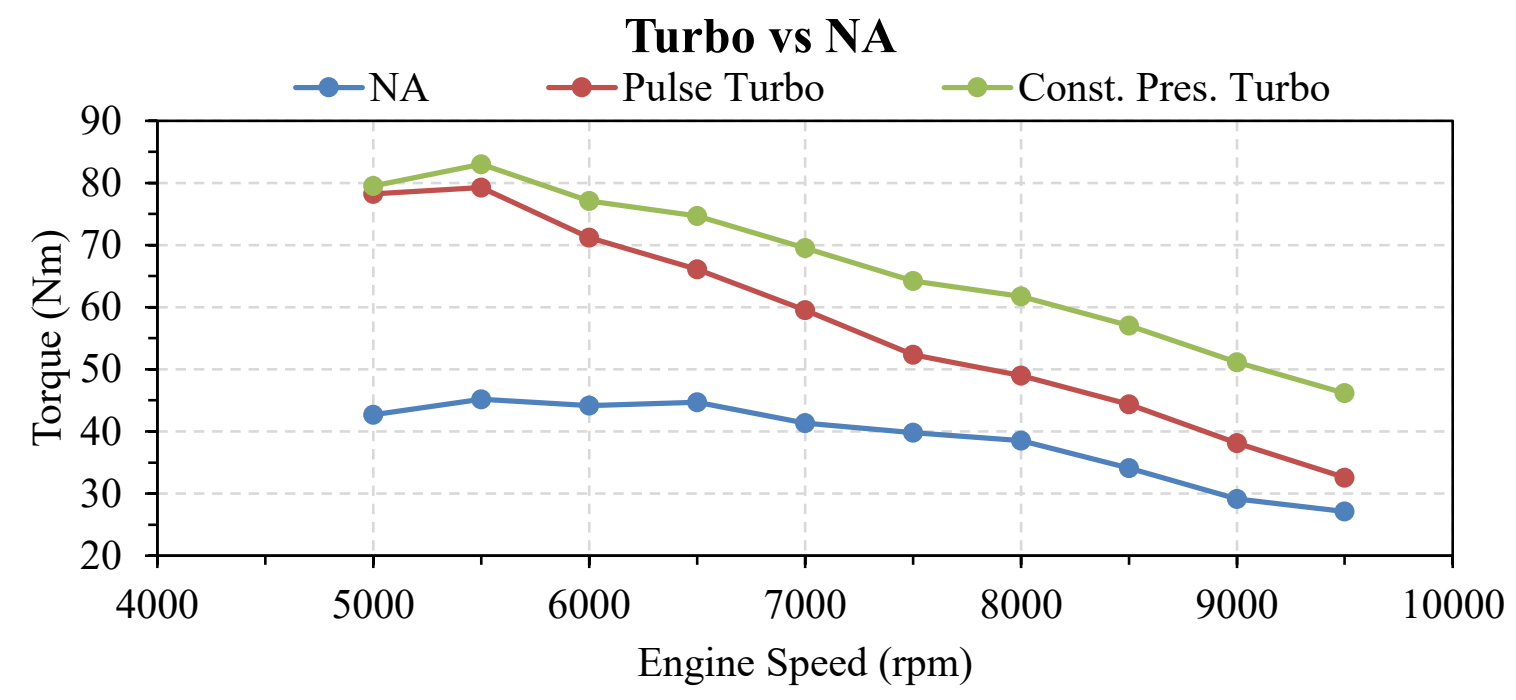

Fonte: Autor

Figura 67 - Comparativo entre curvas de potência do motor aspirado, turboalimentado com coletor de exaustão dimensionado por efeito pulsativo e pressão constante.

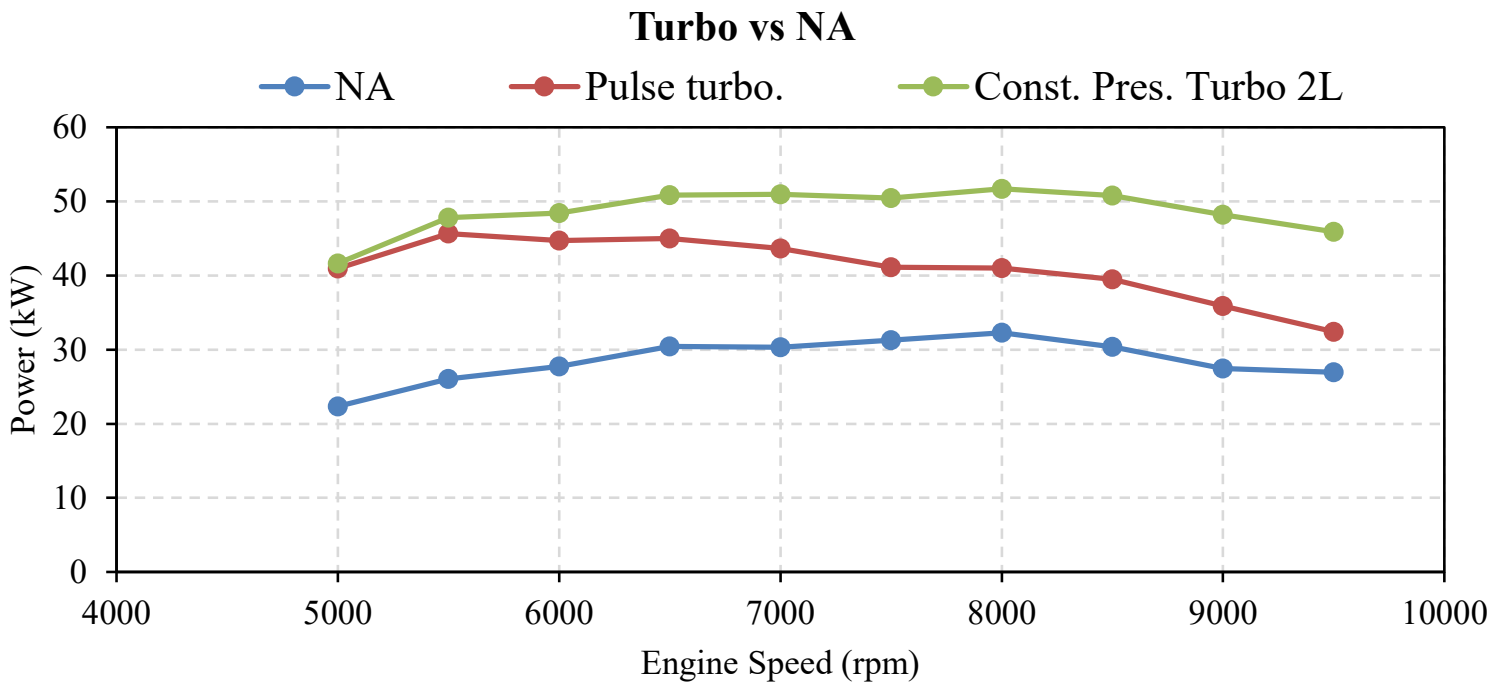

Fonte: Autor 
Figura 68 - Comparativo entre curvas de IMEP do motor aspirado, turboalimentado com coletor de exaustão dimensionado por efeito pulsativo e pressão constante.

\section{Turbo vs NA}

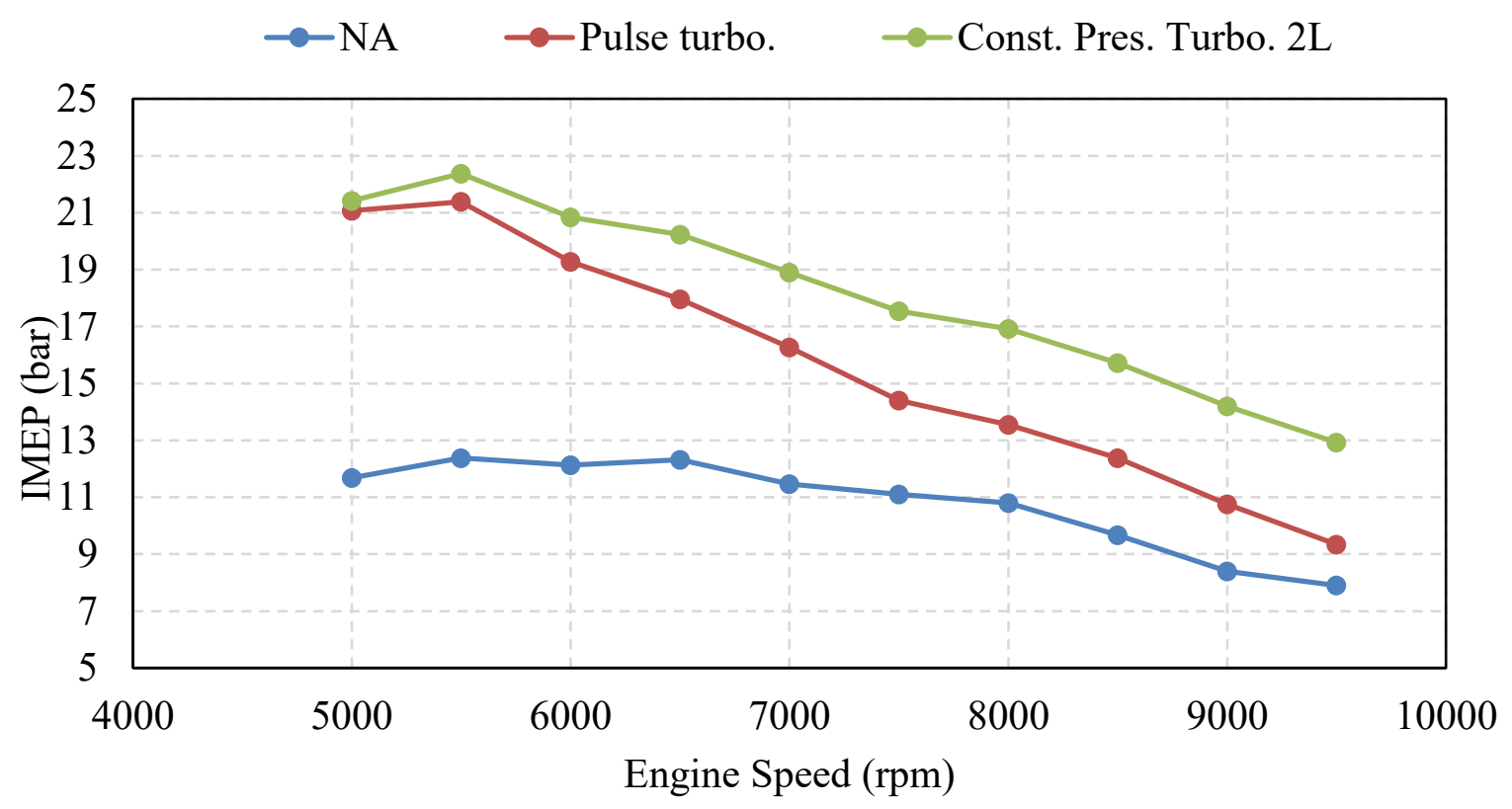

Fonte: Autor 


\section{CONCLUSÕES}

O estudo serviu para incentivar o trabalho com a utilização das ferramentas computacionais mais avançadas existente na indústria de desenvolvimento de motores de combustão interna. O software AVL BOOST, teve uma grande importância nesse trabalho, pois através dele entende-se o potencial que é possível obter usando um sistema de turbocompressor para aumentar a potência do motor sem comprometer a filosofia adotada pela equipe nos últimos 10 anos, que é produzir veículos de baixa massa. Os resultados foram considerados satisfatórios, pois representaram um bom nível de correlação com o motor atual diante dos recursos disponíveis para medição das grandezas necessárias para alimentação do modelo.

A construção do modelo turboalimentado demonstrou resultados promissores, indicando que é possível obter ganho de potência e torque em todas as faixas de rotação para ambos os tipos de aplicação de geometria de coletor de exaustão com o modelo de turbocompressor selecionado. $\mathrm{O}$ estudo apresentado não é conclusivo quanto ao comportamento de ambos sistemas quando submetidos a solicitações de carga em regime transiente. Também não é possível concluir quanto a influência que o método de pressão constante aplicado coletor pode impactar no fenômeno de turbo lag.

Os conceitos abordados por Watson e Janota (1982) e Baines (2005) sobre os métodos de dimensionamento do coletor de exaustão para maximizar o preenchimento da turbina, que posteriormente foram estudados por Attard et al (2007) também se confirmaram através da simulação. Baseado nos resultados obtidos, é possível afirmar que a aplicação dos conceitos da manutenção da pressão constante na alimentação da turbina através da utilização de um coletor com volume de $2 \mathrm{~L}$ em um turbocompressor aplicado a um motor monocilíndrico de baixa cilindrada pode proporcionar um maior ganho de desempenho em termos de torque e potência quando comparado ao dimensionamento convencional do comprimento do coletor de exaustão.

A análise da ferramenta computacional para cálculos das variáveis do modelo pode ser considerada confiável, uma vez que os resultados apresentados obtiveram valores muito próximos dos obtidos através dos testes realizados mesmo com a utilização de modelos simplificados, além disso o comportamento das curvas, assim como a consequência da modificação de parâmetros, demonstrou convergir para o os valores e conceitos que foram abordados na teoria. A queda repentina de torque e potência que podem ser observadas nas 
curvas, se devem ao fato do aumento da rotação, e consequentemente, do atrito entre os componentes somado ao fato da utilização de um restritor de ar no coletor de admissão. Portanto, as curvas obtidas não fogem da expectativa de resultado baseada nas medições realizadas no modelo aspirado e justificadas pelas características do motor.

\section{CONSIDERAÇÕES PARA TRABALHOS FUTUROS}

O modelo do motor normalmente aspirado foi modelado com o máximo de informações disponíveis e conhecidas no momento. Entretanto, faz-se necessário o aprofundamento das medições realizadas no motor, de forma a conseguir a diminuição do erro encontrado entre os valores reais e teóricos. A utilização do dinamômetro de chassi para medições de torque e potência não é o modo mais indicado para este tipo de estudo. Um dinamômetro de bancada permite uma maior riqueza de dados para alimentação do modelo, assim como a possibilidade de explorar regimes de carga e rotação de forma controlada, bem como utilizar mais instrumentações específicas para motores de combustão interna, como por exemplo transdutores de pressão para análises mais precisas de combustão.

A metodologia para medição da pressão de combustão do motor utilizada por Custódio (2015) não foi possível de ser realizada devido a complicações que surgiram durante a realização da pesquisa. Entretanto, recomenda-se que todo o processo de desenvolvimento do motor, tanto no banco de provas, quanto no dinamômetro de chassi, seja feito com a utilização da vela de ignição instrumentada com o objetivo de monitorar a pressão de combustão durante os testes, aquisitar o comportamento desta variável, e assim utilizar seus valores para alimentação do modelo e, por fim, monitorar o valor limite para realização da calibração do sistema de injeção eletrônica. 


\section{REFERÊNCIAS}

ATTARD, William; WATSON, Harry C; KONIDARIS, Steve. Highly Turbocharging a Flow Restricted Two Cylinder Small Engine - Turbocharger Development. University of Melbourne. SAE International. 2007. DOI: https://minervaaccess.unimelb.edu.au/handle/11343/34523

AVL. BOOST Users Guide. Graz, Austria, 2020.

AVL. BOOST Theory. Graz, Austria, 2020.

BAINES, Nicholas C. Fundamentals of Turbocharging. Concepts NRec. 2005.

BEACH, Brian et al. FSAE Turbo-system Design. Major Qualifying Project for the Degree of Bachelor of Science. Worcester polytechnic institute. 2010.

BRUNETTI, Franco. Motores de combustão interna. São Paulo: Blucher, 2012. 1v.

BRUNETTI, Franco. Motores de combustão interna. São Paulo: Blucher, 2012. 2v.

CAMPOS, Ricardo Augusto Seawright. Modelagem e simulação de grupo gerador diesel consumindo óleo vegetal "in natura" enriquecido com hidrogênio e oxigênio visando melhorar sua eficiência energética. 2015.116p. Tese de Doutorado (Pós-graduação em engenharia elétrica). Universidade Federal do Pará, Belém, 2015.

CUSTÓDIO, Adriano P. Instalação de Injeção Eletrônica em um Motor de Combustão Interna e a Metodologia utilizada para Calibração da Unidade de Controle. 2015. 60p. TCC (Bacharel em Engenharia Mecânica) Universidade de Mogi das Cruzes, Mogi das Cruzes, 2015

DUMITRESCU, Cosmin E.; LIU, Jinlong. Single and double Wiebe function combustion model for a heavy-duty diesel engine retrofitted to natural-gas spark-ignition. Applied Energy. Morgantown, WV, USA. 2019. DOI: https://doi.org/10.1016/j.apenergy.2019.04.098

GRIESS, Eric; MCCUTCHEON, Kevin; ROBERTS, Matthew; CHAN, William. Formula SAE Turbocharger System Development. 2012. Senior Project Final Report. California Polytechnic State University, San Luis Bispo, 2012

HARTMAN, Jeff. Turbocharging Performance Handbook. First edition. Wisconsin. Motorbooks Internacional, 2007.

HEISLER, Heinz. Advanced engine Technology. First edition. SAE International. 1995.

HEYWOOD, John B. Internal combustion engine fundamentals. New York; St. Louis: McGraw-Hill, c1988. 
KELLERMAYR, Georg; SCHUTTING, Eberhard; MITTERECKER, Horst. Turbocharging of engines with low cylinder number: a thermodynamic consideration. Automotive and Engine Technology. 2019. DOI: https://link.springer.com/article/10.1007/s41104-01900048-8

MILLER, Jay K. Turbo: Real World High-Performance Turbocharger Systems. Inglaterra Cartech. 2008.

NETO, Rubemar Maia de Azevedo Cruz. Simulação computacional e análise exergética de um motor de motocicleta de baixa cilindrada com misturas de gasolina e etanol. 2013. 175p. Dissertação (Pós-graduação em engenharia mecânica). Universidade Federal do Rio de Janeiro, Rio de Janeiro, fevereiro de 2013.

OBERT, Edward F. Internal Combustion Engines and Air Pollution Intext Educational Publishers, 1973

PASTORELLI, Pedro P. Análise Numérica da Implementação de um Turbocompressor em Motor Monocilíndrico para Competição Fórmula SAE. 2015. 68p. Monografia (Graduação em engenharia Automotiva). Universidade Federal de Santa Catarina, Joinville, 2015.

TAYLOR, Charles Fayette. Análise dos Motores de combustão interna. Segunda Edição. Editora Edgard Blucher LTDA, 1971.

WATSON, N; JANOTA, M.S. Turbocharging the Internal Combustion Engine. First edition. New York.The Macmillan Press LTD, 1982. 